LABORATORY INVESTIGATION ON GELATION BEHAVIOR OF XANTHAN CROSSLINKED WITH BORATE INTENDED TO COMBAT LOST CIRCULATION

A THESIS SUBMITTED TO

THE GRADUATE SCHOOL OF NATURAL AND APPLIED SCIENCES

OF

MIDDLE EAST TECHNICAL UNIVERSITY

BY

MEHDI MOKHTARI

IN PARTIAL FULFILLMENT OF THE REQUIREMENTS

FOR

THE DEGREE OF MASTER OF SCIENCE

IN

PETROLEUM ENGINEERING

JANUARY 2010 
Approval of the thesis:

\section{LABORATORY INVESTIGATION ON GELATION BEHAVIOR OF XANTHAN CROSSLINKED WITH BORATE INTENDED TO COMBAT LOST CIRCULATION}

submitted by Mehdi MOKHTARI in partial fulfillment of the requirements for the degree of Master of Science in Petroleum and Natural Gas Engineering Department, Middle East Technical University by,

Prof. Dr. Canan ÖZGEN

Dean, Graduate School of Natural and Applied Sciences

Prof. Dr. Mahmut PARLAKTUNA

Head of Department, Petroleum and Natural Gas Engineering

Prof. Dr. Mahmut PARLAKTUNA

Supervisor, Petroleum and Natural Gas Engineering Dept., METU

Assoc. Prof. Dr. Evren M. ÖZBAYOĞLU

Co-Supervisor, Petroleum Engineering Dept., University of Tulsa

Examining Committee Members:

Prof. Dr. Tanju MEHMETOĞLU

Petroleum and Natural Gas Engineering Dept., METU

Prof. Dr. Mahmut PARLAKTUNA

Petroleum and Natural Gas Engineering Dept., METU

Assoc. Prof. Dr. Evren M. ÖZBAYOĞLU

Petroleum and Natural Gas Engineering Dept., University of Tulsa

Assoc. Prof. Dr. Hakkı GÜCÜYENER

Petroleum and Natural Gas Engineering Dept., METU

Selcuk Erkekol, M.Sc.

TPAO Research Center

Date: January 21, 2010 
I hereby declare that all information in this document has been obtained and presented in accordance with academic rules and ethical conduct. I also declare that, as required by these rules and conduct, I have fully cited and referenced all material and results that are not original to this work.

Name, Last name: Mehdi Mokhtari

Signature: 


\title{
ABSTRACT \\ LABORATORY INVESTIGATION ON GELATION BEHAVIOR OF XANTHAN CROSSLINKED WITH BORATE INTENDED TO COMBAT LOST CIRCULATION
}

\author{
Mokhtari, Mehdi \\ M.Sc., Department of Petroleum and Natural Gas Engineering \\ Supervisor : Prof. Dr. Mahmut Parlaktuna \\ Co-Supervisor: Assoc. Prof. Dr. Evren M. Ozbayoglu
}

January 2010, 94 pages

This thesis addresses the application of xanthan/borate gel for lost circulation treatment. Steady shear viscometry method was applied in which the gel system was under constant shear rate while apparent viscosity was being recorded. The apparent viscosity was constant up to initial gelation time in which viscosity started to build up. Four parameters: initial and final gelation times as well as initial and final viscosities are defined and a correlation is derived between those parameters and four variables: polymer blended with crosslinker, $\mathrm{pH}$-controller, and magnesium chloride concentration as well as temperature. These correlations can help the drilling industry to manage the lost circulation treatment job in a way to have enough time and pressure to pump the fluid and to optimize the time and quality required for final gel. The effects of those variables besides mixing time and shear history on gelation were also investigated. Temperature and $\mathrm{pH}$-controller shortens initiation of gelation. Poly-cross shifts viscosity upward. Retarder postpones the final gelation time. Shear history does not affect initial gelation time and increase of mixing time reduces initial gelation time. 
This thesis also investigates the rheological model behavior of this gel system before initial gelation time which is the time allowed for pumping the fluid. Shear stress was measured at $0.1,1,50$, and $450 \mathrm{rpm}$ besides the conventional readings. Then residual mean squares for six common rheological models were obtained. Sisko was found to be the best fitting model based on this statistical approach. Moreover a modified Bingham-plastic and low shear yield point model are suggested.

Keywords: Gel, Lost Circulation, Borate, Xanthan, Rheological Model 


\title{
$\ddot{O Z Z}$
}

\section{SİRKÜLASYON KAYBI IYYILESSTTIRMELERİ İÇIN BORAT ILLE ÇAPRAZBAĞLI XANTHA'NIN JELLEŞME DAVRANIŞI}

\author{
Mokhtari, Mehdi \\ Yüksek Lisans, Petrol ve Doğal Gaz Mühendisliği Bölümü \\ Tez Yöneticisi : Prof. Dr. Mahmut PARLAKTUNA \\ Ortak Tez Yöneticisi: Doç. Dr. Mehmet Evren ÖZBAYOĞLU
}

Ocak 2010, 94 sayfa

Çapraz bağlı polimer jeller petrol üretim endüstrisinde su kesimi, profil modifikasyonu ve hidrolik çatlaklarda kullanılmaktadır. Başarılı bir geçmişe sahip olan bu uygulamalar en ağır sondaj sorunlarından biri olan sirkulasyon kaybın çözümü için yeni bir çığır açılmasına öncülük etmiştir. Uygun $\mathrm{pH}$ koşullarında jelleşme kayıp bölgede başlar ve bölgeyi tıkayabilecek bir üç boyutlu jel yapısı ile sonuçlanır.

Sabit hızlı kayma viscometry bir metodur ki onda jel sistemi 3rpm'li sabit bir kayma hızı oranın altındaydi. Görünür viscidity, visciditynin oluşmaya başladığı jel derecesine kadar sabitkalmıştır. İlk jelleşme zamanı, son jelleşme zamanı, ilk viscidity ve son viscidity jel sisteminin davranışlarını tanımlayabilen parametrelerdir ve bu çalışmada belirtilmişlerdir.

Her ne kadar karıştırma zamanındaki artış ilk jelleşme zamanını düşürüyor olsa da, karıştırma zamanı ve ilk jelleşme zamanının toplamı belirli bir örnek için sabit kalmıştır. Diğer bir deyişle jelleşme, karıştırma zamanının uzatılmasıyla 
ertelenememektedir. Kesme tarihçesi ve hızı ilk jelleşme zamanın etkilememektedir. Sabit bir oranda polimer artı çapraz-bağlayıcı konsantrasyonunun artması viscidity grafiğini yukarı doğru kaydırmakta ancak ilk jelleşme zamanını değiştirmemktedir. Sıcaklık ve $\mathrm{pH}$ denetleyicisi çarpaz bağlanma için hazır olan daha yüksek konsantrasyonda borat iyonu sağlayarak jelleşmenin başlamasını hızlandırmaktadır. Diğer taraftan, magnezyum klorid son jelleşme zamanını çoğaltır ve viskositeyi azaltır. Ampirik modeller de bu değişkenlerin bir fonksiyonu olarak jel özelliklerinin tahmini için önerilmektedir.

Ayrıca reolojik model belirlenmesi de araştırılmıştır. Kesme stresi, (3, 6, 100, 200, 300, ve 600) kesme oranlarının yanı sira geleneksel kesme oranları olan 0.1, 1, 50, and 450 rpm oranlarında da ölçülmüştür. Artık kareler ortalaması her örnek için ayrı ayrı hesaplanmış ve Box-Whisker grafiğinde sunulmuştur. Bu reolojik veri kümesine Sisko 'nun uygun olduğu bulunmuştur. Ayrıca, değiştirilmiş bingham plastik ve değişilmiş "low shear yeild point" modelleri öneriliyor.

Anahtar kelimeler: Jel, Sirkülasyon Kaybı, Borat, Xanthan, Reolojik Model 
To My Family 


\section{ACKNOWLEDGEMENTS}

I wish to express my sincere gratitude to my supervisor, Prof. Dr. Mahmut Parlaktuna, and my co-supervisor, Assoc. Prof. Dr. Evren Ozbayoglu. This thesis would not have been possible without their guidance, patience, and encouragement. I am also indebted to invaluable comments of Prof. Dr. Mustafa V. Kok and I would like to appreciate it.

The materials for conducting the experiments were donated generously by Turkish Petroleum Corporation. I would like to appreciate the Research Center, Drilling Technologies Section and specially Mr. Selcuk Erkekol for their attention, support and valuable advice.

It is also my pleasure to appreciate from Prof. Dr. Nurkan Karahanoglu in Geological Engineering Department, and Assoc. Prof. Necati Ozkan in Polymer Science and Technology Department.

Also I would like to show my appreciation to the European Union for the Erasmus Mundus scholarship and to thank Mr. Ibrahim Yorgun in Study Abroad Office of Middle East Technical University for all of his help.

I would like also to thank my parents: Shapoor and Parvin as well as my siblings: Leila, Neda, Mohammad, Ali, Sahar for their love and support throughout all my life.

I am also grateful to my friend, Mr. Reza Ettehadi Osgouei. 


\section{TABLE OF CONTENTS}

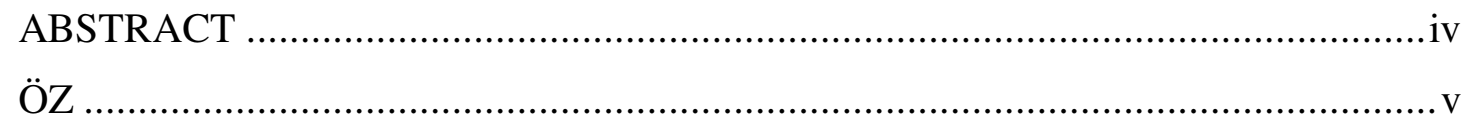

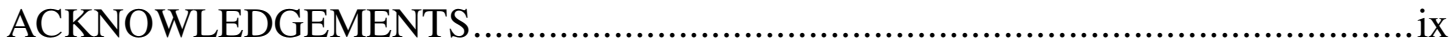

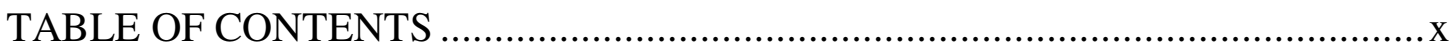

LIST OF TABLES ................................................................................

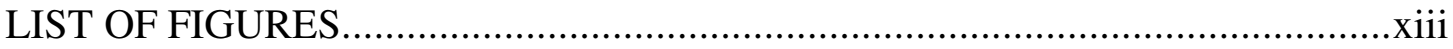

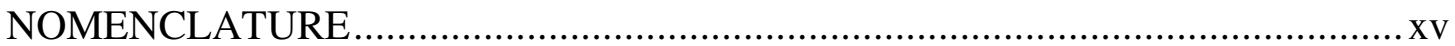

CHAPTERS

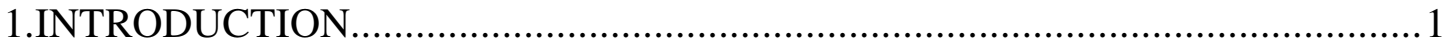

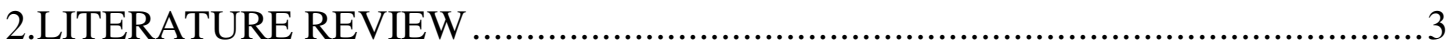

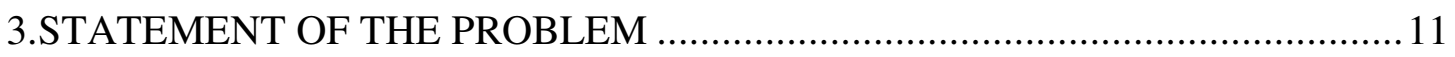

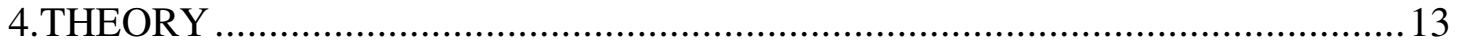

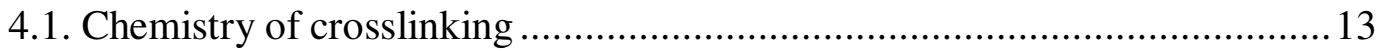

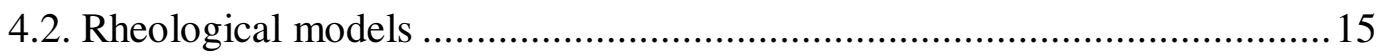

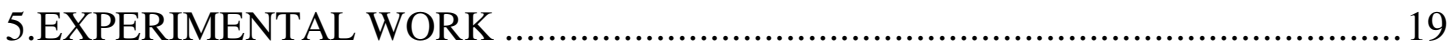

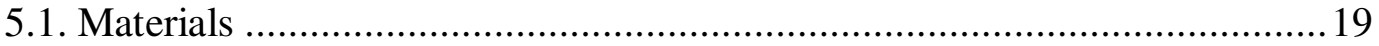

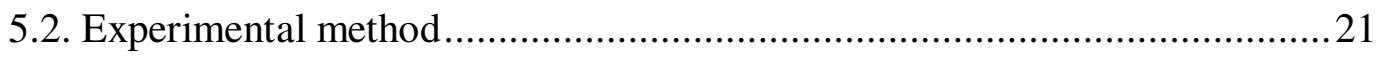

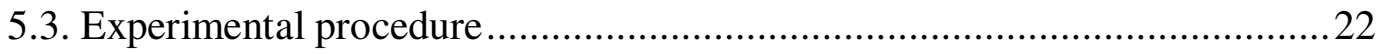

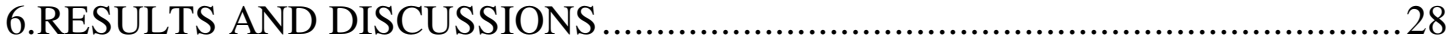

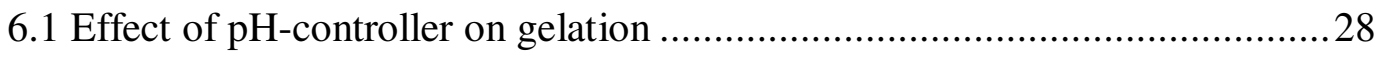

6.2. Effect of poly-cross concentration on gelation ..................................... 31

6.3. Effect of magnesium chloride on gelation .......................................... 34

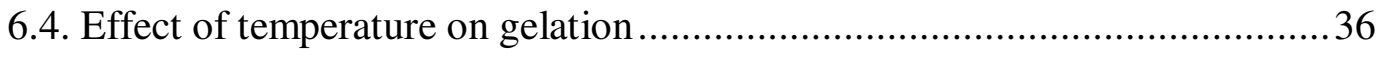

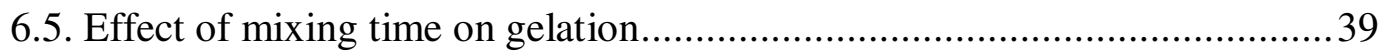

6.6. Effect of Shear history on gelation .................................................... 41 
6.7. Empirical models for gelation behavior estimation................................43

6.8. Empirical models for field application .................................................49

6.9. Rheological model determination ................................................ 51

6.10. Modified Bingham-Plastic model..................................................55

6.11. Modified Herschel-Bulkley model ......................................................58

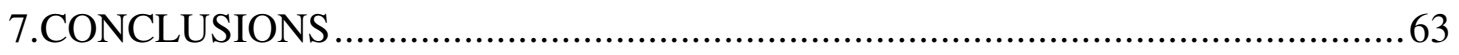

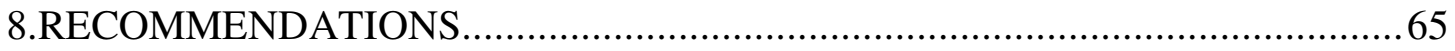

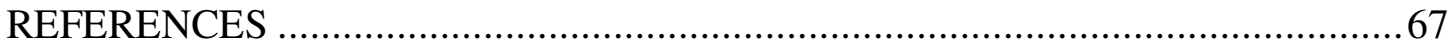

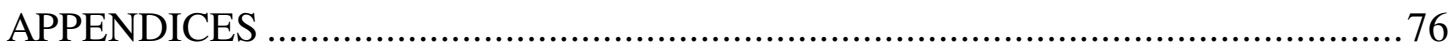

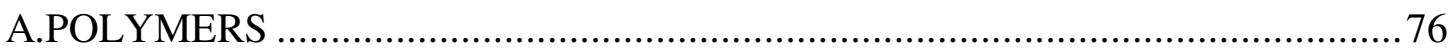

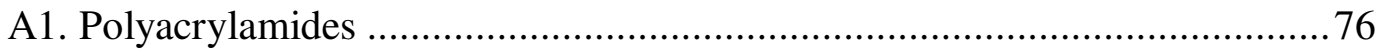

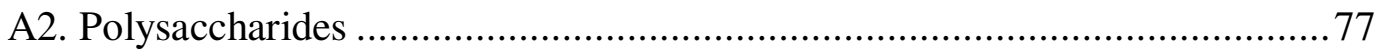

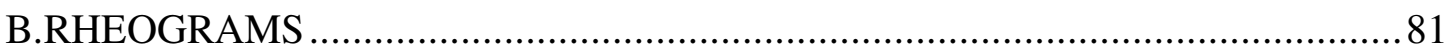

C.OTHER APPLICATIONS OF GELS IN PETROLEUM INDUSRY ................... 86

C1. Application of gels for water shut-off............................................... 87

C2. Application of gels for profile modification........................................ 89

C3. Application of gels in hydraulic fracturing operation..............................92 


\section{LIST OF TABLES}

\section{TABLES}

Table 5.1: Materials used in the experiments and their functions ......................... 19

Table 5.2: Composition of tap water of METU ............................................ 20

Table 5.3: Composition of samples used for empirical models............................24

Table 5.4: Composition of samples for rheological model determination ..............25

Table 6.1: The results for empirical model determination ................................ 44

Table 6.2: Composition of materials in field unit ..............................................50

Table 6.3: Bingham-Plastic parameters.......................................................56

Table A.1: Classification of monosaccharides ................................................ 77

Table A.2: Chemical structure of some linear sugars .......................................77 


\section{LIST OF FIGURES}

\section{FIGURES}

Figure 4.1: Boric acid equilibrium in 5\% KCL ............................................. 14

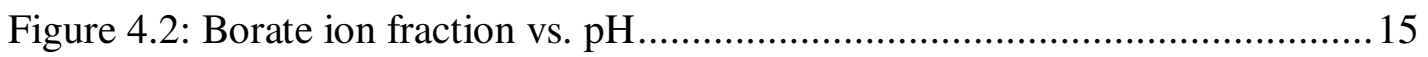

Figure 5.1: Typical steady viscometry method result .....................................26

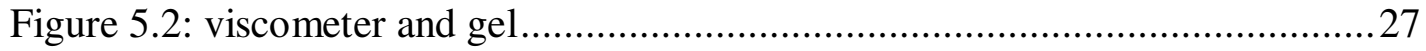

Figure 6.1: Effect of $\mathrm{pH}$-controller on gelation ...............................................29

Figure 6.2: Effect of accelerator on initial gelation time.................................... 30

Figure 6.3: Effect of poly-cross on gelation .................................................. 31

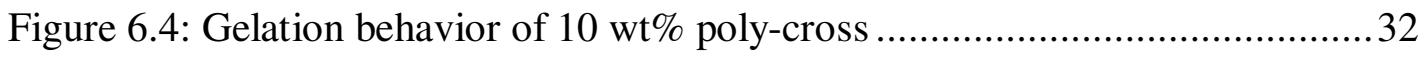

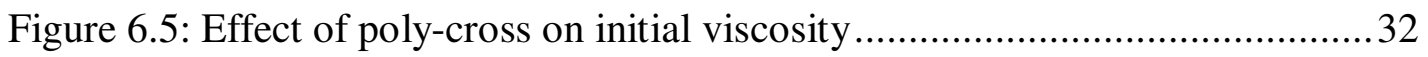

Figure 6.6: Effect of poly-cross on final viscosity ............................................. 33

Figure 6.7: Effect of magnesium chloride on gelation.................................... 34

Figure 6.8: Effect of magnesium chloride on final gelation time .........................35

Figure 6.9: Effect of magnesium chloride on final gel viscosity .........................35

Figure 6.10: Effect of temperature on gelation ............................................... 36

Figure 6.11: Effect of temperature on initial gelation time ............................... 37

Figure 6.12: Effect of temperature on final gelation time ................................. 37

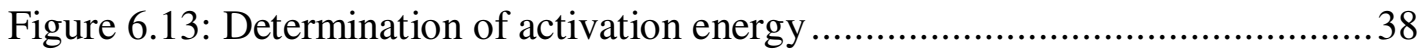

Figure 6.14: Effect of mixing time of solution temperature................................39

Figure 6.15: Effect of mixing time on gelation ............................................ 40

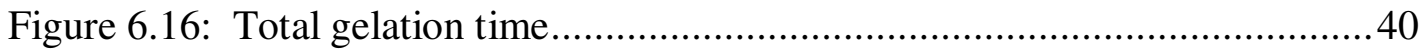

Figure 6.17: Effect of shear on gelation ................................................... 41

Figure 6.18: Effect of shear history on gelation ........................................ 42

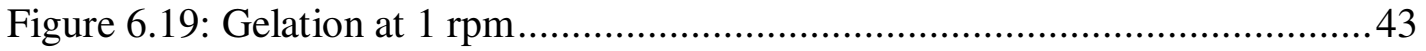


Figure 6.20: Comparison of predicted initial gelation time with measured values ..46

Figure 6.21: Comparison of predicted final gelation time with measured values ....47

Figure 6.22: Comparison of predicted initial viscosity with measured values.........48

Figure 6.23: Comparison of predicted final viscosity with measured values...........49

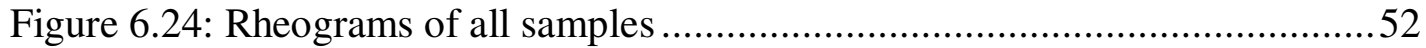

Figure 6.25: Residual mean squares of two-parameter models ..........................53

Figure 6.26: Box-whisker plot of two-parameter models .................................53

Figure 6.27: RMS values of three-parameter models ....................................54

Figure 6.28: Box-Whisker plot of three-parameter models.................................54

Figure 6.29: RSM values for Bingham-Plastic model ..................................57

Figure 6.30: Box-Whisker plot of Bingham-Plastic model...............................57

Figure 6.31: Yield point obtained from regression analysis.............................59

Figure 6.32: Shear stress at $3 \mathrm{rpm}$ correlation with true yield point .....................59

Figure 6.33: Shear stress at 6 rpm correlation with true yield stress ....................60

Figure 6.34: Low shear yield point correlation with true yield point ....................60

Figure 6.35: Modified yield point correlation with true yield point ....................61

Figure 6.36: Box-Whisker illustration of RMS values for LSYP ........................62

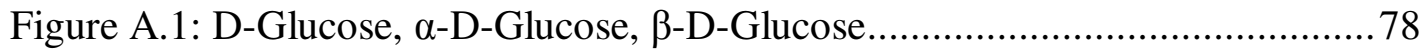

Figure A.2: Chemical structure of amylase and amylopectin............................79

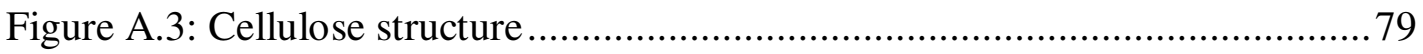

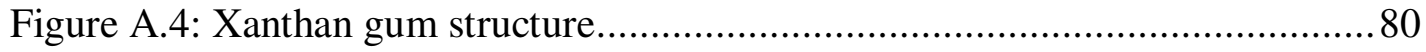

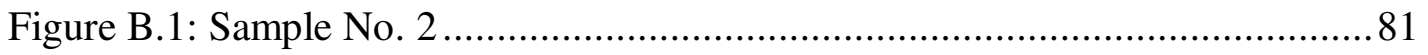

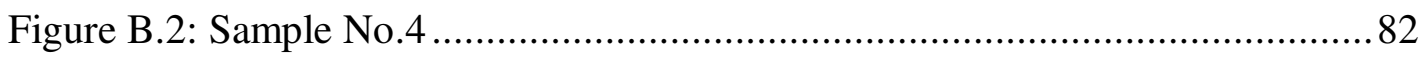

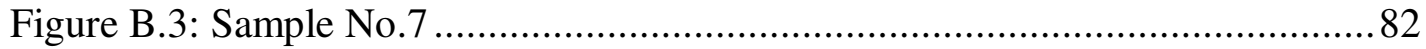

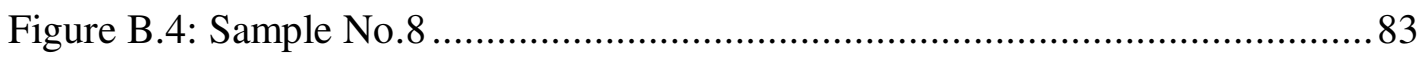

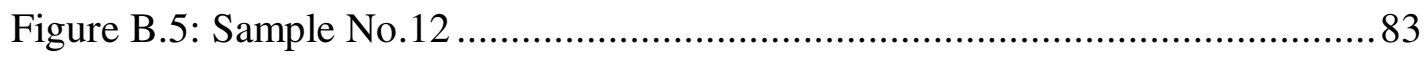

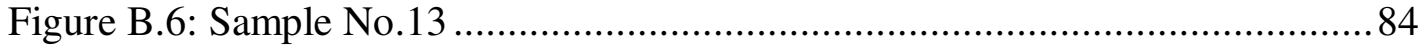

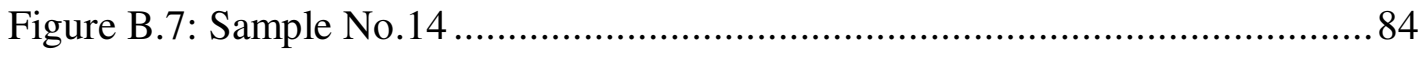

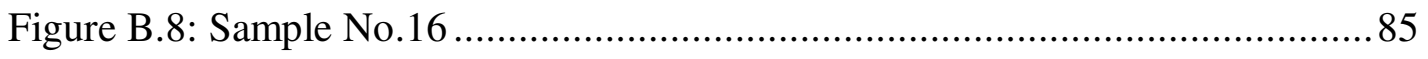

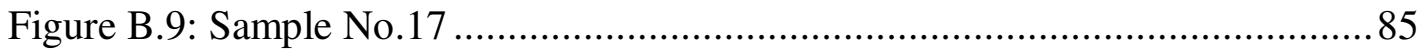




\section{NOMENCLATURE}

\begin{tabular}{|c|c|}
\hline $\mathrm{ACC}$ & Accelerator \\
\hline BHA & Bottom Hole Assembly \\
\hline bopd & barrel of oil per day \\
\hline bgpd & barrel of gas per day \\
\hline BP & Bingham Plastic \\
\hline $\mathrm{CMG}$ & Carboxymethyl Guar \\
\hline CMHPG & Carboxymethyl Hydrapropal Guar \\
\hline DMA & Dynamic Mechanical Analysis \\
\hline DPR & Disproportionate Permeability Reduction \\
\hline DR & Dial Reading \\
\hline ECD & Equivalent Circulating Density \\
\hline EOR & Enhanced Oil Recovery \\
\hline GAG & Gel Alternating Gas \\
\hline GC & Gas Chromatography \\
\hline $\mathrm{H}-\mathrm{B}$ & Herschel Bulkley \\
\hline HMTA & Hexamethylene Tertramine \\
\hline HPG & Hydroxypropyl Guar \\
\hline HQ & Hydroquinone \\
\hline KGM & Konjac Glucomannan \\
\hline LCM & Lost Circulation Material \\
\hline LSYP & Low Shear Yield Point \\
\hline MHHPA & Expoxy-hexaanhydro-4-methylphthalic-anhydride \\
\hline MCC & Magnesia Crosslinked Cement \\
\hline NMR & Nuclear Magnetic Resonance \\
\hline
\end{tabular}




$\begin{array}{ll}\text { OBM } & \text { Oil Based Mud } \\ \text { PAM } & \text { Polyacrylamide } \\ \text { PAtBA } & \text { Polyacrylamide teributyl Acrylate } \\ \text { PEI } & \text { Polyethyleneimine } \\ \text { PHPA } & \text { Partially Hydrolyzed Polyacrylamide } \\ \text { P-L } & \text { Power Law } \\ \text { Poly-Cross } & \text { Polymer-Crosslinker: Form-A-Plug II } \\ \text { RCC } & \text { Regular Crosslinked Cement } \\ \text { Reg } & \text { Regression } \\ \text { RMS } & \text { Residual Mean Squares } \\ \text { RRF } & \text { Residual Resistance Factor } \\ \text { R-S } & \text { Robertson Stiff } \\ \text { RSS } & \text { Residual Sum of Squares } \\ \text { SBM } & \text { Synthetic Based Mud } \\ \text { WGR } & \text { Water Gas Ratio } \\ \text { WBM } & \text { Water Based Mud } \\ \text { YP } & \text { Yield Point } \\ \sigma & \text { Tensile stress } \\ \varepsilon & \text { Tensile strain } \\ \tau & \text { Shear stress } \\ \mu & \text { Viscosity } \\ \gamma & \text { Shear rate } \\ \delta & \text { Phase lag } \\ G^{\prime} & \text { Corage modulus } \\ G^{\prime \prime} & \text { Complex of complex viscosity } \\ \eta^{*} & \end{array}$




\begin{tabular}{|c|c|}
\hline$\alpha$ & Shift factor of frequency \\
\hline$\tau_{y}$ & Yield stress \\
\hline$\mu_{p}$ & Plastic viscosity \\
\hline $\mathrm{k}$ & Consistency factor \\
\hline $\mathrm{n}$ & Flow behavior index, number of data points \\
\hline$\dot{\gamma}_{0}$ & Shear rate corrector of Robertson-Stiff model \\
\hline$\theta_{600}$ & Dial reading at $600 \mathrm{rpm}$ \\
\hline$\theta_{300}$ & Dial reading at $300 \mathrm{rpm}$ \\
\hline$\tau_{m}$ & Measured shear stress \\
\hline$\tau_{p}$ & Predicted shear stress by rheological models \\
\hline $\mathrm{p}$ & Number of parameters \\
\hline $\mathrm{R}$ & Resistance, gas constant \\
\hline$t_{c}$ & Sol-gel transition time \\
\hline$\mu_{i}$ & Initial viscosity \\
\hline$C_{p c}$ & Poly-cross concentration \\
\hline$\mu_{f}$ & Final viscosity \\
\hline $\mathrm{E}$ & Young's modulus, Activation energy \\
\hline$C_{A}$ & Accelerator concentration \\
\hline$C_{r}$ & Retarder concentration \\
\hline $\mathrm{T}$ & Temperature \\
\hline $\mathrm{t}$ & time \\
\hline$t_{i}$ & Initial gelation time \\
\hline$t_{f}$ & Final gelation time \\
\hline$\tau_{3}$ & Shear stress at $3 \mathrm{rpm}$ \\
\hline$\tau_{6}$ & Shear stress at $6 \mathrm{rpm}$ \\
\hline
\end{tabular}




\section{CHAPTER 1}

\section{INTRODUCTION}

Polymer chains can be connected to each other by a crosslinker to make a three dimensional gel structure. Gels represent an intermediate state between liquid and solid that exhibit viscous behavior due to its major portion of solvent as well as elastic behavior due to its network structure. Gels are pumped down in fluid state. Then after a certain time which is called initial gelation time, they are converted to a product that can block subsurface zones for several applications such as: 1. blocking water producing zones due to water coning of oil wells. 2. blocking high permeable zones that prevent low permeable zones of being swept in enhanced oil recovery operations. 3. enhancing hydraulic fracturing by improving the viscosity of fracturing fluid which can increase proppant carrying capacity. In this case, a breaker like an enzyme should accompany the gel system in order to destroy the crosslinking after hydraulic fracturing job for allowing back flow of fluids.

Lost circulation is flow of drilling fluid to subsurface formations due to the natural phenomena like vugular, cavernous or high permeable zones; or due to induced fractures because of high hydraulic pressure on wellbore. It is a big problem which imposes considerable costs on drilling operations. In this thesis, the crosslinking of xanthan with borate has been investigated for blocking the thief zones.

As the best of author's knowledge, for the first time a comprehensive study on gelation behavior of xanthan/borate gel for lost circulation treatment is presented. This thesis will help to understand the effect of key factors on gelation behavior. 
Empirical models will help the drilling industry to manage the concentration of materials required for a well with specific depth and temperature in order to have enough time to pump the fluid, optimize the time for waiting on gel to set, monitor the initial viscosity of gel and final gel quality. In addition rheological model determination helps to understand the fluid flow properties and use it in pressure loss calculation. 


\section{CHAPTER 2}

\section{LITERATURE REVIEW}

In this chapter, a review of publications related to the application of gels for the lost circulation treatment will be given as well as the general studies on gel properties. Then papers on statistical approach for determination of rheological model are presented.

The publications on application of gels for lost circulation treatment are quite rare. Moreover there are some similarities between lost circulation problem and other applications that can help to develop the proposed gel system according to some previous achievements in other areas. For this purpose the literature review of gel applications for water shut-off, profile modification and hydraulic fracturing are given in appendix $\mathrm{C}$.

Sydansk (1988) proposed a qualitative method to examine gelation process. This method is based on observation of inversed bottle flow at different time intervals. Based on these observations, Sydansk proposed a table which appoints a code to any state of flow.

Dawson (1991) employed ${ }^{11} B$ NMR analysis as well as steady and oscillatory measurements in order to examine the crosslinking of galactomannan and borate. He observed that the gel is reversible, thermal and shear thinning. Moreover just at the concentrations higher than $300 \mathrm{lb} / \mathrm{gal}$, di-diol complexes were formed; boric acid 
does not react with polymer and the primary crosslinking is due to ionic association of anionic borate and absorbed cations on second polymer.

Basta et al. (1991) demonstrated the relation between gel kinetics and electrical conductivity referring to geometrical percolation theory. They concluded that there is a correlation between electrical resistance and sol-gel transition time $\left(t_{c}\right)$ : $R \alpha\left(t-t_{c}\right)^{\alpha}$

Kesavan and Prud'humme (1992) measured the rheological properties of guar and hydraoxypropyl guar (HPG) crosslinked with borate ions. Measurements were conducted on $0.48 \mathrm{wt} \%$ polymer and temperatures between 15 to $65^{\circ} \mathrm{C}$ and $\mathrm{pH}$ from 6.35 to 9.5 . The storage and loss modulus obeyed time-temperature and time-pH superposition. Moreover the activation energy of this reaction was obtained to be from 90 to $115 \mathrm{~kJ} / \mathrm{mol}$.

Harris (1993) elucidated the chemistry of borate-crosslinked fluids. Two types of crosslinking are 1:1 complexes which are very predominant but do not change viscosity and 2:1 complexes which are real crosslinking and raise viscosity. Gelation is a function of polymer and borate ion concentration, temperature and $\mathrm{pH}$. He proposed a diagram for borate ion fraction versus $\mathrm{pH}$ at different temperatures for $7.2 \mathrm{lb} / 1000 \mathrm{gal}$ boric acid in $2 \% \mathrm{KCL}$. It shows that with increasing $\mathrm{pH}$, borate ion fraction increases and with increasing temperature, borate ion decreases.

Kruijf et al. (1993) also investigated the chemistry of borate crosslinking fracturing fluids. They described that crosslinking occurs in three steps. First, boric acid dissociates in water and produces borate ion. Then, when enough borate ions are available, 1:1 complex (monodiol) is produced. Finally it will react further with another polymer chain and produces 2:1 complex. This final complex forms a network that increases the fluid viscosity. 
Kolnes et al. (1997) studied the effect of $\mathrm{pH}$ on gelation time of xanthan crosslinked with three different sources of chromium (chromium nitrate, chromium triacetate and basic chromium acetate). $\mathrm{pH}$ was kept at a constant value by autotitrator. The effect of $\mathrm{pH}$ was lower when autotitrator was used compared to $\mathrm{pH}$ control by buffer or no control at all. Moreover, gelation time decreased by factor of 4 and 1.5 for one unit of $\mathrm{pH}$ increased in chromium nitrate and chromium triacetate respectively. However with basic chromium acetate as crosslinker, when $\mathrm{pH}$ was less than 5.5, the gelation time increased by the $\mathrm{pH}$ rise but decreased for $\mathrm{pH}$ values above 5.5.

Shah et al. (1997) were the first to investigate the shear history of borate-crosslinked fracturing fluid by fracturing fluid characterization facility. They observed that gel behavior is dependent on shear history. However an optimum gel at a certain $\mathrm{pH}$ and temperature was found to be shear history independent.

Quinn et al. (1999) explained three methods to solve the lost circulation: 1. the traditional method of solving lost circulation is carried out by employing the lost circulation materials (LCM). If it does not work, cement plugs can be used. However cement plugs cause the formation damage and are expensive due to wait on cement time as well as materials cost. 2. gunk: In this method one fluid is injected through drill pipe and another one through annulus. They are squeezed in to the lost zone by pressure. Then the fluids react and build a rubbery solid material in lost zone which consequently blocks the zone. 3. crosslinked polymer gels: these gels mostly have enough strength to seal formations. They also mentioned that the drawback of gels is that gelation may set in bottom hole assembly (BHA) since gels are mixed on the surface. A new drilling fluid was designed to solve lost circulation. It is an invert emulsion (water in oil) in which a crosslinker is encapsulated inside oil phase. This encapsulation is shear sensitive. As a result it breaks at a minimum shear encountered in BHA. It takes from 30 seconds to 30 minutes for a rigid gel to be obtained which can mitigate lost circulation. 
Boey and Qiang (1999) determined the gel point of an expoxy-hexaanhydro-4methylphthalic anhydride (MHHPA) by dynamic viscometry method. It was concluded that the common $G^{1}-G^{\|}$crossover is not appropriate for finding a gel point. Instead $\tan \delta$ can estimate gel point since it is frequency-independent. In addition the activation energy for crosslinking reaction was obtained to be 75.1 $\mathrm{kJ} / \mathrm{mol}$.

Harris and Batenburg (1999) compared fresh water borate base gel with the one prepared with sea water. Magnesium ion available in sea water reacts with hydroxide and precipitates. In other words it consumes the hydroxide which results in less borate ion available for complexation. The effect of different breakers on viscosity reduction after proppant transportation, the fracture face damage due to leak off of fracturing fluid as well as the damage due to remained polymer in fractures were also studied.

Nishinari et al. (2000) stated that gel represent an intermediate state between liquid and solid states. Gels exhibit fluid like properties since they contain major liquid state as well as solid like behavior because they have a network.

Douglas et al. (2002) described some case studies of applying a crosslinking pill in deepwater of Gulf of Mexico to combat the lost circulation and gave some recommendation for this operation. They suggested the use of $100 \%$ excess slurry volume besides the volume across thief zone as well as explaining the lessons learned from this lost circulation treatment job.

Romero-Zeron et al. (2004) employed low-field nuclear magnetic resonance (NMR) in order to investigate crosslinking of partially hydrolyzed polyacrylamide chromium acetate gel. They found that this method was reliable for finding gel point since it did not affect gelation process at all. The results of NMR were compared 
with bottle testing method and dynamic viscoelastic method but the steady shear viscometry was not included.

Mata and Veiga (2004) reported the use of crosslinked cement to combat lost circulation. Two types of crosslinked cement were suggested: 1. magnesia crosslinked cement (MCC). This cement is a blend of magnesium, calcium oxides, carbonates and sulfate besides carboxy-methyl hydraoxy-ethyl-celulose as a gallant and fluid loss control, a borax based retarder, and zirconium as crosslinker. MCC is designed for the lost circulation in productive zone and is $98 \%$ acid soluble. 2 . regular crosslinked cement (RCC): it is $73 \%$ soluble with acid. As a result it can be used in non-productive zones.

Lecolier et al. (2005) reported the use of a nanocomposite gel to solve the lost circulation problem. However the composition of this gel is not clear. The rheological studies have been conducted using Haake RS 150 viscometer in a controlled shear stress manner. It was observed that the gel system is environmentally friendly, does not degrade after 16 hours at $120^{\circ} \mathrm{C}$, and can effectively plug high permeable zone.

Zhang et al. (2008) investigated crosslinking of partially hydrolyzed polyacrylamide with phenolic aldehyde. They observed three stages of crosslinking: first, in an induction period, intra-molecular crosslinking occurs which leads to a small decrease of viscosity. In the second period as viscosity increases rapidly, intermolecular cross-linking happens. Finally, a long period in which networks is strengthened. It was also concluded that increasing concentration of polymer or crosslinker makes gel stronger due to increasing probability of crosslinking bonds.

Gao et al. (August 2008) examined crosslinking of konjac glucomannan (KGM) with borax at different concentration of konjac and borax as well as strain and temperature by dynamic viscoelastic measurement. At low frequencies, the gel 
system behaves like liquid but it demonstrates elastic relaxation response at higher frequencies. A plateau of storage modulus as well as a maximum and minimum of loss modulus were obvious at this relaxation period. In another study, Gao et al. (December 2008) investigated sol-gel transition time of KGM crosslinked with organic borate using Winter-Chambon criterion. The sol-gel transition time decreased when concentrations of KGM or organic borate as well as temperature increased.

\subsection{Rheological models}

Gucuyener (1983) proposed the following rheological model:

$$
\left.\tau^{1 / m}=\tau_{y}^{1 / m}+\eta \gamma^{1 / 2}, \tau\right\rangle \tau_{y} \text { and } \gamma=0, \tau \leq \tau_{y}
$$

The proposed model is analyzed for 71 drilling fluid and cement samples and it was found that it can describe the behavior of that set of data better than previous models.

Ratkowsky (1990) emphasized that use of $R^{2}$, goodness of fit, is misleading for evaluating non-linear models. " $R^{2}$ has no role to play in such evaluation and need never be calculated".

Okafor and Evers (1992) studied Robertson-Stiff model accuracy in comparison to power law and Bingham Plastic. They concluded that Robertson-Stiff could predict rheological behavior of two types of clay drilling fluids better than those of conventional models.

Weir and Bailey (1996) conducted an extensive statistical study on 414 Fann viscometer data sets in order to find the most fitted rheological model. Twenty rheological models were compared based on residual mean square values shown on 
box-whisker plots. It was found that several other rheological models can exhibit better fitting than conventional models. Moreover interval of confidence and test of significance were calculated.

Bailey and Weir (1998) investigated the best rotational viscometer readings for direct parameter estimation of rheological models. Based on residual mean squares, it was concluded that conventional readings were not appropriate and they suggested new default readings such as: 600/30 combination instead of 600/300 for Bingham Plastic model or 600/100 combination for power law model etc. They also found Sisko as the best fitted model.

Davison et al. (1999) investigated the rheological behavior of drilling fluids which experience cold temperatures in riser for deepwater drilling. They concluded that Herschel-Bulkley and Casson models fit the data for oil based mud (OBM) and synthetic based mud (SBM). For water based muds (WBM), Herschel-Bulkley fitted salt/polymer fluids and unweighted bentonite while Casson was the best for weighted bentonite muds. Since in deepwater drilling the gap between fracture pressure and pore pressure is very narrow, mud weight should be designed very carefully. Therefore equivalent circulating density (ECD) was compared between the proposed model and the one without considering temperature effect. It was found that ECD is underestimated $6.1 \%$ for SBM and overestimated $3.1 \%$ for a WBM which confirmed the importance of accurate rheological model estimation.

Kok et al. (2000) studied the effect of different type of bentonite and concentration on rheological properties. Three bentonite types (karakaya1 and 2, API) bentonite types at 6 concentrations (20-22.5-24-26-28-30) were analyzed. Higher rheology and wall building behavior was observed when cation exchange capacity (CEC) and clay content was increased. It was found that the samples exhibited pseudoplastic behavior at low concentrations while they showed yield pseudoplastic behavior at higher concentrations. 
Power and Zamora (2003) studied yield stress by vane rheometer type. They concluded that among 6 candidates for yield stress measurement: shear stress at 3 rpm, shear stress at $6 \mathrm{rpm}$, low-shear yield point $\left(2 \tau_{3}-\tau_{6}\right)$, zero gel strength, initial gel strength, and 10 minute gel strength, the third one can best represent yield stress based on comparison with vane rheometer results.

Kok and Alikaya (2004) examined $45 \mathrm{KCL} /$ polymer samples in variety of concentrations in order to find the best rheological model. The selection was based on residual mean squares. However $R^{2}$ was also calculated in order to give a rough estimation. It is concluded that power law model can best fit rheograms of KCL/ Polymer drilling fluids.

Kelessidis et al. (2006) employed the golden section search method to find yield stress since non-linear regression of shear stress versus shear rate for finding Herschel-Bulkley parameters may results in unrealistic (negative) values for yield stress. Then the other two parameters by linear regression were calculated. Moreover they demonstrated the effect of these parameters on pressure drop, velocity profile and penetration rate estimation.

Lachement et al. (2008) studied rheological behavior of raw cements as a function of concentration and particle size. Herscehl-Bulkley best fitted the set of data and yield stress was correlated as exponential function of concentration. The rheological behavior depended on both concentration and particle size.

Gucuyener proposed a model for calculating of yield point:

$$
\tau_{y}=\frac{\tau_{3} \tau_{600}-\bar{\tau}^{2}}{2 \bar{\tau}-\tau_{3}-\tau_{600}}
$$

In which $\bar{\tau}$ is shear stress at shear rate of $72.3 \mathrm{sec}^{-1}$. 


\section{CHAPTER 3}

\section{STATEMENT OF THE PROBLEM}

Drilling fluids circulation is a crucial parameter in drilling operation and any induced fracture or a natural event that leads to loss of drilling fluids is quite costly or even may lead to some dangerous consequences. Cost of lost circulation depends on both non-productive time (NPT) spent for treatment and cost of materials. Lost circulation may lead to kick if the hole can not be filled while there is flow of fluid from another formation.

In this thesis, a comprehensive study on a gel behavior was carried out with respect to lost circulation treatment. Gelation behavior of xanthan crosslinked with borate was studied. Initial gelation time, final gelation time, initial viscosity, and final viscosity are necessary parameters for managing a successful lost circulation treatment job by gels. By steady viscometry method, these values were obtained for different polymer blended with cross-linker concentration, $\mathrm{pH}$-controller concentration, magnesium chloride concentration, temperature, mixing time, shear rate and shear history. Knowledge of initial gelation time and viscosity helps us to have enough time and power to pump the fluid down. As a result, blockage of mixer or drillpipe with gel can be prevented. Moreover knowledge of final gelation time and viscosity can help to manage time required for waiting on gel as well as gel final quality to be high enough to resist pressure.

Rheological model determination of this gel was also carried out since it affects several factors in drilling operation. For instance, hydraulics or pressure loss 
calculation is a function of rheological model. A rheological model that best fitted to available data was proposed. Since some models are easier and more popular in industry, some modifications to more common rheological models (Bingham Plastic, and Herschel Bulkley) were sought. This part will help to understand flow of fluid in drillpipe.

As the best of author's knowledge, it is for the first time that xanthan/borate gel system is used for combating lost circulation and effect of variety of parameters are investigated with respect to this high concentration solution. Besides the initial gelation time, three other parameters are defined (final gelation time, initial viscosity, and final viscosity) and the proposed empirical models will fully predict the gel behavior. Therefore, this thesis will help the drilling industry to rely more on this solution to lost circulation problem and manage the job effectively in order to prevent problems and decrease the price by optimizing the concentrations. 


\section{CHAPTER 4}

\section{THEORY}

This chapter explains the chemistry of xanthan crosslinking with borate. Then it will go through the rheological models and the statistical approach to find the best rheological model.

\subsection{Chemistry of crosslinking}

The crosslinking of xanthan gum with borax is a function of borax/borate ion equilibrium. First, Borax $\left(\mathrm{Na}_{2} \mathrm{~B}_{4} \mathrm{O}_{7} \cdot 10 \mathrm{H}_{2} \mathrm{O}\right)$ dissociates into equal amount of boric acid and monoborate ion (Gao, 2007)

$$
\mathrm{B}_{4} \mathrm{O}_{7}^{2-}+7 \mathrm{H}_{2} \mathrm{O} \rightarrow 2 \mathrm{~B}(\mathrm{OH})_{3}+2 \mathrm{~B}(\mathrm{OH})_{4}^{-}
$$

Then there is equilibrium between boric acid and monoborate generation depending on $\mathrm{pH}$ and temperature. (Sinton et al., 1987)

$$
\mathrm{B}(\mathrm{OH})_{3}+\mathrm{H}_{2} \mathrm{O} \stackrel{\mathrm{K}_{A}}{\longleftrightarrow} \mathrm{B}(\mathrm{OH})_{4}^{-}+H^{+} \quad p k_{A}=9-9.2
$$

Figure 4.1 illustrates the dependency of borate ion generation from boric acid on $\mathrm{pH}$ and temperature (Harris and Batenburg, 1999). At a constant temperature, as $\mathrm{pH}$ increases the borate ion fraction increases as well. On the other hand, at a constant $\mathrm{pH}$, as temperature increases, the fraction of borate ion decreases. The Figure also 
reveals that if the solution is not basic, no borate ion will be produced. Figure 4.2 shows borate ion fraction represented by Kruijf et al. (1993). The borate ion fraction increases with increasing $\mathrm{pH}$ till a peak at about 11 . This part is similar to the study by Harris and Batenburg; and the $\mathrm{pH}$ in this thesis is also in this range. However, Kruijf shows the rise of borate ion with increase of temperature in the left section which is in opposition to Harris and Batenburg.

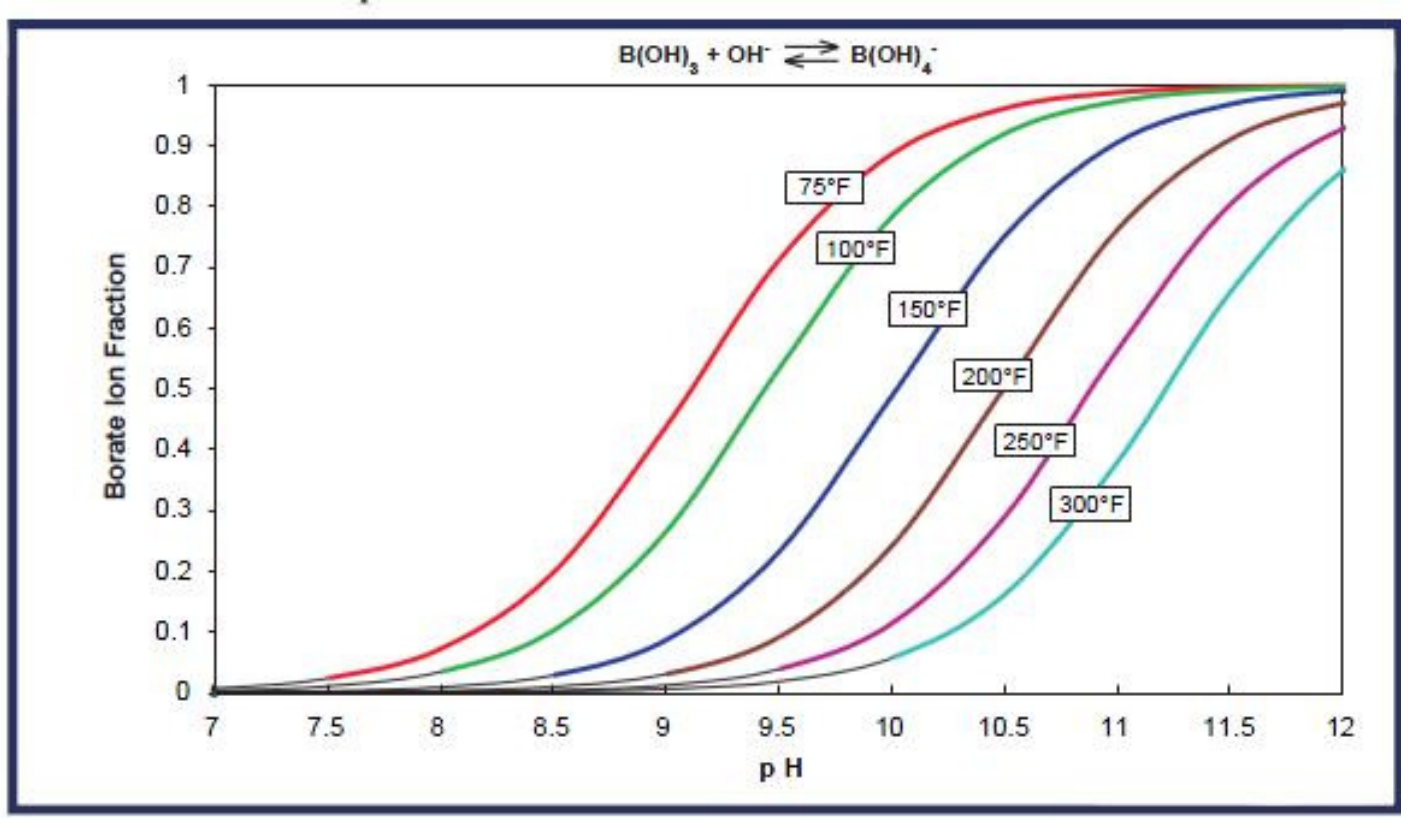

Figure 4.1: Boric acid equilibrium in 5\% KCL [Harris and Batenburg, 1999] 


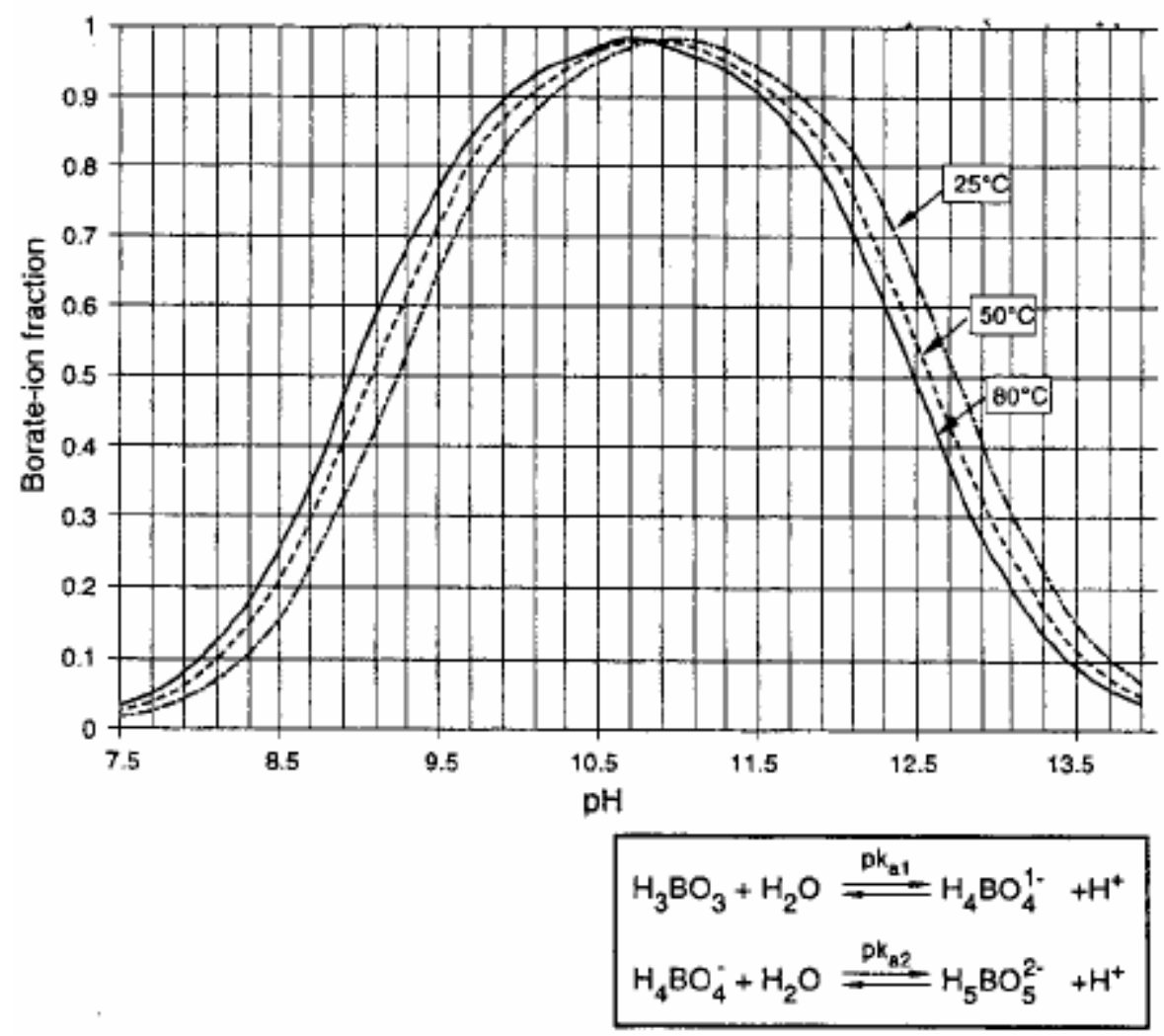

Figure 4.2: Borate ion fraction vs. $\mathrm{pH}$ [Kruijf et al., 1993]

\subsection{Rheological models}

Several models have been suggested to describe the shear stress versus shear rate behavior of fluids. Some of them are reviewed below.

1. Bingham Plastic Model (1957)

Bingham plastic is one of the most common models in petroleum industry. This model defines yield stress $\left(\tau_{y}\right)$, the stress below which there is no flow, and plastic $\operatorname{viscosity}\left(\mu_{p}.\right)$.

$\tau=\tau_{y}+\mu_{p} \cdot \gamma$ 
2. Power law model(de waele 1923, Ostwald 1925)

This is another two parameter model which also called Ostwald-de Waele. The parameters of this model, $\mathrm{k}$ and $\mathrm{n}$, are called consistency index and flow behavior index respectively.

$$
\tau=k \dot{\gamma}^{n}
$$

3. Herschel-Bulkley model(1926)

This is a three-parameter model. It is similar to the Power Law with yield stress term included.

$$
\tau=\tau_{y}+k \dot{\gamma}^{n}
$$

4. Robertson-Stiff model(1976)

It is also a three parameter model with $\gamma_{0}$ as a shear rate corrector.

$\tau=\underset{0}{(\dot{\gamma}+\dot{\gamma})^{B}}$

5. Casson model(1959)

$\tau=\left(\sqrt{\tau_{y}}+\sqrt{(\mu \gamma)^{2}}\right.$

6. Sisko model(1958)

$\tau=a \dot{\gamma}+b \dot{\gamma}^{c}$

For two-parameter models, it is possible to find the coefficients directly since there are two unknowns and it is possible to write two equations with two combinations of data. For Bingham Plastic and power law model, shear stress at 600 and $300 \mathrm{rpm}$ 
is usually used to find the coefficients. Bingham Plastic coefficients can be calculated as:

$$
\mu_{p}=\frac{\tau_{2}-\tau_{1}}{\dot{\gamma}_{2}-\dot{\gamma}_{1}}
$$

$$
\tau_{y}=\tau_{1}-\mu \gamma_{1}
$$

In FANN rotational viscometer with bob/rotor geometry of $1 / 1$, yield stress and plastic viscosity can be obtained directly as a function of shear stress at 600 and 300 rpm:

$\mu_{p}=\theta_{600}-\theta_{300}$

$\mu_{p}=$ plastic viscosity in centipoises (cp)

$\theta_{600}, \theta_{300}=$ dial readings of viscometer at 600 and $300 \mathrm{rpm}$

$$
\tau_{y}=2 \theta_{300}-\theta_{600}
$$

or

$$
\tau_{y}=\theta_{300}-\mu_{p}
$$

$\tau_{y}=$ yield stress in $l b / 100 f t^{2}$

In the same way, power law coefficients can be obtained as:

$$
n=3.3219 \log \left(\frac{\theta_{600}}{\theta_{300}}\right)
$$


$k=\frac{510.88\left(\theta_{300}\right)}{(511)^{n}}$

Flow behavior index is dimensionless and consistency index has unit of cp.

In Herschel-Bulkley method, it is possible to estimate yield stress in some ways, then find other two parameters by linear regression. In regression analysis, any model predicts a shear stress for any shear rate. The sum of square of difference between measured shear stress $\left(\tau_{m}\right)$ and predicted shear stress $\left(\tau_{p}\right)$ for one set of shear rates is called residual sum of squares (RSS).

$$
R S S=\sum_{i=1}^{n}\left[\tau_{m i}-\tau_{p i}\right]^{2}
$$

Then residual mean square (RMS) can be calculated as a criterion for accuracy of models.

$$
R M S=\frac{R S S}{(n-p)}
$$

$\mathrm{n}=$ number of data points (10 points in this study)

$\mathrm{p}=$ number of parameters which are two for Bingham Plastic, Power Law and Casson and three for the other models.

RMS calculations are carried out by Statistica software. The range of RMS values for each model can be depicted in Box-Whisker plots and best model can be chosen based on the smallest median RMS. 


\section{CHAPTER 5}

\section{EXPERIMENTAL WORK}

One of the first tasks of this study was to elucidate the function of each material and obtain a reasonable concentration range for the following experiments. Steady shear viscometry method was chosen and some experiments were conducted to approve that this method can be suitable. The procedure of conducting the experiments is explained in detail at the end of this chapter.

\subsection{Materials}

Turkish Petroleum Corporation generously donated the materials for this thesis. The preliminary purpose of this thesis was to find the theory behind this kind of gelation. After several experiments, this could be obtained and a reasonable concentration range for each material was appointed. Consequently this information is mentioned in Table 5.1. The composition of tap water of METU used in the experiments is given in Table 5.2.

Table 5.1: Materials used in the experiments and their functions

\begin{tabular}{|c|c|c|}
\hline Name & Composition & Function \\
\hline Poly-cross & Xanthan/Borax/ Starch & $\begin{array}{c}\text { Increasing viscosity } \\
\text { (primary polymer and } \\
\text { crosslinker) }\end{array}$ \\
\hline Retarder & Magnesium Chloride & $\begin{array}{c}\text { Decreasing the rate of gelation } \\
\text { and lowering viscosity }\end{array}$ \\
\hline $\begin{array}{c}\mathrm{pH} \text { controller } \\
\text { (Accelerator) }\end{array}$ & Inorganic salt/ Alkali & $\begin{array}{c}\text { Increasing crosslinking rate by } \\
\text { manipulating } \mathrm{pH}\end{array}$ \\
\hline
\end{tabular}


Table 5.2: Composition of tap water of METU (Personal communication with Prof. Dr. Filiz B. Dilek, Environmental Engineering Department, METU)

\begin{tabular}{|c|c|}
\hline Parameter & Concentration(mg/l) \\
\hline $\mathrm{Cr}$ & $<0.02$ \\
\hline $\mathrm{Pb}$ & $<0.001$ \\
\hline As & $<1.0$ \\
\hline $\mathrm{Se}$ & $<1.0$ \\
\hline Cyanide & $<1.0$ \\
\hline $\mathrm{Cd}$ & $<0.001$ \\
\hline Fluoride & 0.34 \\
\hline Nitrate & 1.12 \\
\hline Chloride & 54.6 \\
\hline $\mathrm{Cl}$ & $<0.02$ \\
\hline Sulfate & 147 \\
\hline $\mathrm{Fe}$ & 0.042 \\
\hline $\mathrm{Mn}$ & $<0.03$ \\
\hline $\mathrm{Cu}$ & $<0.001$ \\
\hline $\mathrm{Zn}$ & 0.011 \\
\hline $\mathrm{Ag}$ & $<0.005$ \\
\hline $\mathrm{Ca}$ & 151 \\
\hline $\mathrm{Mg}$ & 26.3 \\
\hline Detergent & $<0.01$ \\
\hline Phenol & $<0.01$ \\
\hline $\mathrm{pH}$ & 7.21 \\
\hline
\end{tabular}

Borax as the raw material of crosslinker and xanthan, primary polymer, are available in a blend called poly-cross to show that it is a blend of polymer and crosslinker. There was no direct access to control the effect of cross-linker or polymer separately. However, the effect of increasing the polymer and cross-linker concentration at a contact ratio was studied. 
Accelerator is a $\mathrm{pH}$-controller agent. When it was not added to the drilling fluid, no gelation occurred even after some days. However, when different concentrations of $\mathrm{pH}$ controller are added, there was no significant change in $\mathrm{pH}$. As it was explained in the chemistry of xanthan/borate crosslinking, $\mathrm{pH}$ controller is used to convert borax to borate ions. Therefore, by increasing the amount of this material, the $\mathrm{pH}$ can be adjusted easier and more borate ions will be available for complexation.

Retarder is magnesium chloride. This material reduces $\mathrm{pH}$ and consequently the amount of borate ions available for complexation. In addition, it decreases the viscosity of primary polymer. Therefore, when the concentration of poly-cross is too high such as $25 \mathrm{wt} \%$, Retarder should be used as the thinner of the drilling fluid.

\subsection{Experimental method}

Model 900 OFITE viscometer was used for the experiments which is a coquette coaxial rotational viscometer. The speed range of motor is between 0.006 to 1000 rpm. The R1B1 geometry combination was employed in this equipment in which bob radius is $1.7245 \mathrm{~cm}$, bob height is $3.8 \mathrm{~cm}$ and rotor radius is $1.8415 \mathrm{~cm}$. As a result, the shear gap is $0.117 \mathrm{~cm}$ and the ratio of bob radius to rotor radius is 0.9365 . Rotation of rotor exerts a shear stress on bob. This stress results in an angle change of bob and a transducer measures it.

A PC software was accompanied with the viscometer. Therefore, all the operations were controlled from computer. The temperature unit was adjusted to centigrade, shear stress to dial reading (DR). However shear stress was later converted to Pascal (Pa) by multiplying with 0.5107 for analysis and shear rate converted to $S^{-1}$ by multiplying with 1.7023 . 
A thermocup with thermocouple was applied for heating the drilling fluid and measuring the temperature. The maximum allowed temperature was $88^{\circ} \mathrm{C}$. Therefore the effect of temperature was studied in the range of room temperature up to $80{ }^{\circ} \mathrm{C}$.

\subsection{Experimental procedure}

The mixing time for the comparison experiments was 10 minutes and for the empirical model determination was 7 minutes. Since the mixing time affects the gelation time, this value was measured carefully. Later for the rheological model determination part, 10 minutes mixing time was applied. The mixer was MULTIMIXER model (Sterling Multi-Products Inc.). Besides the mixer, manually mixing was also done to make sure that mixing was homogenous. The procedure of conducting the experiments is given in below:

1. Weight the materials

2. Turn on the heater of viscometer and set the temperature

3. Pour the water in the mixer cup

4. Add the retarder

5. Start the mixing. Simultaneously start measuring time.

6. Add the poly-cross and mix properly

7. Add the accelerator rapidly at the end

8. Pour the fluid in the viscometer cup

9. Put the cup in the heater of viscometer

10. Start shear rate at $3 \mathrm{rpm}$ and heating simultaneously

11. Observe the apparent viscosity changes with time.

12. Confirm the end of gelation with the results and observation

Thirty six samples at different concentrations and temperatures are prepared by 10 minutes mixing. The concentrations were chosen by trial and error in order to give a reasonable range of initial gelation time, initial viscosity, final gelation time and 
final gel quality. Therefore if some samples had some deficiencies like: very thick initial viscosity, very short gelation time, very long gelation time or very weak final gel, they were removed from the list. Temperatures used are mostly at $60^{\circ}$ and $80^{\circ}$ in order to simulate behavior of gel at lost zone which depends on depth and location. Table 5.3 shows the composition of those samples.

The shear stress was monitored and recorded while the rotor was rotating at steady shear rate of $3 \mathrm{rpm}$. Shear rate at three rpm was chosen since it is the lowest shear rate available in conventional viscometers in order to avoid gel rupture by rotation. However experiments conducted later on lower shear rates like $1 \mathrm{rpm}$ and gel at rest determined similar initial gelation time. 
Table 5.3: Composition of samples used for empirical models

\begin{tabular}{|c|c|c|c|}
\hline $\begin{array}{c}C_{p c} \\
\mathrm{Wt} \%\end{array}$ & $\begin{array}{c}C_{A} \\
\mathrm{Wt} \%\end{array}$ & $\begin{array}{c}C_{r} \\
\mathrm{Wt} \%\end{array}$ & $\begin{array}{l}\mathrm{T} \\
{ }^{\circ} \mathrm{C}\end{array}$ \\
\hline 15 & 5 & 0.25 & 80 \\
\hline 15 & 5 & 0.25 & 60 \\
\hline 15 & 5 & 0 & 60 \\
\hline 15 & 5 & 0 & 80 \\
\hline 15 & 5 & 1 & 80 \\
\hline 15 & 10 & 0.5 & 80 \\
\hline 15 & 10 & 0.25 & 80 \\
\hline 15 & 10 & $\overline{0}$ & 60 \\
\hline 15 & 10 & 0 & 80 \\
\hline 15 & 15 & 0.5 & 80 \\
\hline 15 & 15 & 0.25 & 80 \\
\hline 20 & 5 & 0.5 & 60 \\
\hline 20 & 5 & 0.25 & 80 \\
\hline 20 & 5 & 0 & 60 \\
\hline 20 & 5 & 0 & 80 \\
\hline 20 & 5 & 1 & 60 \\
\hline 20 & 10 & 0.5 & 40 \\
\hline 20 & 10 & 0.5 & 60 \\
\hline 20 & 10 & 0.5 & 80 \\
\hline 20 & 10 & 0.25 & 40 \\
\hline 20 & 10 & 0.25 & 60 \\
\hline 20 & 10 & 0 & 80 \\
\hline 20 & 10 & 1 & 60 \\
\hline 20 & 15 & 0.5 & 40 \\
\hline 20 & 15 & 0 & 60 \\
\hline 20 & 15 & 1 & 80 \\
\hline 25 & 5 & 0.5 & 80 \\
\hline 25 & 5 & 0.25 & 80 \\
\hline 25 & 5 & 0 & 60 \\
\hline 25 & 5 & $\overline{0}$ & 80 \\
\hline 25 & 5 & 1 & 80 \\
\hline 25 & 10 & 0.5 & 80 \\
\hline 25 & 10 & 0.25 & 80 \\
\hline 25 & 10 & 0 & 60 \\
\hline 25 & 10 & 1 & 80 \\
\hline 25 & 15 & 1 & 40 \\
\hline
\end{tabular}


In the rheological model studies, twenty samples were prepared at different concentrations and temperatures. The compositions of samples are depicted in Table 5.4. Shear stress was measured at 10 different shear rates $(0.1,1,3,6,50,100,200$, $300,450,600 \mathrm{rpm})$. The experiments were conducted at different shear rates before initial gelation time. If the initial gelation time was long enough, the experiments were conducted two times, once in decreasing order of shear rate and then in increasing order. Otherwise the experiments were conducted two times and the average value was appointed to it. There is increasing of viscosity due to 1:1 comlexation. On the other hand there is decreasing of viscosity due to thixotropic behavior of xanthan especially in presence of magnesium chloride. There is also error of measuring. The graphs in appendix B show that there is no significant difference between the rheograms. Therefore time independent behavior is assumed.

Table 5.4: Composition of samples for rheological model determination

\begin{tabular}{||c|c|c|c|c||}
\hline & $C_{p c}$ & $C_{A}$ & $C_{r}$ & $\mathrm{~T}$ \\
\hline Sample & $\mathrm{wt} \%$ & $\mathrm{wt} \%$ & $\mathrm{wt} \%$ & ${ }^{\circ} \mathrm{C}$ \\
\hline 1 & 15 & 10 & 0 & 80 \\
\hline 2 & 15 & 5 & 0 & 60 \\
\hline 3 & 15 & 5 & 0 & 80 \\
\hline 4 & 15 & 5 & 1 & 80 \\
\hline 5 & 15 & 10 & 0 & 40 \\
\hline 6 & 15 & 10 & 0 & 60 \\
\hline 7 & 15 & 10 & 1 & 40 \\
\hline 8 & 15 & 10 & 1 & 60 \\
\hline 9 & 15 & 10 & 1 & 80 \\
\hline 10 & 15 & 10 & 0 & 80 \\
\hline 11 & 15 & 7.5 & 0 & 80 \\
\hline 12 & 20 & 5 & 0.5 & 40 \\
\hline 13 & 20 & 5 & 0 & 40 \\
\hline 14 & 20 & 5 & 0 & 60 \\
\hline 15 & 20 & 5 & 0 & 80 \\
\hline 16 & 20 & 5 & 1 & 40 \\
\hline 17 & 20 & 5 & 1 & 60 \\
\hline 18 & 20 & 5 & 1 & 80 \\
\hline 19 & 20 & 10 & 1 & 40 \\
\hline 20 & 20 & 10 & 1 & 80 \\
\hline \hline
\end{tabular}


Figure 5.1 shows a typical result of steady shear viscometry experiment. It demonstrates four parameters measured: 1 . Initial gelation time which is the time of sudden viscosity build up. 2. Initial viscosity which is the viscosity at the first period in which viscosity is almost constant. In this period, there are two opposite effects of 1:1 comlexation and thixotropic effect of xanthan especially in presence of magnesium chloride which results in a little change of viscosity. 3. Final gelation time which is the time when viscosity reaches its peak and the observation confirms this phenomenon as well. Measuring this time is difficult and not accurate since when the final gel is about to produced; the readings are fluctuating and not any more meaningful. 4. Final viscosity is the viscosity at its peak, at the time of final gelation time. Moreover the rate of crosslinking is the slope of line (or the trend of the curve) between the initial gelation time and final gelation time. Figure 5.2 shows the viscometer and the final gel.

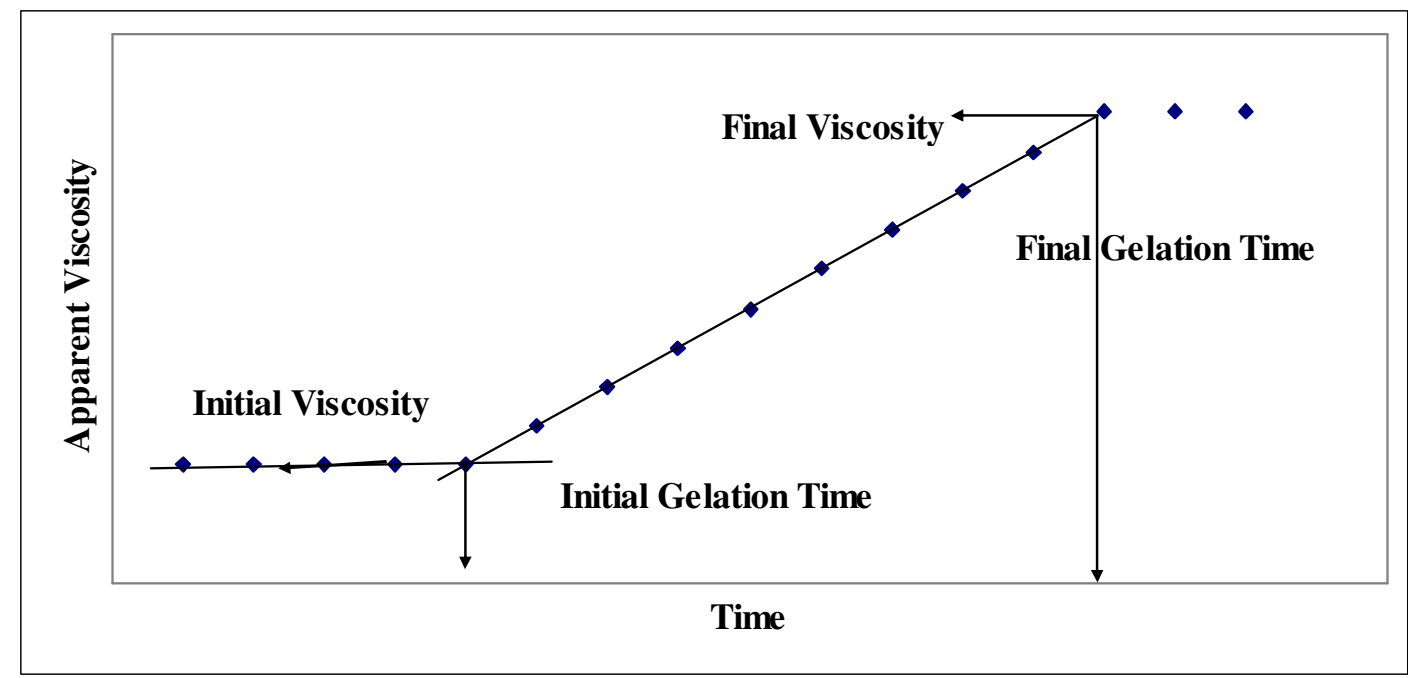

Figure 5.1: Typical steady viscometry method result 


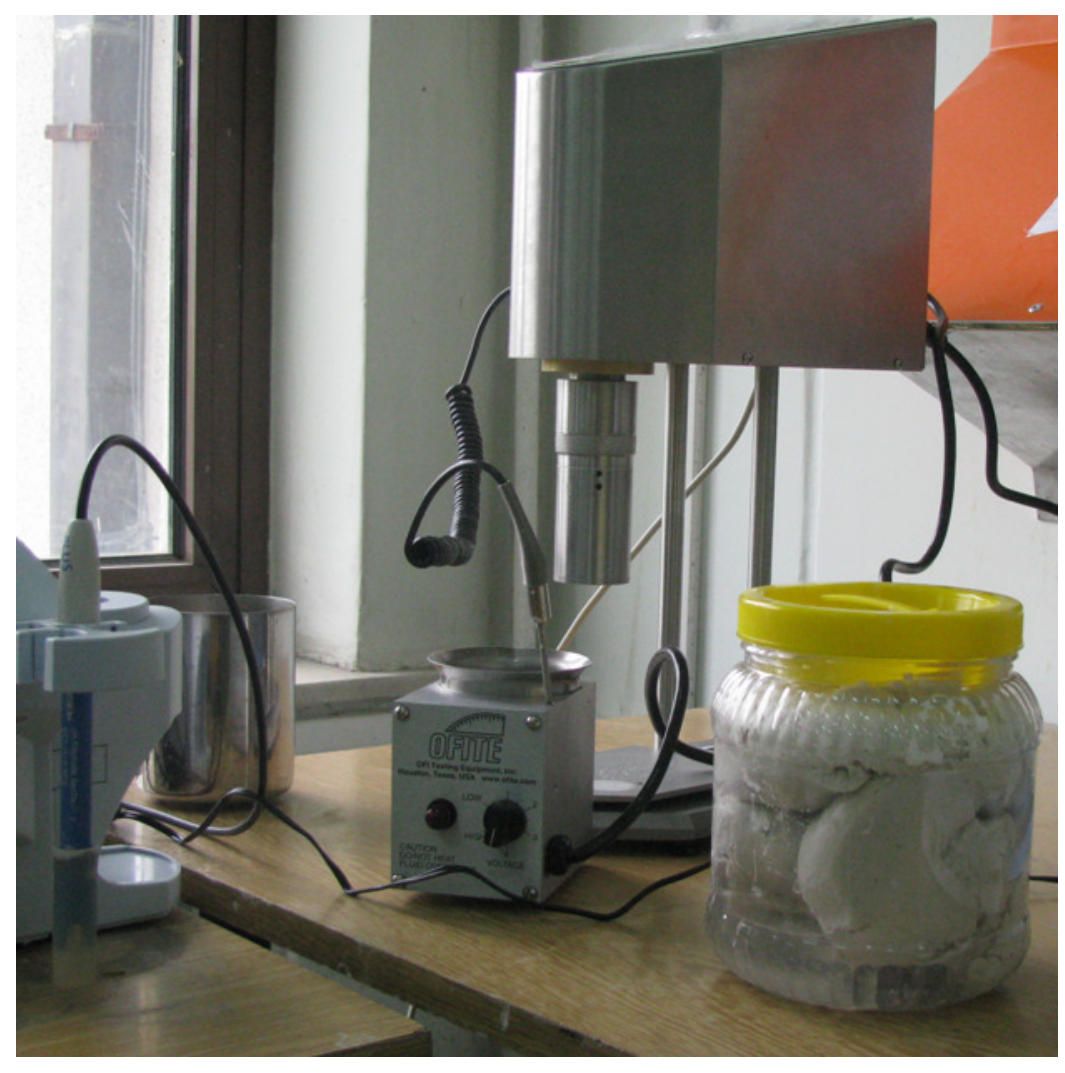

Figure 5.2: viscometer and gel 


\section{CHAPTER 6}

\section{RESULTS AND DISCUSSIONS}

This chapter is divided into three sections: In the first section, the effect of variety of parameters ( $\mathrm{pH}$ controller, magnesium chloride, poly-cross, temperature, shear rate and history, and mixing time) on initial gelation time, final gelation time, initial viscosity, and final viscosity are discussed. In the second section, empirical models for initial gelation time, final gelation time, initial viscosity and final viscosity are given. In the last section, rheological models studies based on shear stress versus shear rate data were conducted and the best fitted rheological model is obtained by a statistical approach. Finally modified Bingham Plastic and yield point models are suggested for this gel system to facilitate use of the rheological model in field operations.

The unit of time is minute, unit of apparent viscosity is cp and the unit of concentration is wt $\%$ throughout this thesis. Otherwise it will be mentioned.

\subsection{Effect of pH-controller on gelation}

It was observed that without adding the $\mathrm{pH}$-controller (accelerator), no gelation occurred even after several days. By adding of accelerator in concentrations of 2.5, $5,7.5$, and $10 \mathrm{wt} \%$, (these concentrations were selected by trial and error in order to have a reasonable range of initial gelation time) the $\mathrm{pH}$ rose to $10.20,10.30,10.40$, and 10.40 respectively. Therefore the accelerator is a necessary part of this system for making an alkaline environment for solution to release borate ion from borax. In 
other words, without adding accelerator, no gelation occurs since no crosslinker (borate ions) can exist without having appropriate $\mathrm{pH}$. Although $\mathrm{pH}$ does not change significantly by adding accelerator, more borate ions can be released by increasing concentration of accelerator. Moreover the amount of borate ion can be more than enough for crosslinking. Therefore initiation of gelation can be accelerated since the possibility of complexation increases. The rate of crosslinking also increases when the ph-controller concentration increases from 2.5 to $5 \mathrm{wt} \%$. Figure 6.1 depicts the effect of $\mathrm{pH}$-controller on gelation.

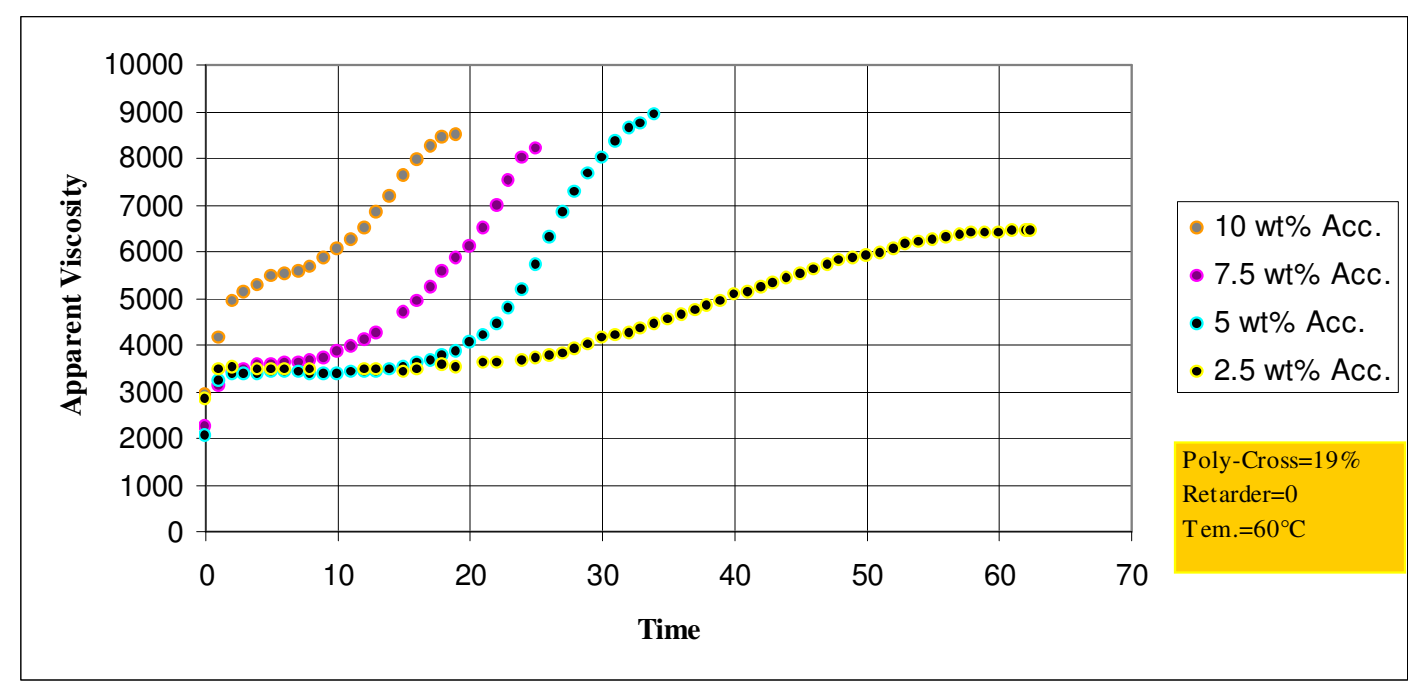

Figure 6.1: Effect of $\mathrm{pH}$-controller on gelation

Initial viscosity depends on xanthan properties. Figure 6.1 reveals that $\mathrm{pH}$-controller has negligible effect on initial viscosity. For $10 \mathrm{wt} \% \mathrm{pH}$-controller, initial viscosity is not clear since the gelation is very rapid.

Final gel viscosity can represent final gel quality. Figure 6.1 also shows the effect of $\mathrm{pH}$-controller on final gel viscosity. Since by adding more $\mathrm{pH}$-controller, more borate ion is available for crosslinking, the final gel network will be stronger. This is clear when $2.5 \mathrm{wt} \%$ is compared with $5 \mathrm{wt} \%$ with 6450 and $8900 \mathrm{cp}$ final viscosities respectively. However there is negligible difference between 5, 7.5, and $10 \mathrm{wt} \%$. It 
can be explained in this way that after a certain $\mathrm{pH}$-controller concentration, more borate ion simply helps initiation of crosslinking, however the final number of crosslinkings do not change. This idea can be strengthened by observing almost constant slope for the first three lines and lower slope for the lowest concentration. Therefore after a certain $\mathrm{pH}$ concentration, the borate ion concentration will be constant. As a result the rate of crosslinking and final viscosity will be constant but initiation of gelation is always accelerated by increasing $\mathrm{pH}$ controller concentration since the possibility of initial attack increases.

Moreover, the final gelation time increases with decreasing $\mathrm{pH}$-controller concentration. Again there is little difference for the first three high concentrations while there is a major increase for the lowest concentration.

Since the main function of $\mathrm{pH}$-controller is to decrease the initial gelation time, the effect of $\mathrm{pH}$-controller on initial viscosity is derived from Figure 6.1 and is depicted in Figure 6.2.

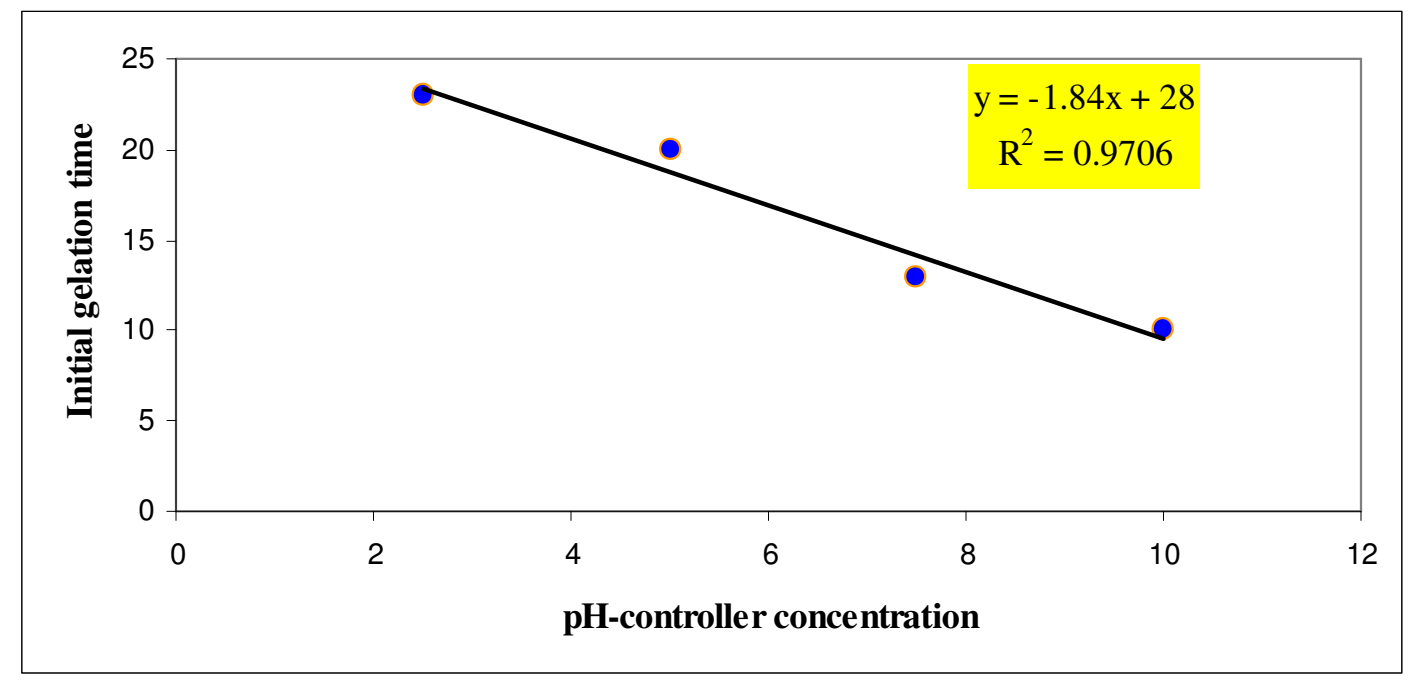

Figure 6.2: Effect of accelerator on initial gelation time 


\subsection{Effect of poly-cross concentration on gelation}

Poly-cross is a blend of polymer, xanthan, and raw crosslinker, borax. (if the concentration of poly-cross is changed, the ratio of polymer to crosslinker remains constant). Figure 6.3 illustrates the effect of poly-cross on gelation. The initial gelation time is almost constant when poly-cross concentration increases.

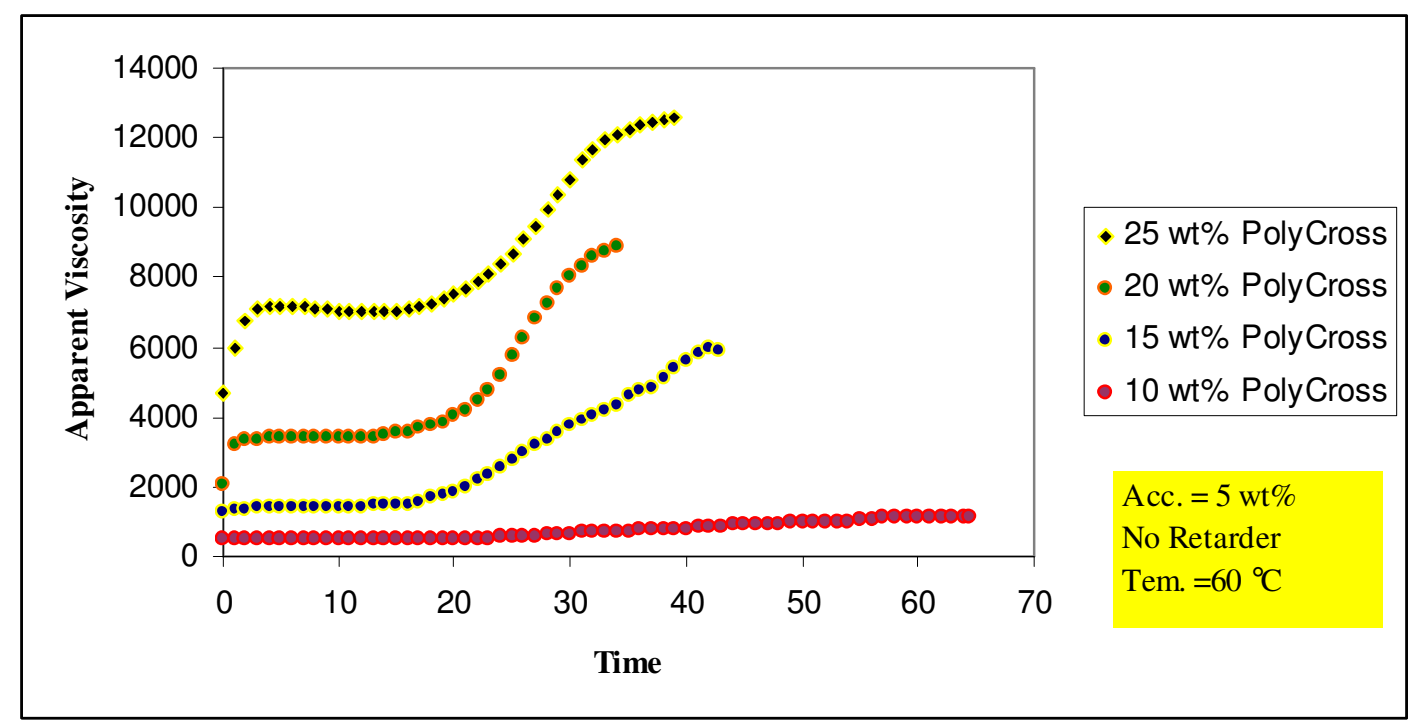

Figure 6.3: Effect of poly-cross on gelation

Final gelation time increases very rapidly when poly-cross concentration drops from $15 \mathrm{wt} \%$ to $10 \mathrm{wt} \%$ since there is not enough borax and xanthan for crosslinking reaction in $10 \mathrm{wt} \%$ poly-cross. However after a certain concentration, the number of crosslinking will be constant and the poly-cross concentration contributes to solution just by increasing viscosity.

The initial gelation time for the $10 \mathrm{wt} \%$ poly-cross is not clear since it has lower viscosity in comparison with others. Therefore, it is shown in a Figure 6.4 separately. 


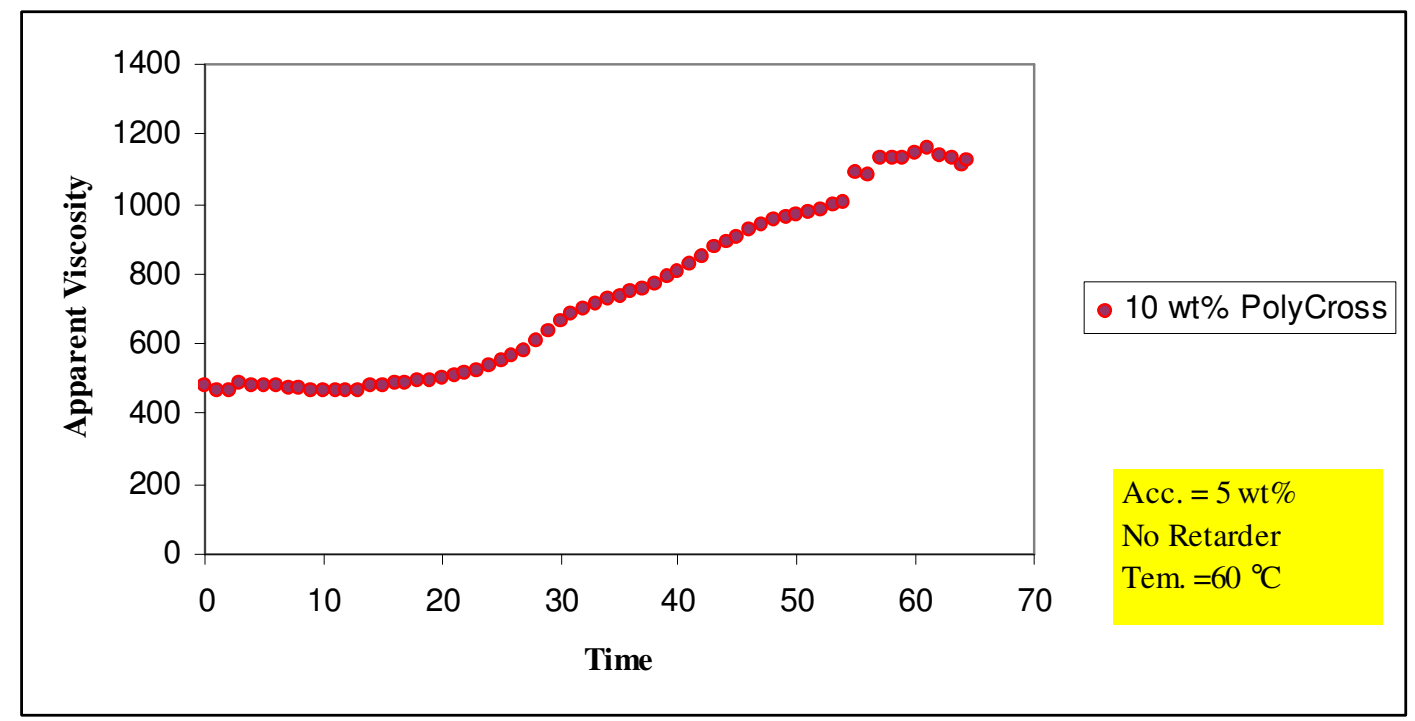

Figure 6.4: Gelation behavior of $10 \mathrm{wt} \%$ poly-cross

The main function of poly-cross is increasing of viscosity. Therefore the initial viscosity of sample in Figure 6.3 is obtained and depicted in Figure 6.5.

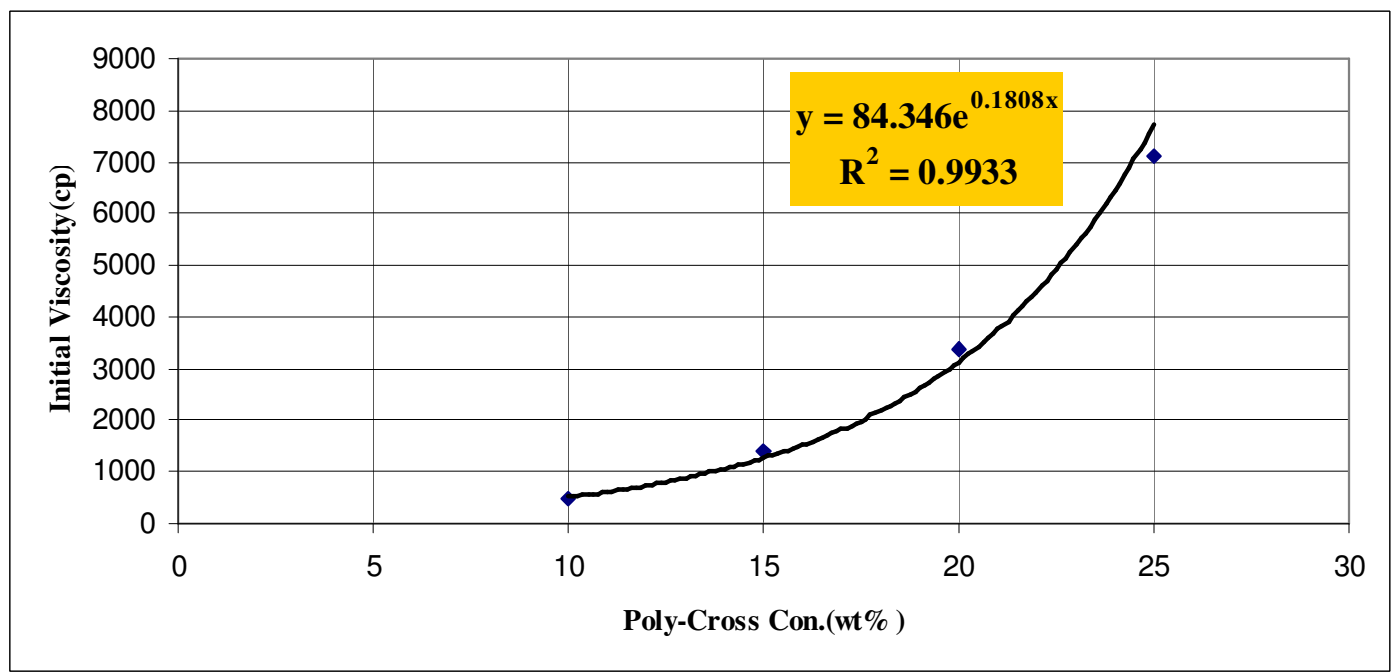

Figure 6.5: Effect of poly-cross on initial viscosity 
According to Figure 6.5, initial viscosity is a significant function of poly-cross concentration and it grows up in an exponential manner but final viscosity is a kind of a linear function of poly-cross concentration (Figure 6.6).

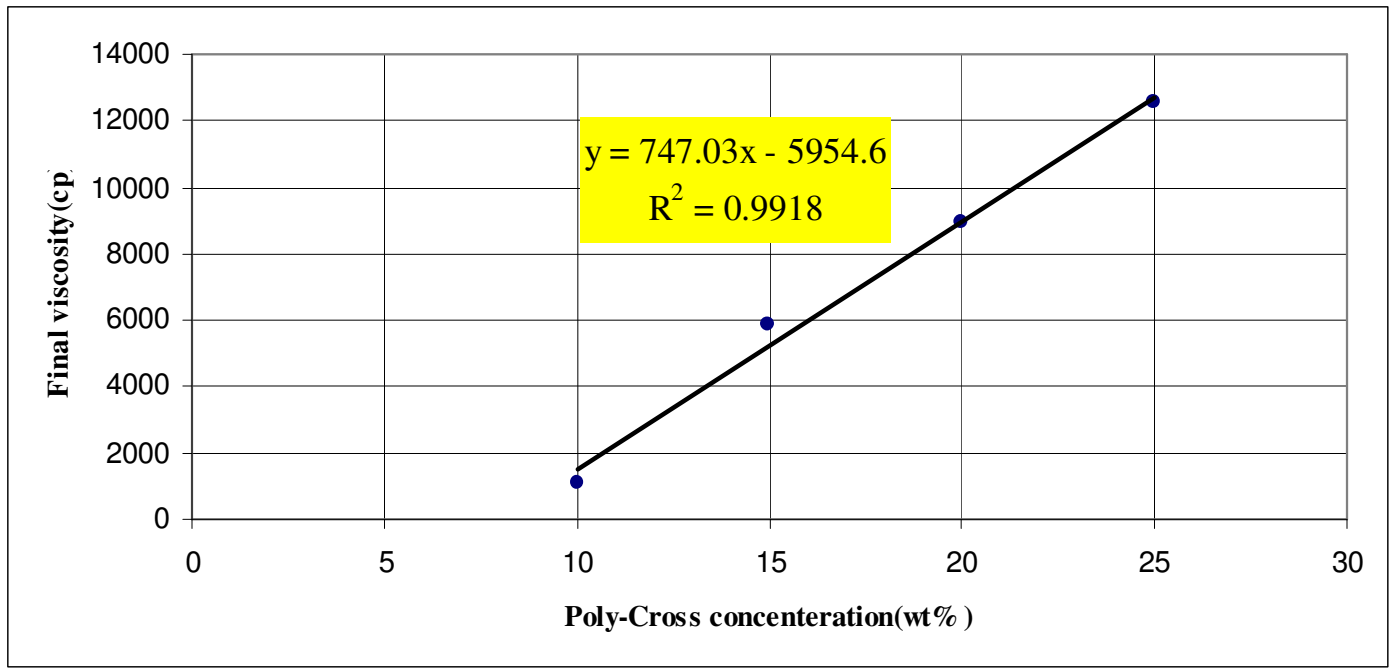

Figure 6.6: Effect of poly-cross on final viscosity

Finally, for this sample initial and final viscosity equations can be obtained from correlating of the data points in Figure 6.5 and 6.6.

$$
\begin{aligned}
& \mu_{i}=84.346 e^{0.181 C_{p c}} \\
& \mu_{f}=747.03 C_{p c}-5954.6
\end{aligned}
$$

$\mu_{i}=$ initial viscosity (cp)

$C_{p c}=$ Poly-cross concentration (wt \%)

$\mu_{f}=$ final viscosity (cp) 


\subsection{Effect of magnesium chloride on gelation}

Magnesium chloride or Retarder contributes to solution by reducing borate ions. Magnesium ions react with $\mathrm{OH}^{-}$ions and precipitates as insoluble $\mathrm{Mg}(\mathrm{OH})_{2}$.

$\mathrm{Mg}^{2+}+2 \mathrm{OH}^{-} \rightarrow \mathrm{Mg}(\mathrm{OH})_{2} \quad$ [Harris and Batenburg]

Therefore hydroxide ions of solution are consumed with magnesium ions which results in less borate ions available for crosslinking. Figure 6.7 illustrates the effect of magnesium chloride concentration $(0,0.25,1$ and $2 \mathrm{wt} \%)$ on gelation process.

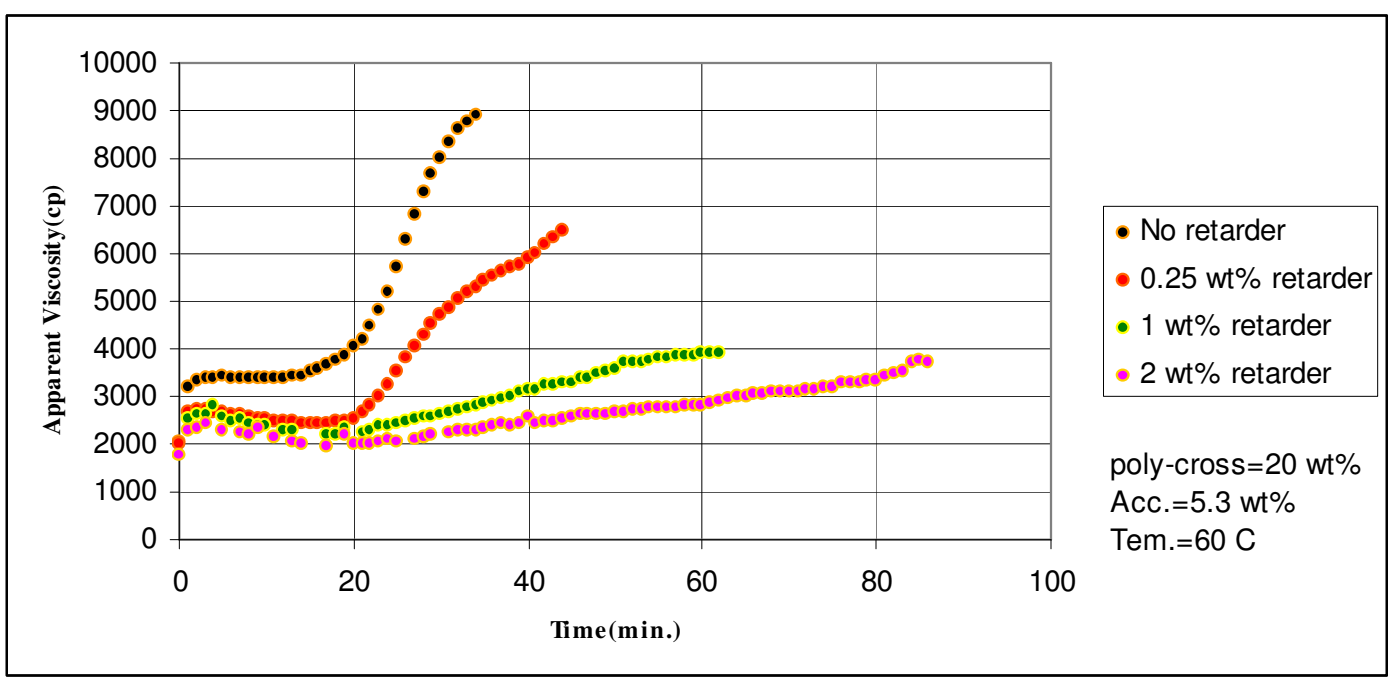

Figure 6.7: Effect of magnesium chloride on gelation

At more than $2 \mathrm{wt} \%$, the solution becomes very dilute and a weak gel will be produced in a long period of time which is not appropriate for lost circulation purposes in which a strong gel in a shortest time after placement in thief zone is reasonable. Initial gelation time changes negligibly with increasing retarder concentration. However rate of crosslinking is significantly higher at lower magnesium chloride concentration. 
Consequently the final gelation time is longer (Figure 6.8). Initial viscosity is a function of xanthan viscosity and xanthan viscosity decreases with the attacks of magnesium chloride on this biopolymer. The final gel is also weaker due to less networks generation shown by lower viscosity (Figure 6.9).

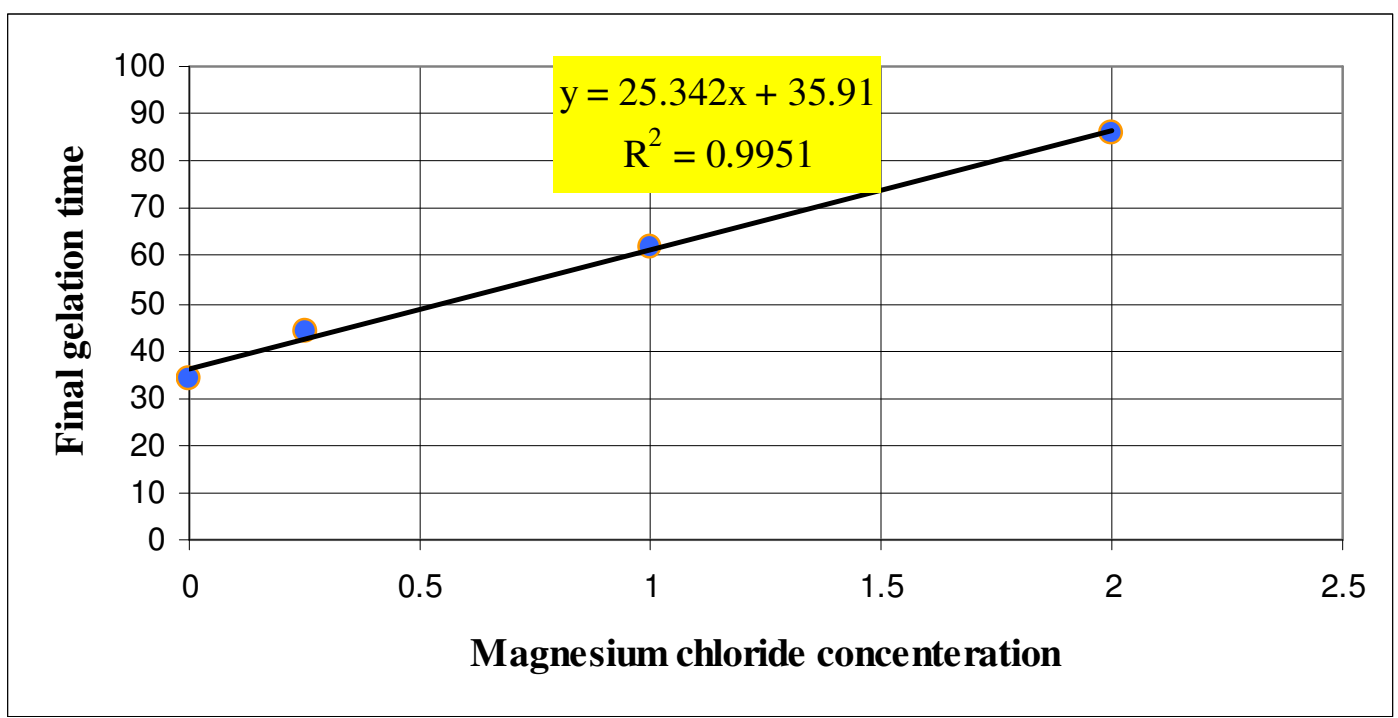

Figure 6.8: Effect of magnesium chloride on final gelation time

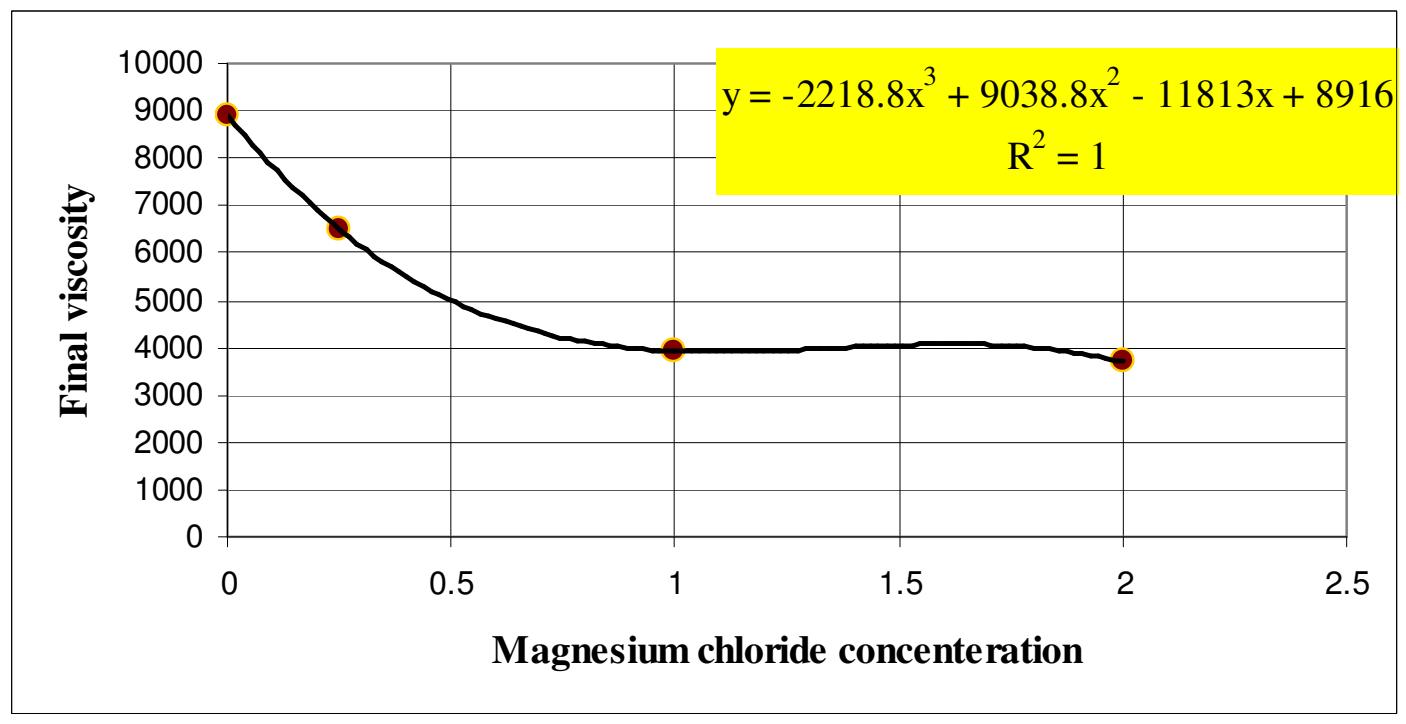

Figure 6.9: Effect of magnesium chloride on final gel viscosity 


\subsection{Effect of temperature on gelation}

This effect is much more complicated. According to borate ion equilibrium by kruijf, more borate ions are available at higher temperature at a constant $\mathrm{pH}$ (however it is in contradiction with what Harris et al. (1993) concluded). Crosslinking is a function of borate ion concentration as well as activation energy of crosslinking. Therefore at higher temperatures, more borate ions are available as well as more energy to overcome enthalpy of crosslinking (according to Harris less borate ions are available at higher temperature. However it can be explained in the way that enthalpy is dominant here).Figure 6.10 shows the effect of temperature on the progress of gelation.

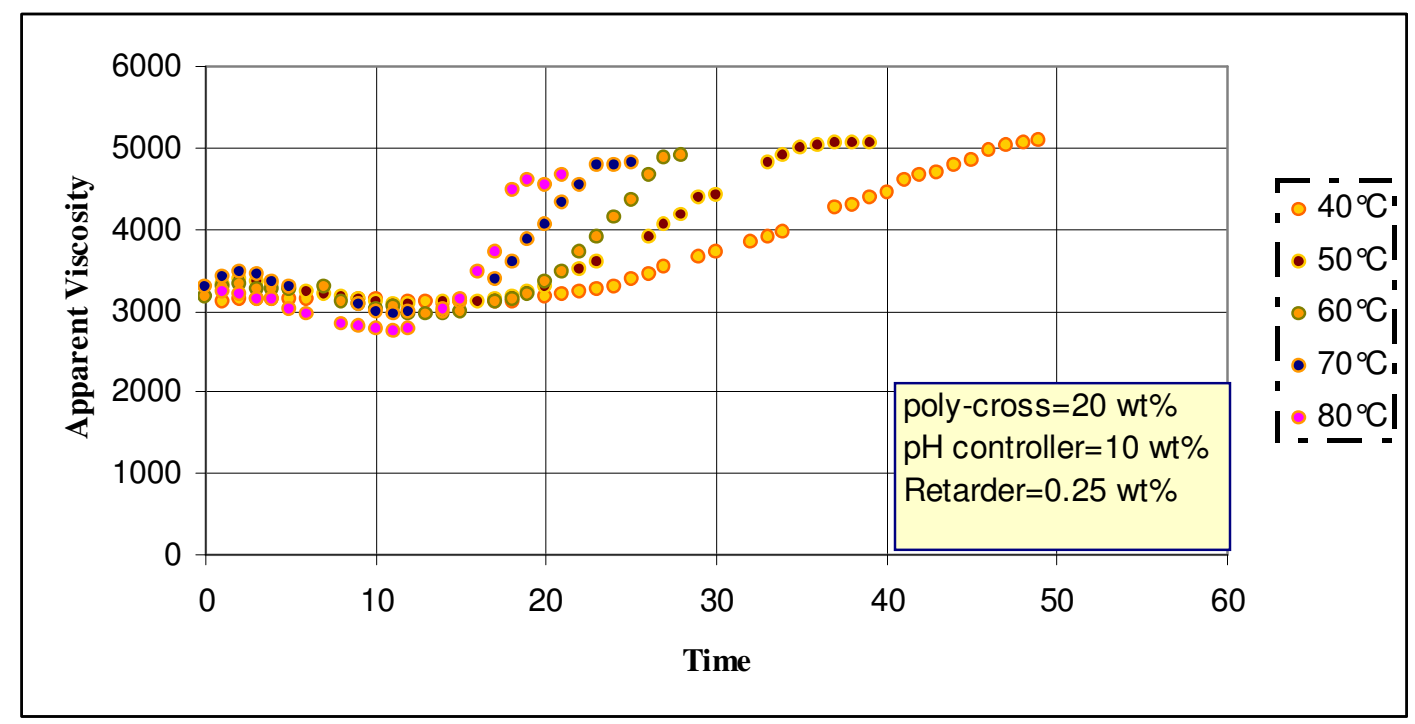

Figure 6.10: Effect of temperature on gelation

Initial gelation time decreases with increasing temperature since more borate ions as well as energy are available for crosslinking reaction. The major effect of temperature is on initial gelation time. Therefore the initial gelation time is obtained from the Figure 6.10 is depicted below in Figure 6.11. Final gelation time is longer at lower temperatures. The effect is shown in Figure 6.12. 


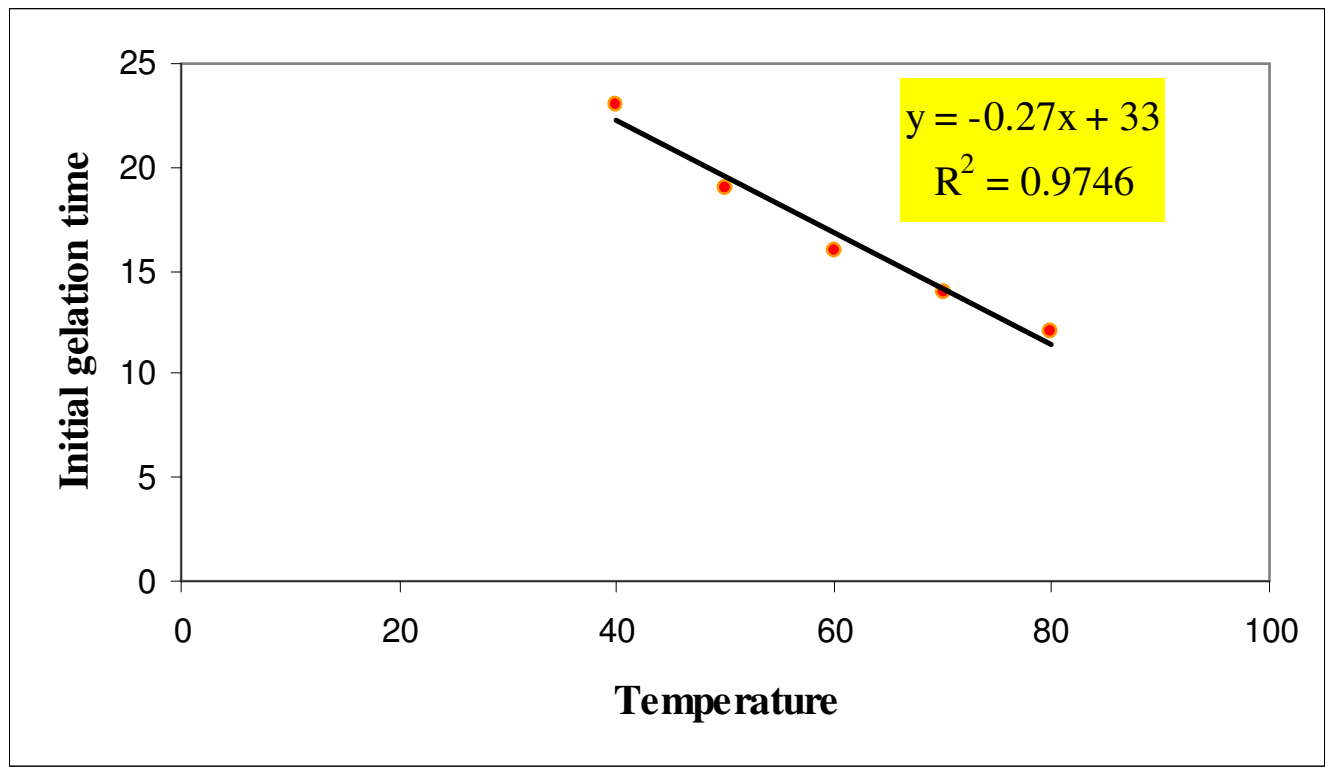

Figure 6.11: Effect of temperature on initial gelation time

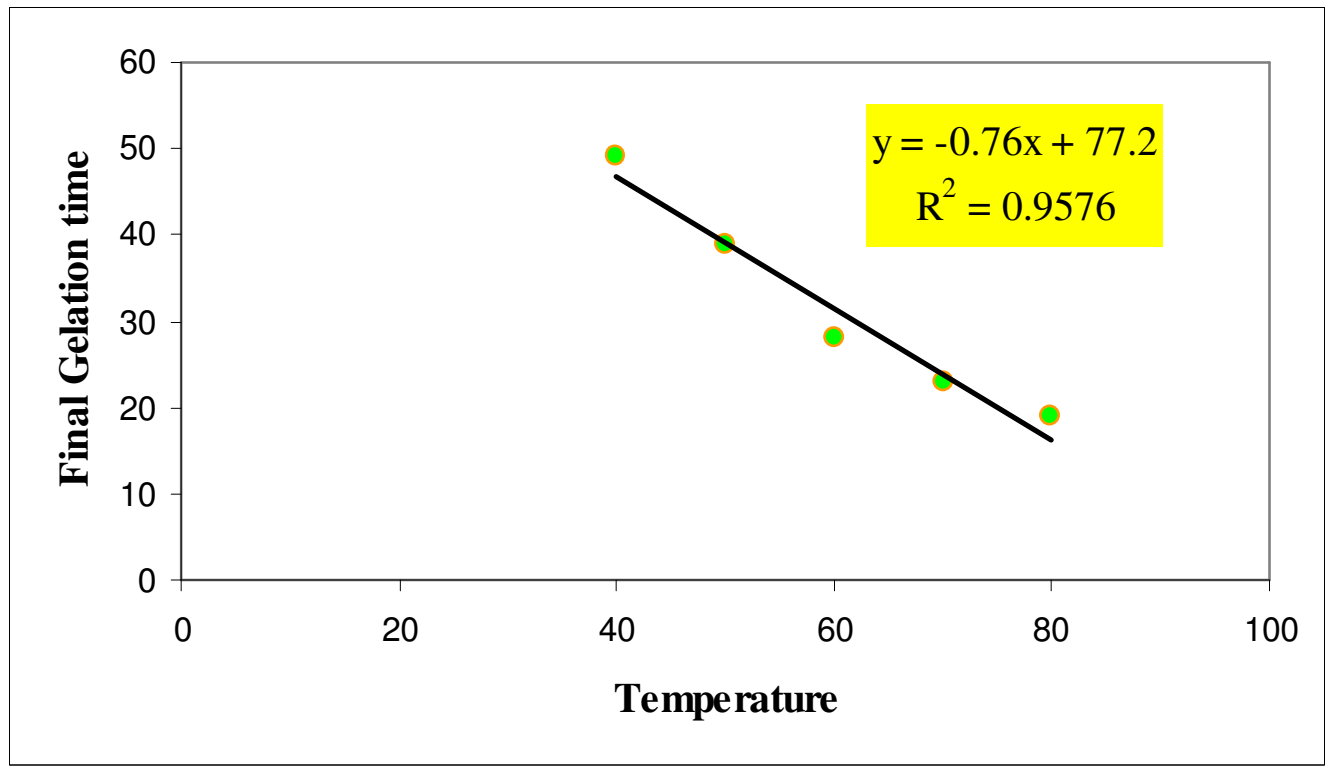

Figure 6.12: Effect of temperature on final gelation time 
The effect of temperature on gelation can be represented by Arrhenius plot of $\ln (1 / \mathrm{t})$ against $1 / \mathrm{T}$ in which $\mathrm{t}$ is time in seconds and $\mathrm{T}$ is temperature in Kelvin.

$\frac{1}{t}=A e^{-E_{a} / R T}$

$\ln (1 / t)=\ln A-\frac{E_{a}}{R} \times \frac{1}{T}$

The slope is equal to $-\mathrm{E} / \mathrm{R}$ in which $\mathrm{E}$ is activation energy and $\mathrm{R}$ is gas constant $(8.314 \mathrm{~J} / \mathrm{K} . \mathrm{mol})$. As a result activation energy calculated is $14.792 \mathrm{~kJ} / \mathrm{mol}$. Figure 6.13 shows the Arrhenius plot for calculating activation energy. When activation energy is known then it is possible to correlate the initial gelation time at other temperatures.

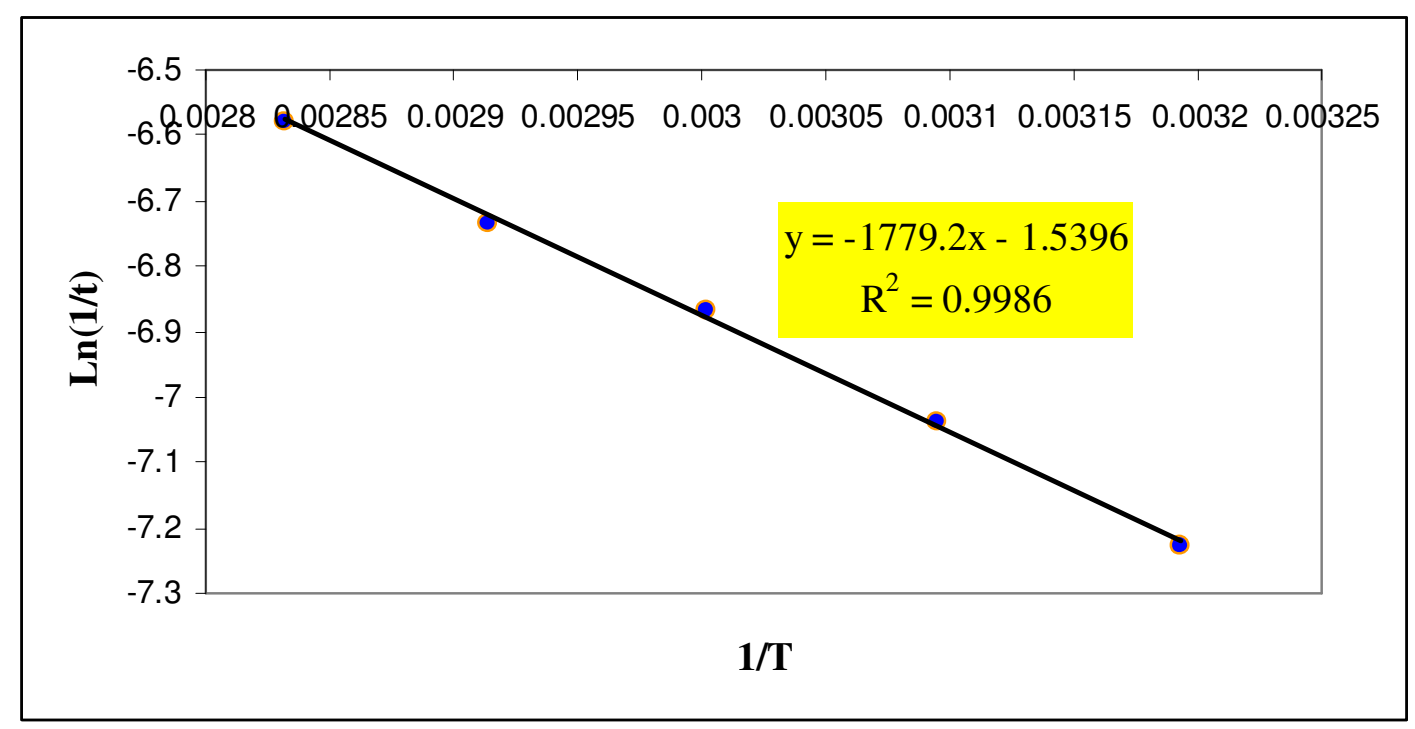

Figure 6.13: Determination of activation energy 


\subsection{Effect of mixing time on gelation}

In this case, solutions (poly-cross $=20 \mathrm{wt} \%$, accelerator $=5.3 \mathrm{wt} \%$, no retarder, temperature $\left.=60^{\circ} \mathrm{C}\right)$ were prepared during different mixing periods $(7,10,15,20,30$ minutes). Then a constant shear rate of $3 \mathrm{rpm}$ was employed. In the end of mixing, the drilling fluid temperature was measured as it is illustrated in Figure 6.14. It increases linearly with increasing mixing time.

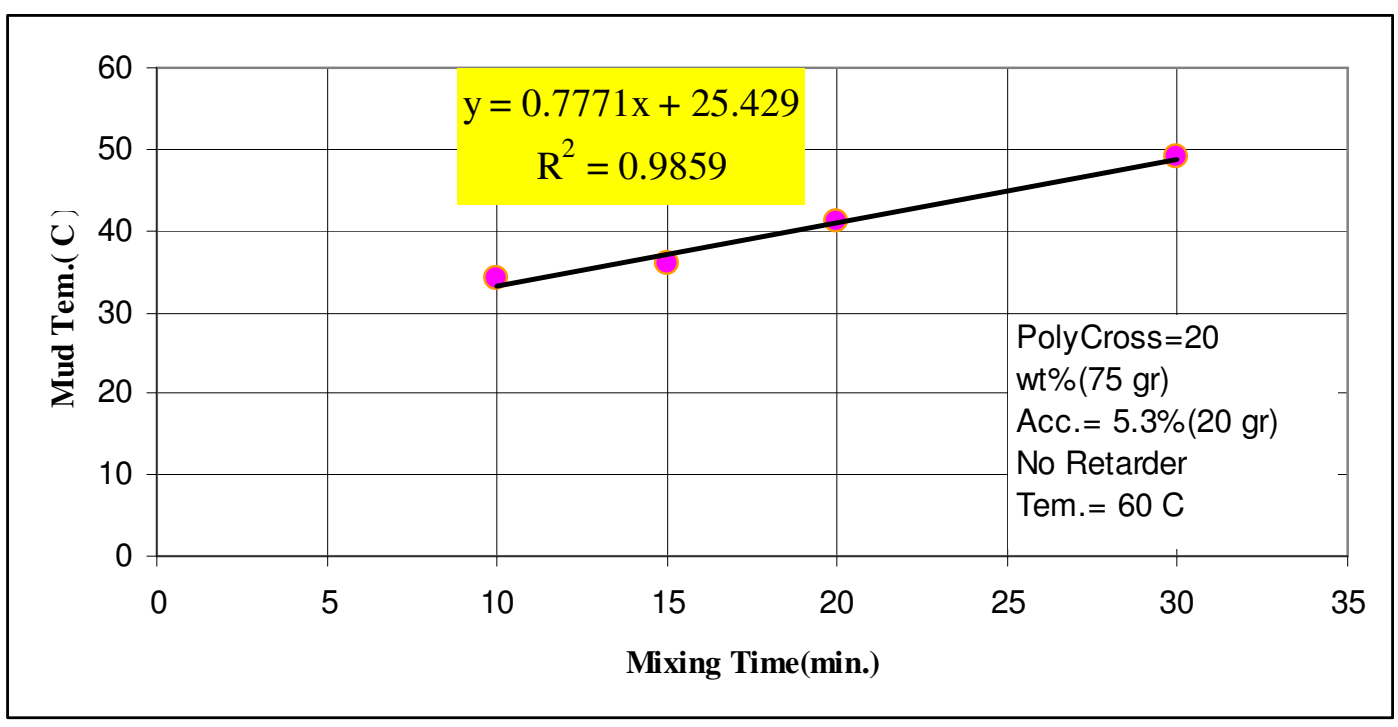

Figure 6.14: Effect of mixing time of solution temperature

Increasing of mixing time, decreases initial gelation time .For the fluid prepared by 30 minutes mixing, a sharp increase of viscosity is observed from the early beginning. Decreasing of initial gelation time can be attributed to increase of fluid temperature as well as to the fact that from beginning of mixing crosslinking starts. Other parameters such as initial viscosity, rate of cross-linking, and final viscosity are almost not affected by mixing time. The gelation behavior can be observed in Figure 6.15.

However when initial gelation time was added to mixing time, all of samples with different mixing time periods had almost the same total time of mixing plus gelation 
time. It proves that from beginning of mixing, time is counted. In other words, gelation can not be delayed by mixing the solution for a longer period of time. Figure 6.16 shows that addition of initial gelation time and mixing time is almost constant.

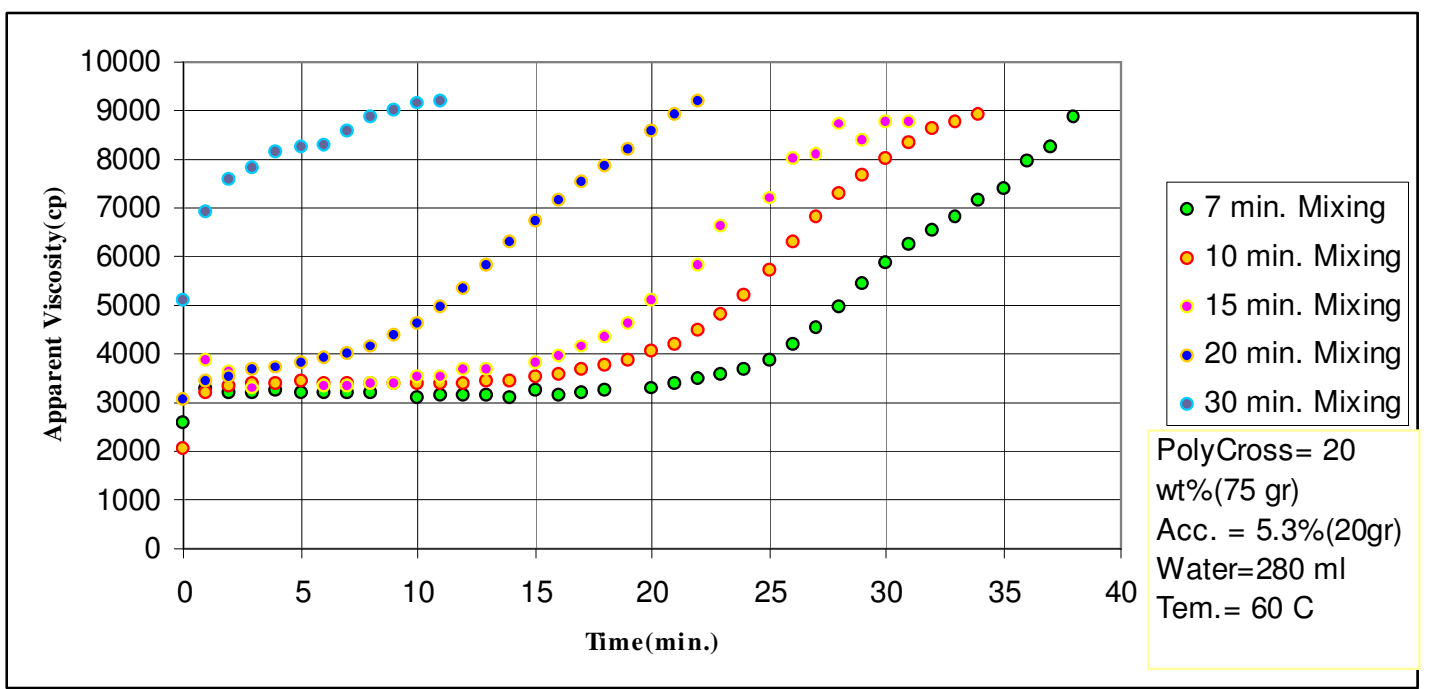

Figure 6.15: Effect of mixing time on gelation

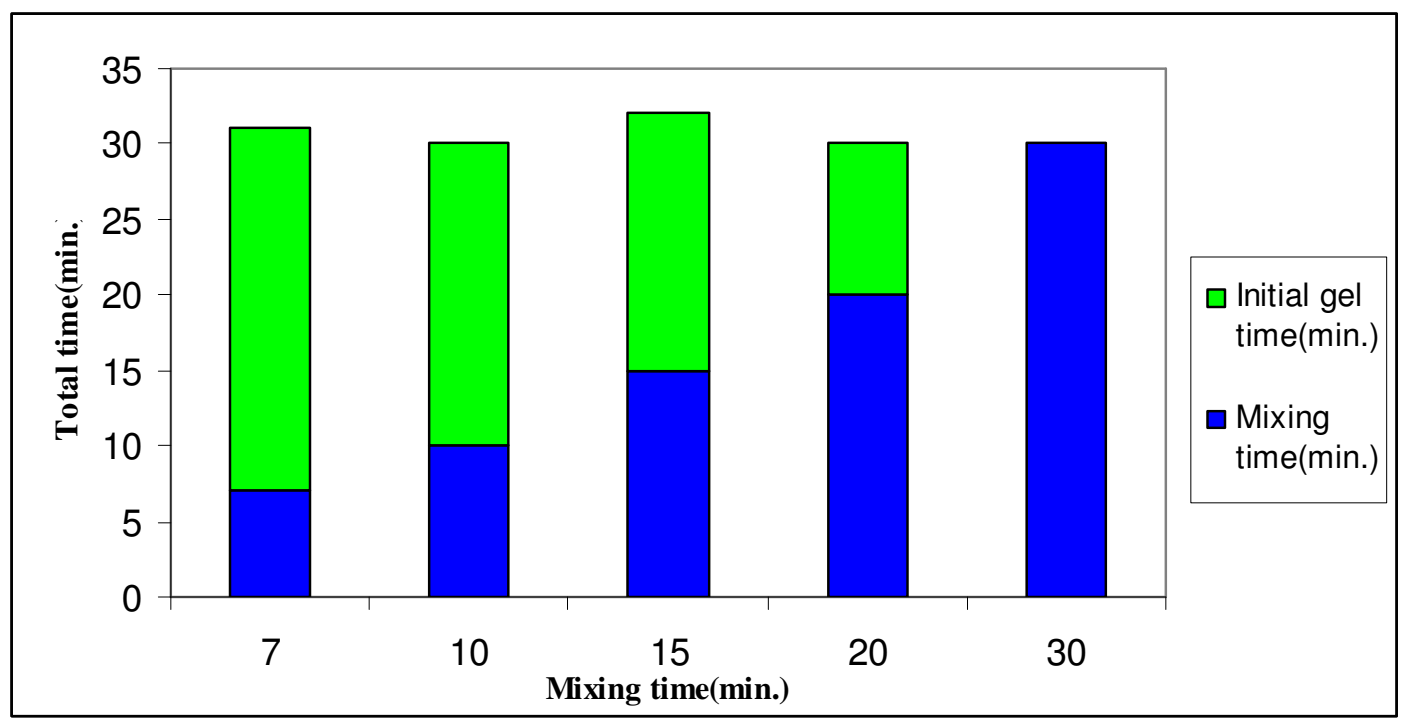

Figure 6.16: Total gelation time 


\subsection{Effect of Shear history on gelation}

Since there is some criticizes from supporters of dynamic viscometry method that shear may cause dissociation of some crosslinks in steady shear viscometry method, the effect of shear on gelation was also investigated.

For a sample, initial gelation time was measured with normal procedure of steady shear viscometry as explained before. Later a similar sample was prepared and put in rest for 15 minutes before initiation of gelation that was obtained from previous experiment (the flat pink line in Figure 6.17 shows this rest time). Then the shear rate at $3 \mathrm{rpm}$ was applied. Figure 6.17 shows that both samples exhibited almost similar gelation time. Thus, the shear did not have any effect on initial gelation time determination. However, the viscosity after initiation of gelation is little higher for the sample being at rest for 15 minutes.

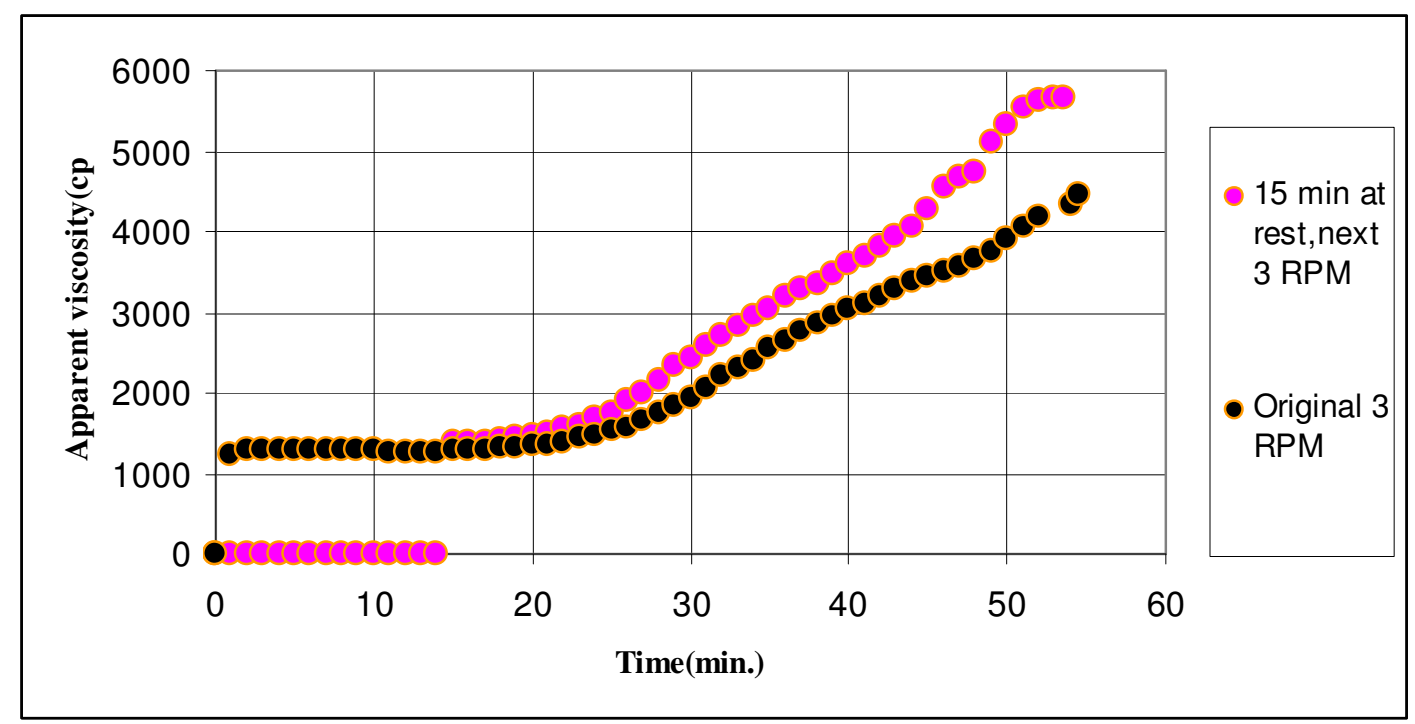

Figure 6.17: Effect of shear on gelation

In order to simulate what happens to gel during its flow inside drillpipe in field operation, experiments were conducted at high shear rates. Two samples were under 100 and 300 rpm for 10 minutes in order to simulate fluid flow in drillpipe. Then the 
shear rate switched to $3 \mathrm{rpm}$ to simulate rest condition at thief zone. Figure 6.18 illustrates that this high shear rate history does not affect initial gelation time. ( The time for shear is not counted in initial gelation time. In other words gelation is postponed here). However the viscosity is higher in this case. Time zero shows the time that the shear rate was switched from 100 or $300 \mathrm{rpm}$ to $3 \mathrm{rpm}$ for the last two samples. It should be noticed that gel can be produced near the wall since the velocity is low there.

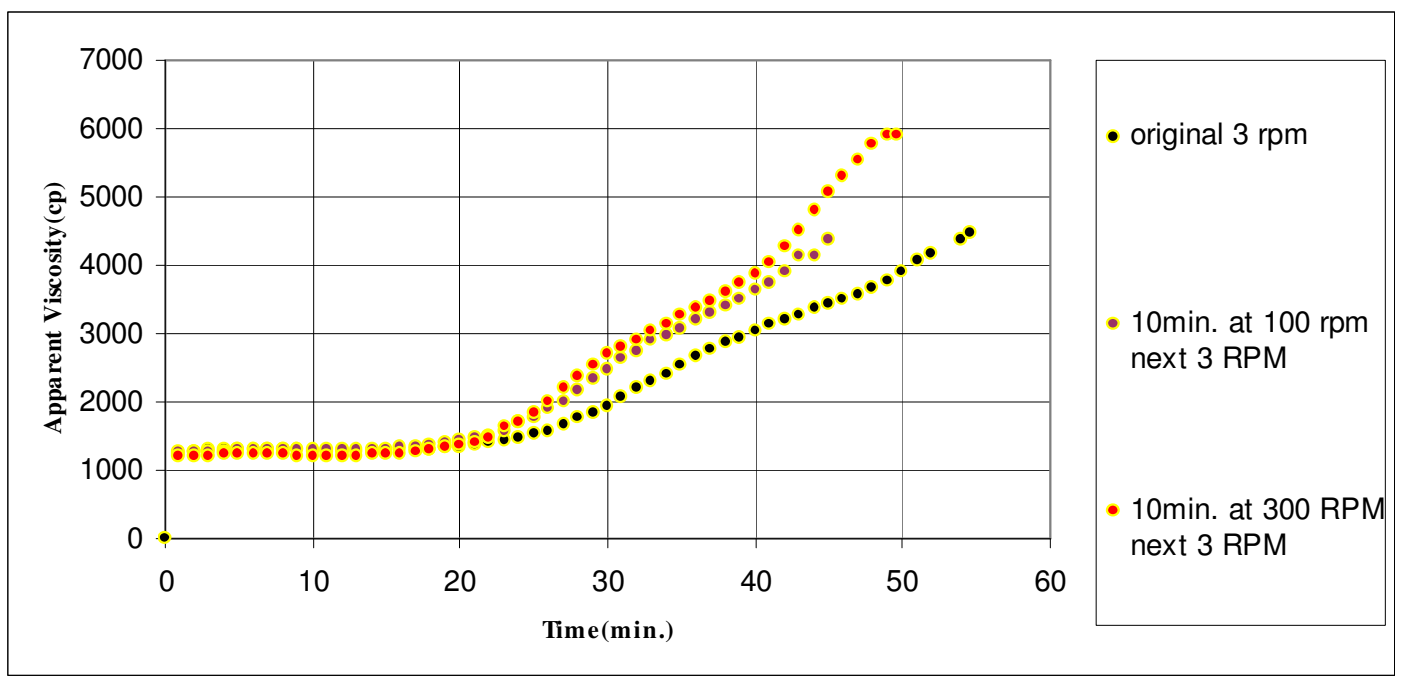

Figure 6.18: Effect of shear history on gelation

Finally an experiment was conducted at shear rate of $1 \mathrm{rpm}$ to see whether lower shear rates( in comparison to $3 \mathrm{rpm}$ ) may change initial gelation time or not. Figure 6.19 shows that the sample at $1 \mathrm{rpm}$ has similar initial gelation time as one at $3 \mathrm{rpm}$ depicted before in Figure 6.17.Therefore it also confirms that rotation at $3 \mathrm{rpm}$ does not have effect on gel destruction on gel. As a result, it is better to conduct experiments at a common $3 \mathrm{rpm}$ shear rate instead of very low ones. 


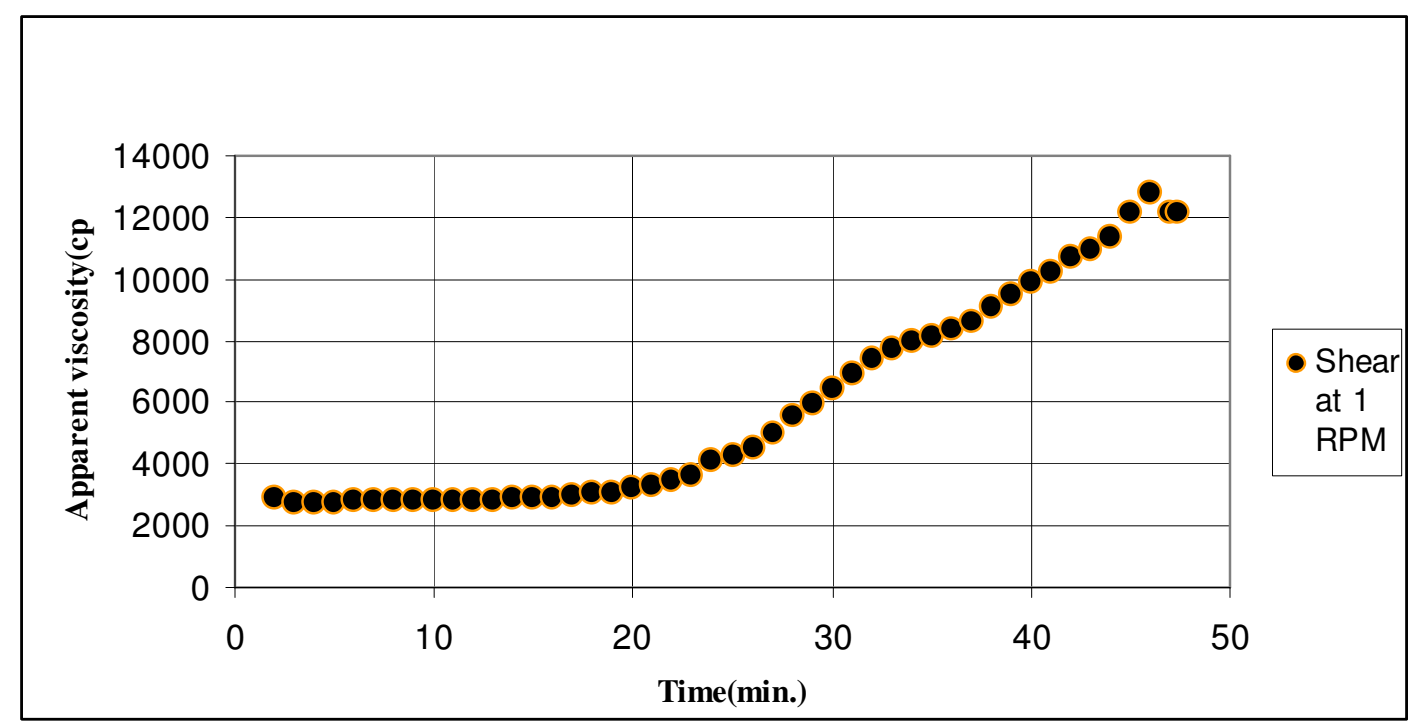

Figure 6.19: Gelation at $1 \mathrm{rpm}$

\subsection{Empirical models for gelation behavior estimation}

In this section, an empirical model for initial gelation time prediction is suggested. Similar models for final gelation time, initial viscosity and final viscosity estimation are given. However the initial gelation time is much more of quantitative importance.

Regression analysis by Statistica software was used to generate empirical models. The models are linear function of four parameters: poly-cross concentration, accelerator concentration, retarder concentration and temperature. By regression analysis and least square method the coefficients were obtained. Then the results from the models and what was obtained from experiments were compared to see the how well they are correlated. The results are depicted in Table 6.1. 
Table 6.1: The results for empirical model determination

\begin{tabular}{|c|c|c|c|c|c|c|c|}
\hline $\begin{array}{c}C_{p c} \\
\mathrm{Wt} \%\end{array}$ & $\begin{array}{c}C_{A} \\
\mathrm{Wt} \%\end{array}$ & $\begin{array}{c}C_{r} \\
\mathrm{Wt} \%\end{array}$ & $\begin{array}{c}\mathrm{T} \\
{ }^{\circ} \mathrm{C}\end{array}$ & $\begin{array}{c}t_{i} \\
\text { Min. }\end{array}$ & $\begin{array}{c}t_{f} \\
\mathrm{Min} .\end{array}$ & $\begin{array}{c}\mu_{i} \\
\mathrm{cp}\end{array}$ & $\begin{array}{c}\mu_{f} \\
\mathrm{cp}\end{array}$ \\
\hline 15 & 5 & 0.25 & 80 & 17 & 35 & 1000 & 1795 \\
\hline 15 & 5 & 0.25 & 60 & 21.5 & 60 & 950 & 2185 \\
\hline 15 & 5 & 0 & 60 & 23 & 50 & 1370 & 6723 \\
\hline 15 & 5 & 0 & 80 & 17 & 36 & 1200 & 6015 \\
\hline 15 & 5 & 1 & 80 & 18 & 51 & 750 & 1138 \\
\hline 15 & 10 & 0.5 & 80 & 15 & 27 & 1200 & 1800 \\
\hline 15 & 10 & 0.25 & 80 & 15 & 23 & 1500 & 2076 \\
\hline 15 & 10 & 0 & 60 & 16.5 & 28 & 1660 & 3100 \\
\hline 15 & 10 & 0 & 80 & 11.5 & 20 & 2300 & 4200 \\
\hline 15 & 15 & 0.5 & 80 & 11 & 23 & 1500 & 2200 \\
\hline 15 & 15 & 0.25 & 80 & 11 & 21 & 1625 & 2765 \\
\hline 20 & 5 & 0.5 & 60 & 25 & 60 & 2400 & 4300 \\
\hline 20 & 5 & 0.25 & 80 & 19 & 31 & 2700 & 5200 \\
\hline 20 & 5 & 0 & 60 & 22 & 45 & 3170 & 10600 \\
\hline 20 & 5 & 0 & 80 & 17 & 23 & 4000 & 8300 \\
\hline 20 & 5 & 1 & 60 & 22 & 75 & 1900 & 4200 \\
\hline 20 & 10 & 0.5 & 40 & 22 & 53 & 3700 & 5400 \\
\hline 20 & 10 & 0.5 & 60 & 16 & 27 & 3400 & 4800 \\
\hline 20 & 10 & 0.5 & 80 & 14 & 23 & 3850 & 5050 \\
\hline 20 & 10 & 0.25 & 40 & 20 & 50 & 3150 & 5250 \\
\hline 20 & 10 & 0.25 & 60 & 18 & 43 & 3100 & 7200 \\
\hline 20 & 10 & 0 & 80 & 9 & 15 & 6200 & 9400 \\
\hline 20 & 10 & 1 & 60 & 19 & 59 & 2100 & 5900 \\
\hline 20 & 15 & 0.5 & 40 & 18 & 48 & 6200 & 7700 \\
\hline 20 & 15 & 0 & 60 & 10 & 17 & 7350 & 8230 \\
\hline 20 & 15 & 1 & 80 & 10 & 17 & 3300 & 4300 \\
\hline 25 & 5 & 0.5 & 80 & 19 & 40 & 5030 & 11600 \\
\hline 25 & 5 & 0.25 & 80 & 19 & 27 & 6000 & 9930 \\
\hline 25 & 5 & 0 & 60 & 20 & 44 & 8280 & 17900 \\
\hline 25 & 5 & 0 & 80 & 15 & 21 & 9600 & 14385 \\
\hline 25 & 5 & 1 & 80 & 19 & 36 & 5170 & 6900 \\
\hline 25 & 10 & 0.5 & 80 & 13 & 20 & 9000 & 9580 \\
\hline 25 & 10 & 0.25 & 80 & 12 & 18 & 9100 & 10600 \\
\hline 25 & 10 & 0 & 60 & 14 & 25 & 11500 & 20000 \\
\hline 25 & 10 & 1 & 80 & 13 & 26 & 7600 & 8500 \\
\hline 25 & 15 & 1 & 40 & 17 & 35 & 9600 & 11500 \\
\hline & & & & & & & \\
\hline
\end{tabular}


The following model was obtained for initial gelation time:

$t_{i}=40.65-0.15 C_{p c}-0.94 C_{A}+2.62 C_{r}-0.20 T$

$t_{i} \quad$ : Initial gelation time (min.)

$C_{p c}:$ Poly-cross concentration (wt \%)

$C_{A}:$ Accelerator concentration (wt \%)

$C_{r}:$ Retarder concentration (wt \%)

$\mathrm{T}$ : Temperature $\left({ }^{\circ} \mathrm{C}\right)$

In equation 6.6, the negative sign of poly-cross, accelerator and temperature coefficients show that they decrease the initial gelation time. On the other hand, retarder with positive coefficient sign increases initial gelation time.

The range of input of these parameters is as follows: poly-cross (15-25 wt \%), accelerator (5-15 wt \%), retarder (0-1 wt \%) and temperature (40-80). Therefore if they are substituted in the formula, they can contribute to the equation in this way: Poly-cross $(-2.25$ to -3.75$)$, accelerator $(-4.75$ to -14.1$)$, retarder $(0$ to +2.62$)$ and temperature (-8 to -16$)$.

Therefore if they are compared with the constant of equation, it can be concluded that retarder and poly-cross has negligible effect while accelerator and temperature have major effect on initial gelation time. This is in absolute agreement with what was explained before during the investigation of effect of parameters on gelation.

Figure 6.20 compares the results from the model with what was measured for initial gelation time. The line is almost passing through $\mathrm{y}=\mathrm{x}$ and $R^{2}$ of 0.875 shows that the model is fairly good. 


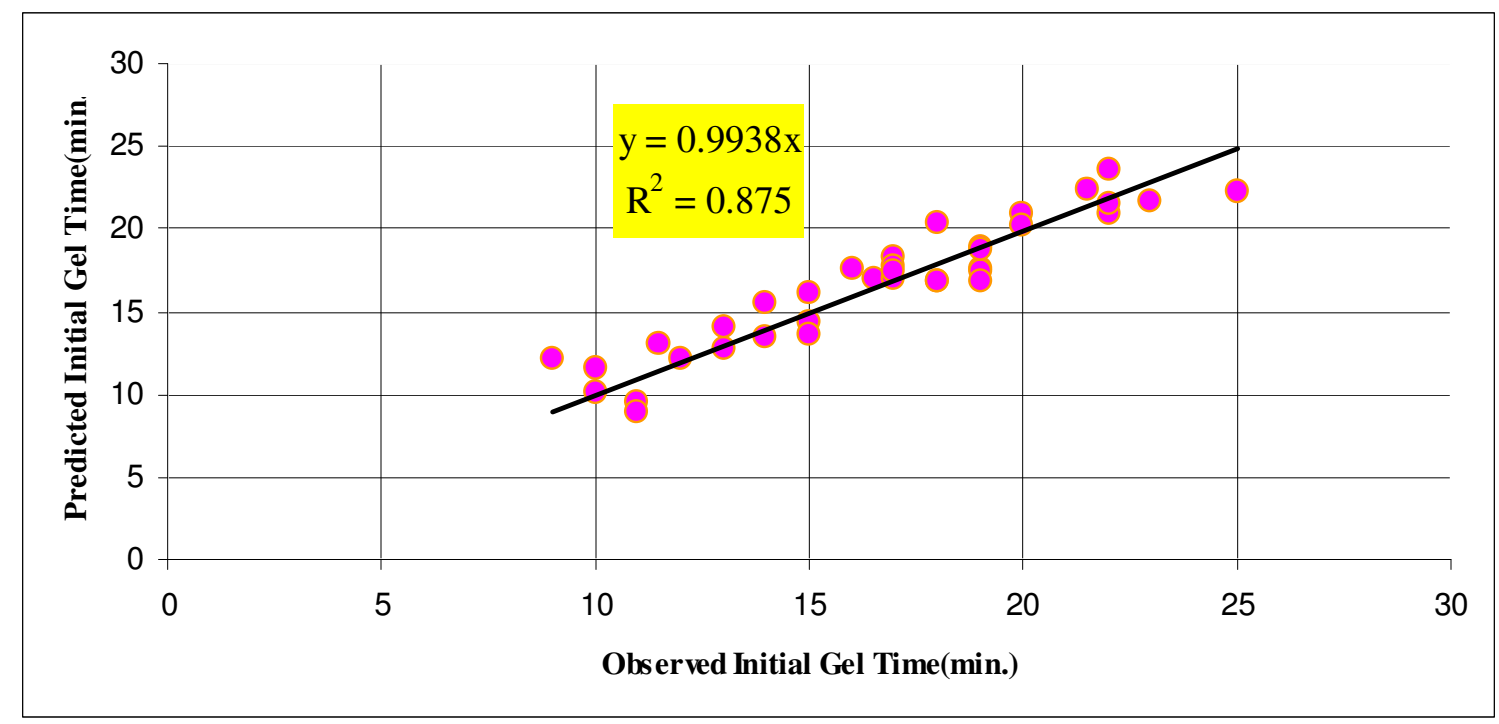

Figure 6.20: Comparison of predicted initial gelation time with measured values

Similar regression analysis on final gelation time was conducted. The following equation was obtained for prediction of final gelation time.

$$
t_{f}=130.47-1.20 C_{p c}-2.81 C_{A}+19.20 C_{r}-0.80 T
$$

Due to the sign of coefficients, only retarder increases final gelation time. According to their range of input, the following range of contribution is obtained: Poly-cross (-18 to -30$)$, accelerator $(-14.05$ to -42.15$)$, retarder (0 to +19.2$)$, temperature (-32 to -64).Therefore temperature and accelerator has major effect on decreasing of final gelation time while retarder increases final gelation time.

Figure 6.21 shows the comparison of results from the model with the measurements of experiments. 


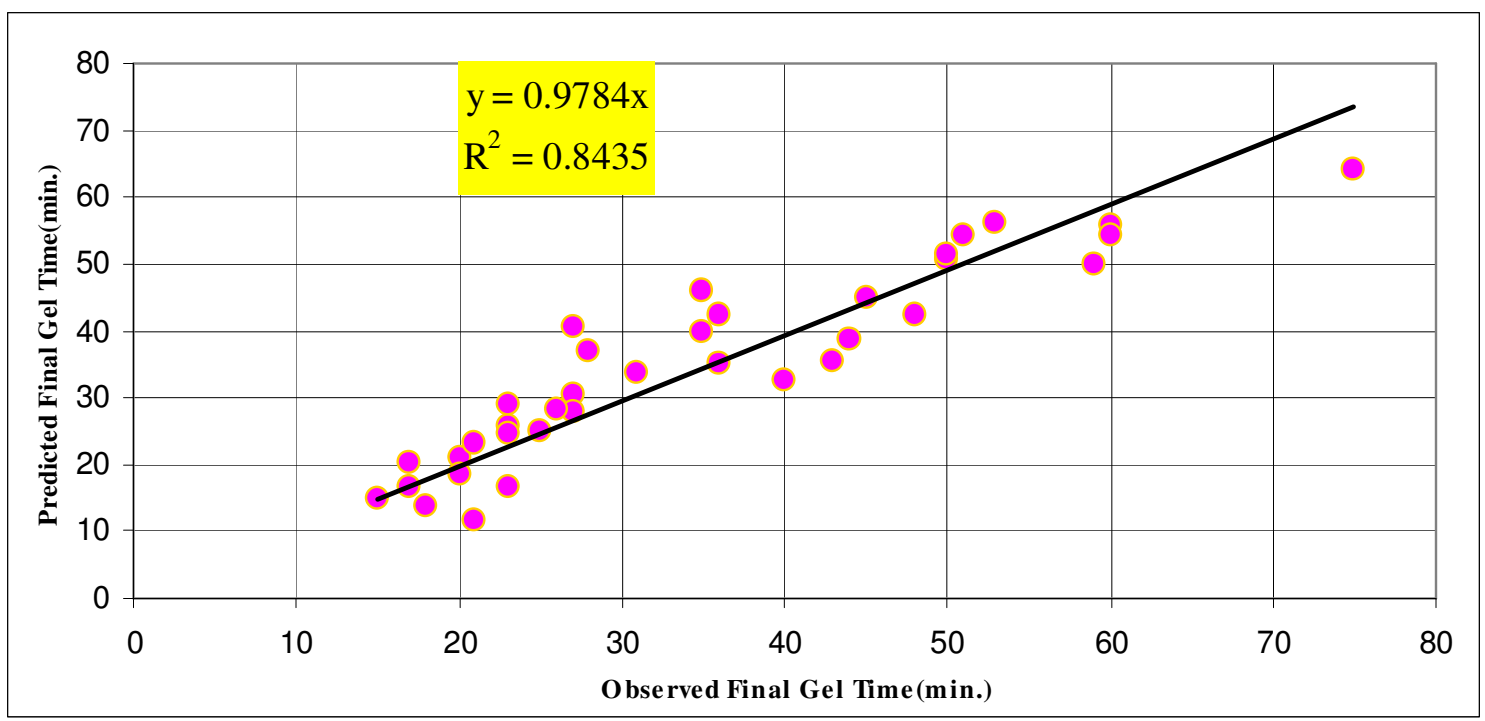

Figure 6.21: Comparison of predicted final gelation time with measured values

Initial viscosity is criteria of fluidity of fluid before start of gelation which is the time for pumping the fluid. Equation 6.8 was obtained after regression analysis as follows:

$\mu_{i}=-11887.7+729.24 C_{p c}+249.40 C_{A}-2480.28 C_{r}+5.87 T$

From the coefficient analysis, it can be obtained that retarder decrease initial viscosity while others have positive effect. Temperature effect is negligible and poly-cross has a major effect on increase of initial viscosity. The results from experiments and the model are compared in Figure 6.22. 


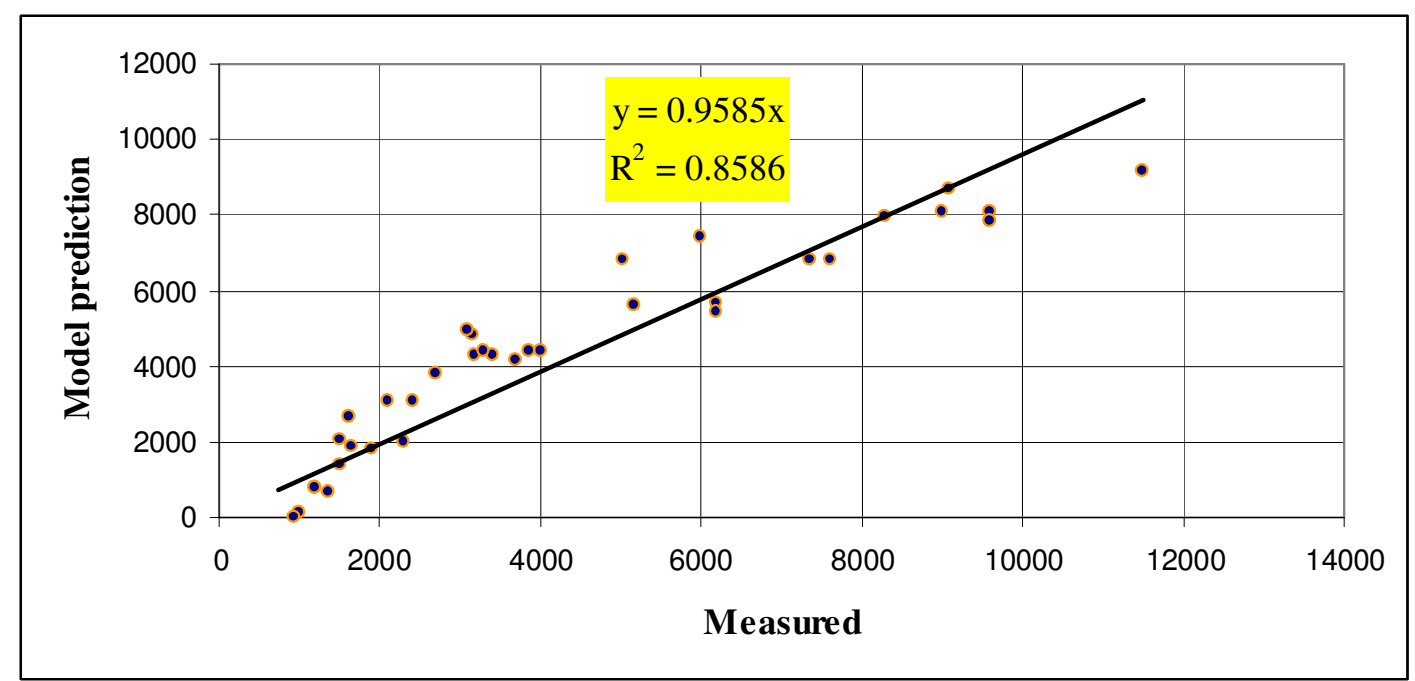

Figure 6.22: Comparison of predicted initial viscosity with measured values

Final viscosity can be criteria for final gel quality. Equation 6.9 is suggested for prediction of final viscosity.

$\mu_{f}=-8695.86+985.77 C_{p c}+14.22 C_{A}-5472.57 C_{r}-28.34 T$

According to the coefficients, poly-cross has a major effect on increase of final viscosity. On the other hand, retarder has a significant effect on decrease of final viscosity. Temperature decrease final viscosity while accelerator has negligible effect. The results from the model and measured values from experiments are compared in Figure 6.23. 


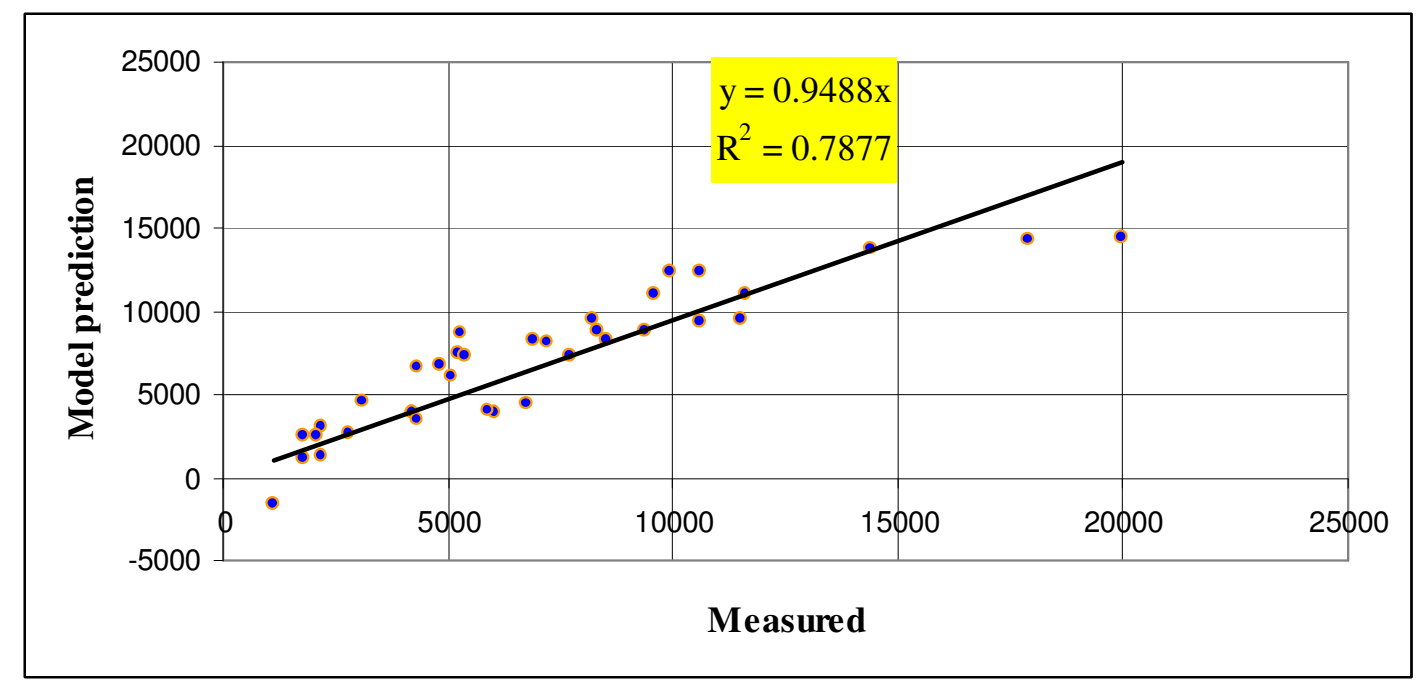

Figure 6.23: Comparison of predicted final viscosity with measured values

\subsection{Empirical models for field application}

For facilitating the use of empirical models in field application, the conversion of units was done and the following models are suggested in which the unit of concentrations is $l b / b b l$ and unit of temperature is ${ }^{\circ} \mathrm{C}$. Table 6.2 shows the composition of materials in these units. These equations are obtained by statistical approach and the units of opposite sides are not similar. It should be mentioned that the values obtained from these experiments may be different from what exactly happens in the field. This can be due the mixing procedure (the mixer heats the drilling fluid and accelerates the gelation), the water composition (the gelation is dependent on ions such as magnesium chloride, etc.), the temperature of water and environment, the period of mixing, etc. Moreover these equations have also some amount of errors.

$$
\begin{aligned}
& t_{i}=38.309-0.013 C_{p c}-0.168 C_{A}+0.590 C_{r}-0.205 T \\
& t_{f}=120.820-0.167 C_{p c}-0.483 C_{A}+3.940 C_{r}-0.808 T \\
& \mu_{i}=-7900.430+118.209 C_{p c}+20.673 C_{A}-561.517 C_{r}+8.105 T
\end{aligned}
$$




$$
\mu_{f}=-4056.740+165.393 C_{p c}-28.997 C_{A}-1146.090 C_{r}-27.816 T
$$

Table 6.2: Composition of materials in field unit

\begin{tabular}{|c|c|c|c|}
\hline $\begin{array}{c}C_{p c} \\
l b / b b l\end{array}$ & $\begin{array}{c}C_{A} \\
l b / b b l\end{array}$ & $\begin{array}{c}C_{r} \\
l b / b b l\end{array}$ & $\begin{array}{c}\mathrm{T} \\
{ }^{\circ} \mathrm{C}\end{array}$ \\
\hline 65.83 & 21.94 & 1.09 & 80.00 \\
\hline 65.83 & 21.94 & 1.09 & 60.00 \\
\hline 65.63 & 21.88 & 0.00 & 60.00 \\
\hline 65.63 & 21.88 & 0.00 & 80.00 \\
\hline 66.46 & 22.15 & 4.43 & 80.00 \\
\hline 70.47 & 46.98 & 2.35 & 80.00 \\
\hline 70.23 & 46.82 & 1.17 & 80.00 \\
\hline 70.00 & 46.67 & 0.00 & 60.00 \\
\hline 70.00 & 46.67 & 0.00 & 80.00 \\
\hline 75.54 & 75.54 & 2.51 & 80.00 \\
\hline 75.27 & 75.27 & 1.25 & 80.00 \\
\hline 93.96 & 23.49 & 2.34 & 60.00 \\
\hline 93.64 & 23.41 & 1.17 & 80.00 \\
\hline 93.33 & 23.33 & 0.00 & 60.00 \\
\hline 93.33 & 23.33 & 0.00 & 80.00 \\
\hline 94.59 & 23.65 & 4.73 & 60.00 \\
\hline 100.72 & 50.36 & 2.51 & 40.00 \\
\hline 100.72 & 50.36 & 2.51 & 60.00 \\
\hline 100.72 & 50.36 & 2.51 & 80.00 \\
\hline 100.36 & 50.18 & 1.25 & 40.00 \\
\hline 100.36 & 50.18 & 1.25 & 60.00 \\
\hline 100.00 & 50.00 & 0.00 & 80.00 \\
\hline 101.45 & 50.72 & 5.07 & 60.00 \\
\hline 108.52 & 81.39 & 2.70 & 40.00 \\
\hline 107.69 & 80.77 & 0.00 & 60.00 \\
\hline 109.38 & 82.03 & 5.47 & 80.00 \\
\hline 125.90 & 25.18 & 2.51 & 80.00 \\
\hline 125.45 & 25.09 & 1.25 & 80.00 \\
\hline 125.00 & 25.00 & 0.00 & 60.00 \\
\hline 125.00 & 25.00 & 0.00 & 80.00 \\
\hline 126.81 & 25.36 & 5.07 & 80.00 \\
\hline 135.66 & 54.26 & 2.70 & 80.00 \\
\hline 135.13 & 54.05 & 1.35 & 80.00 \\
\hline 134.62 & 53.85 & 0.00 & 60.00 \\
\hline 136.72 & 54.69 & 5.47 & 80.00 \\
\hline 148.31 & 88.98 & 5.93 & 40.00 \\
\hline
\end{tabular}




\subsection{Rheological model determination}

In this section, rheological model determination was intended to analyze behavior of drilling fluid during its flow. Twenty samples were prepared at different concentrations and temperatures. The shear stress was measured at 10 shear rates $(0.1,1,3,6,50,100,200,300,450,600 \mathrm{rpm})$.

The experiments were conducted at different shear rates before initial gelation time. The experiments are conducted once in decreasing order of shear rate, then in increasing order or conducted two times if initial gelation time is not enough and average value is assigned to them. The graphs in appendix B shows that the samples are almost time independent since the 1:1 comlexation starts from beginning while the thixotropic behavior of xanthan especially in presence of magnesium chloride is also present. It is assumed that the fluid shows time independent behavior in order to find the rheological models.

Rheograms shows shear stress versus shear rate behavior of fluids. From this piece of information, rheological models can be obtained. Figure 6.24 shows the rheograms of all the samples. Each color represents a sample (the number is appointed on the right of diagram) and the sample composition can be found in table 6.2. Interception with y axes, shear stress axes, determines yield stress of drilling fluid and the slope determines plastic viscosity of drilling fluid in Bingham-Plastic model. All the rheograms are illustrated below for the comparison.

Residual mean square (RMS) values were obtained for two-parameter models (Bingham Plastic, Power Law, and Casson) and three-parameter models (RobertsonStiff, Herschel-Bulkley, and Sisko). Since the RMS values for two-parameter models are much higher than three-parameter models, they are shown in two separate charts. 
Column charts for two-parameter models (Figure 6.25) reveals that Bingham Plastic model has the highest RMS values (least fitting) and Power Law has the lowest one (except the samples 1 and 20). Moreover samples 17 and 18 have unusual high RMS values. According to Box-Whisker plots (Figure 6.26), Power Law model has the least median RMS value (Power law: 11.13, Casson: 43.99, Bingham Plastic: 140.37). Therefore Power Law is the best fitted model among two-parameter models. Other information obtained from this plot (sample minimum, sample maximum, lower quartile, and upper quartile) also confirms this superiority.

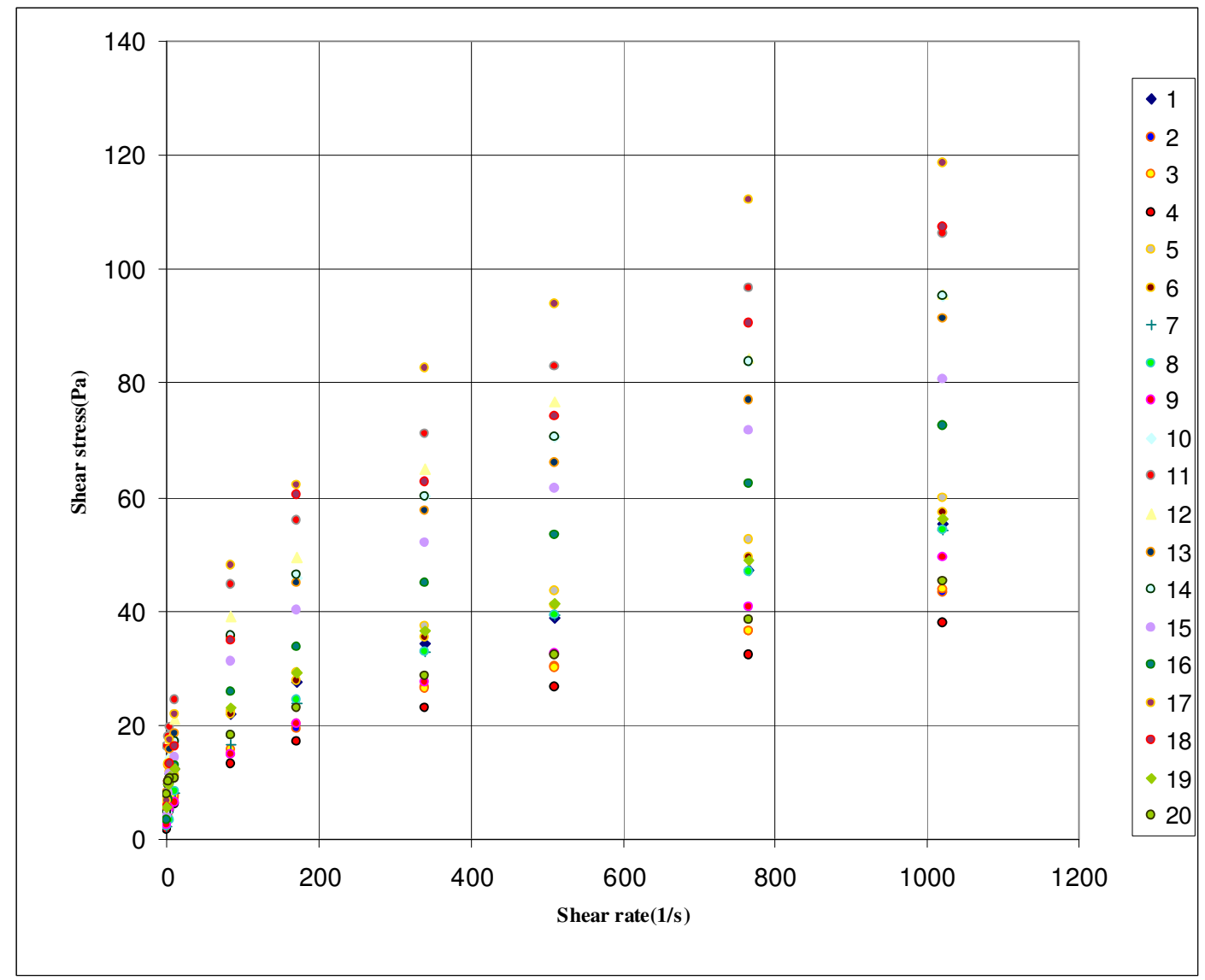

Figure 6.24: Rheograms of all samples

In three-parameter models, again samples 17 and 18 have very high values of RMS. Mostly Sisko models have the least RMS values according to column chart (Figure 6.27.). However sample number 11 shows very high RMS values for Sisko model. Figure 6.28 shows that Sisko is the best model to represent this gel system. 


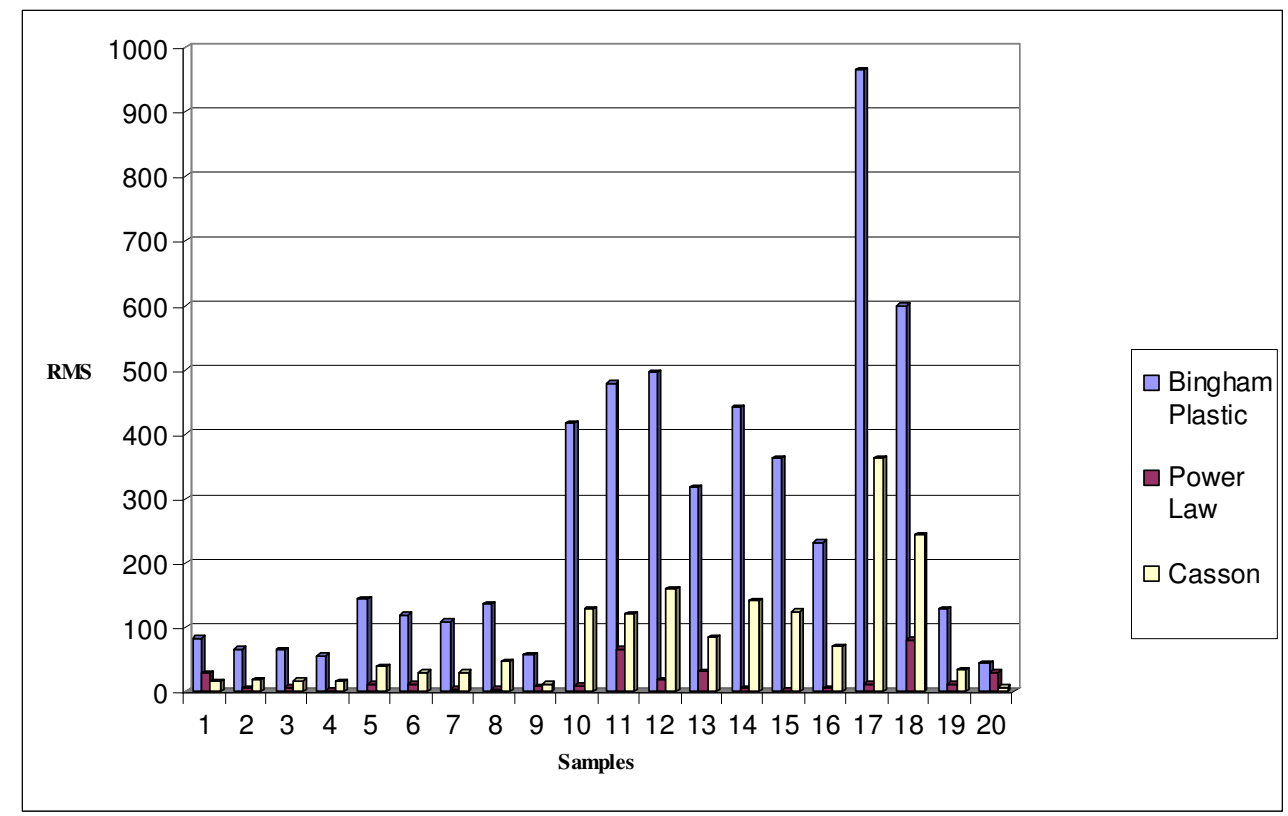

Figure 6.25: Residual mean squares of two-parameter models
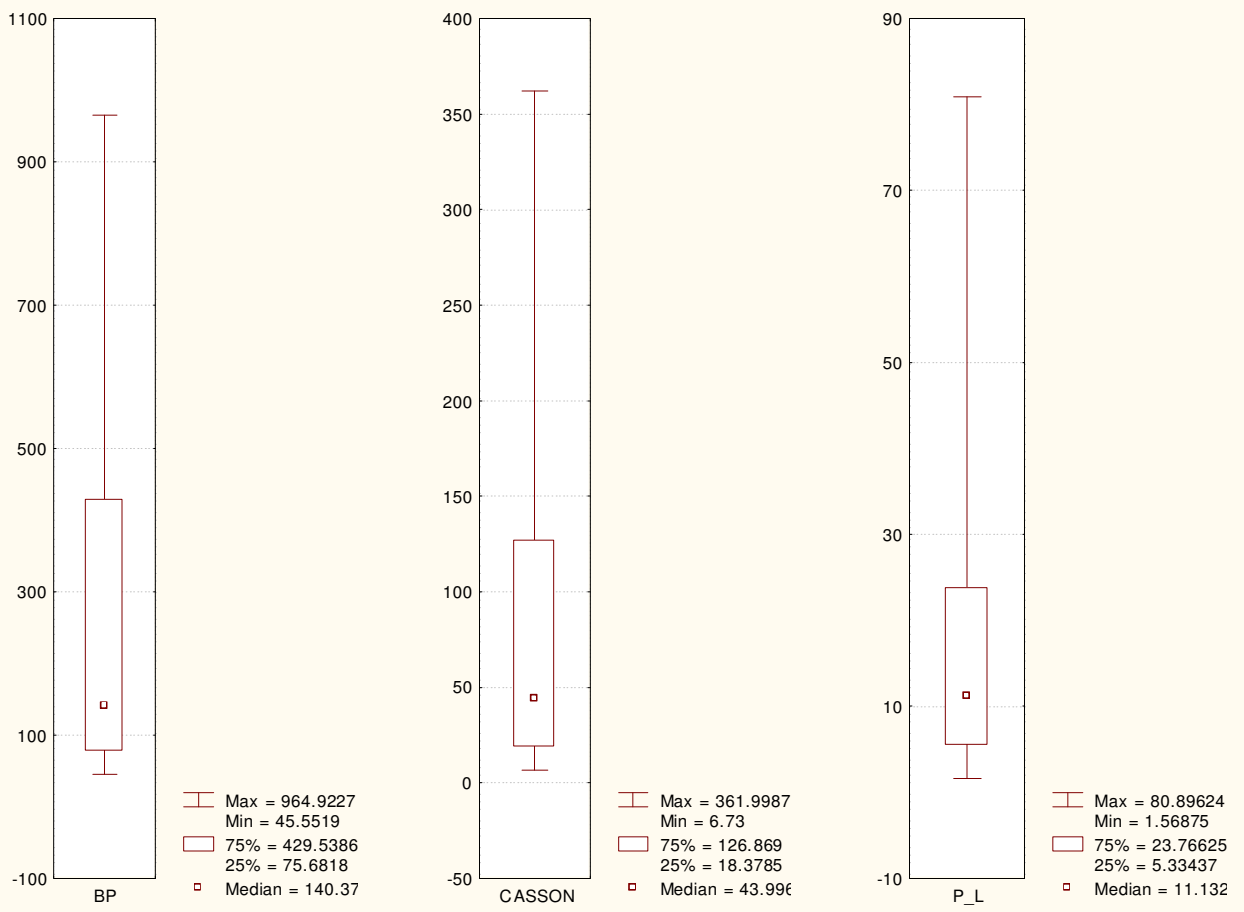

Figure 6.26: Box-whisker plot of two-parameter models (Bingham-Plastic, Casson, Power-Law) 


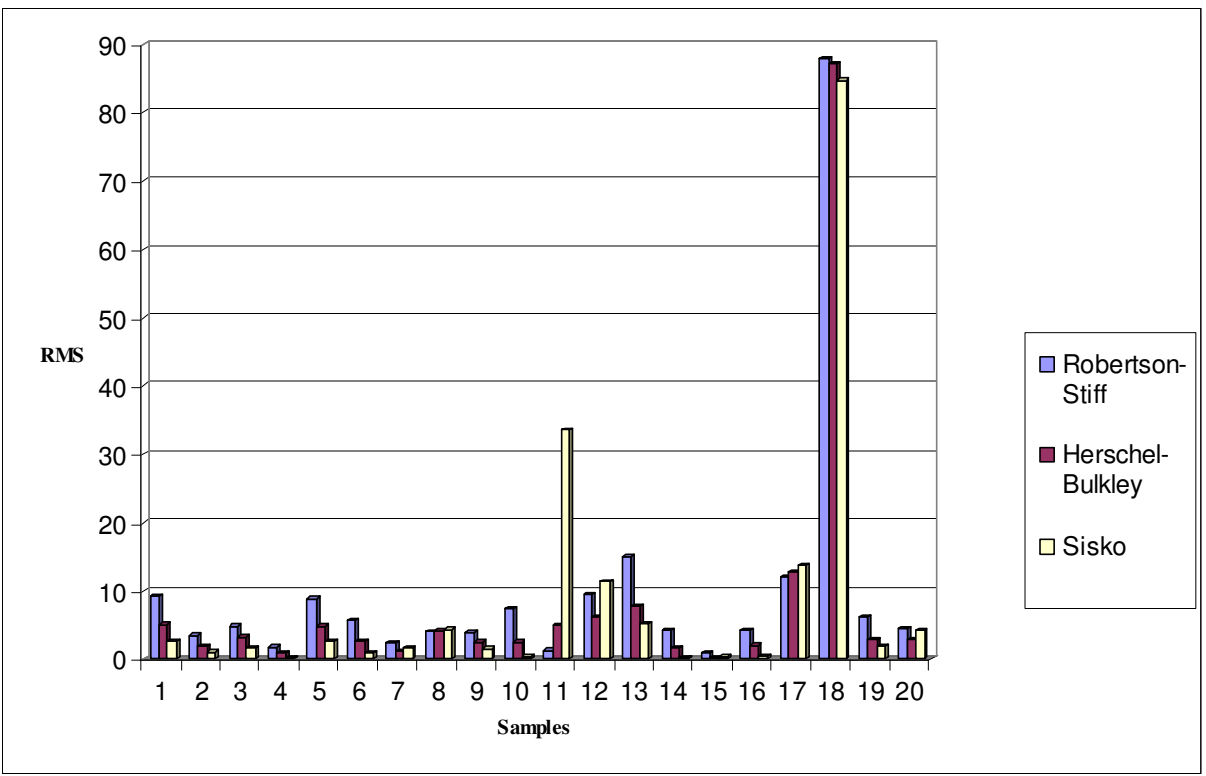

Figure 6.27: RMS values of three-parameter models
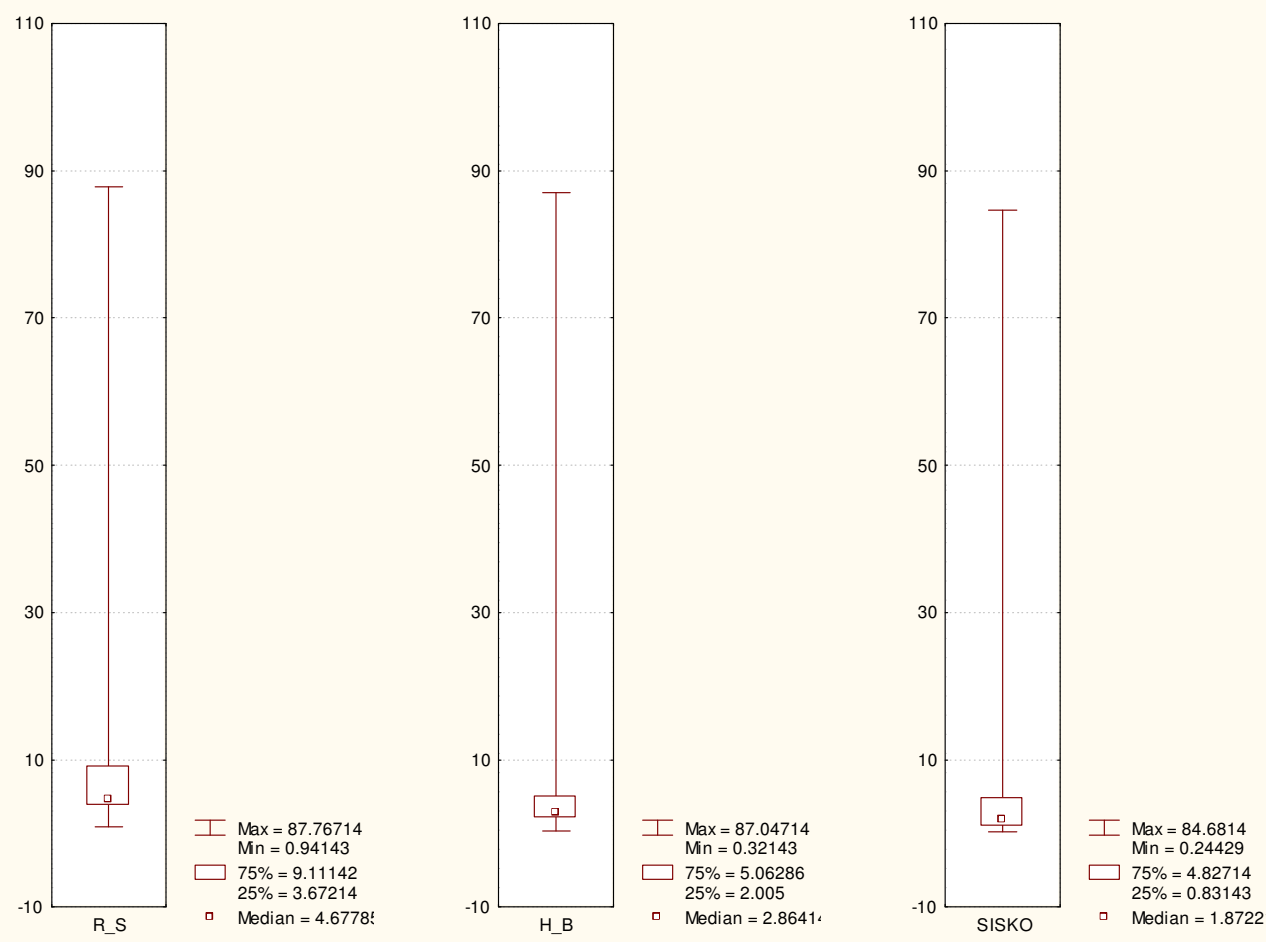

Figure 6.28: Box-Whisker plot of three-parameter models (Robertson-Stiff, Herschel-Bulkley, Sisko) 


\subsection{Modified Bingham-Plastic model}

Direct estimation of rheological model parameters is more popular in petroleum industry. However this method usually does not give reasonable results. That is why a modified Bingham-Plastic model using just reading shear stress at 600 and 300 rpm was considered.

First yield point and plastic viscosity were obtained by direct calculation from $600 / 300 \mathrm{rpm}$ combination. Then the parameters were obtained from regression analysis of all data points. By comparing these two values, some shift factors were suggested in order to minimize RMS.

Bingham-Plastic model is:

$\tau=\tau_{0}+\mu_{p} \gamma$

$\tau=$ Shear stress $\left(l b / 100 f t^{2}\right)$

$\tau_{0}=$ yield stress $\left(l b / 100 f t^{2}\right)$

$\mu_{p}=$ Plastic viscosity $\left(l b . s / 100 f t^{2}\right)$

$\gamma=$ Shear rate $(1 / \mathrm{s})$

And the modified one is suggested as follows:

$\tau=\alpha \tau_{0(600 / 300)}+\beta \mu_{p_{(600 / 300)}} \dot{\gamma}$

$\alpha=0.435$

$\beta=1.707$

Table 6.3 shows Bingham-Plastic parameters obtained in three conditions: regression of all data, direct calculation from 600/300 combination, and modified model. 
Table 6.3: Bingham-Plastic parameters (Total data points regression, direct calculation from 600/300 combination, modified model)

\begin{tabular}{||c|c|c|c|c|c|c||}
\hline Sample & $\tau_{0}$ & $\mu_{p}$ & $\tau_{0}$ & $\mu_{p}$ & $\tau_{0}$ & $\mu_{p}$ \\
Total & Total & $600 / 300$ & $600 / 300$ & Modified & Modified \\
\hline 1 & 26.680 & 0.087 & 43.500 & 0.063 & 18.923 & 0.108 \\
\hline 2 & 15.680 & 0.075 & 34.450 & 0.049 & 14.986 & 0.084 \\
\hline 3 & 16.420 & 0.074 & 31.900 & 0.053 & 13.877 & 0.090 \\
\hline 4 & 13.380 & 0.066 & 30.550 & 0.042 & 13.289 & 0.072 \\
\hline 5 & 24.970 & 0.102 & 53.500 & 0.062 & 23.273 & 0.106 \\
\hline 6 & 24.260 & 0.096 & 48.600 & 0.062 & 21.141 & 0.106 \\
\hline 7 & 17.670 & 0.098 & 47.400 & 0.058 & 20.619 & 0.099 \\
\hline 8 & 17.311 & 0.098 & 48.600 & 0.056 & 21.141 & 0.096 \\
\hline 9 & 14.710 & 0.087 & 31.200 & 0.064 & 13.572 & 0.109 \\
\hline 10 & 37.230 & 0.166 & 89.800 & 0.094 & 39.063 & 0.160 \\
\hline 11 & 54.030 & 0.170 & 116.700 & 0.089 & 50.765 & 0.152 \\
\hline 12 & 45.300 & 0.161 & 112.700 & 0.073 & 49.025 & 0.125 \\
\hline 13 & 39.810 & 0.151 & 79.500 & 0.097 & 34.583 & 0.166 \\
\hline 14 & 36.840 & 0.167 & 89.850 & 0.095 & 39.085 & 0.162 \\
\hline 15 & 32.010 & 0.142 & 83.150 & 0.073 & 36.170 & 0.125 \\
\hline 16 & 26.670 & 0.127 & 66.850 & 0.070 & 29.080 & 0.119 \\
\hline 17 & 50.880 & 0.213 & 135.600 & 0.095 & 58.986 & 0.162 \\
\hline 18 & 39.080 & 0.185 & 80.900 & 0.126 & 35.192 & 0.215 \\
\hline 19 & 27.030 & 0.091 & 51.300 & 0.057 & 22.316 & 0.097 \\
\hline 20 & 23.997 & 0.069 & 37.700 & 0.050 & 16.400 & 0.085 \\
\hline
\end{tabular}

Figure 6.29 shows that RMS values obtained from modified model are close to the RMS values obtained from regression analysis for all the samples. Moreover RMS values for three conditions are shown in Box-Whisker plots for the 20 samples in Figure 6.30. It shows that the median of RMS values as a measure of accuracy of models has improved from 805.87 in direct estimation model to 156.83 in modified model. As a result, the simple modified model proposed can predict the rheological properties almost similar to what regression analysis of all data points can do. (Median of total regression=144.06, median of modified model=156.83). Therefore the proposed model can be attractive for field application due to its simplicity. 


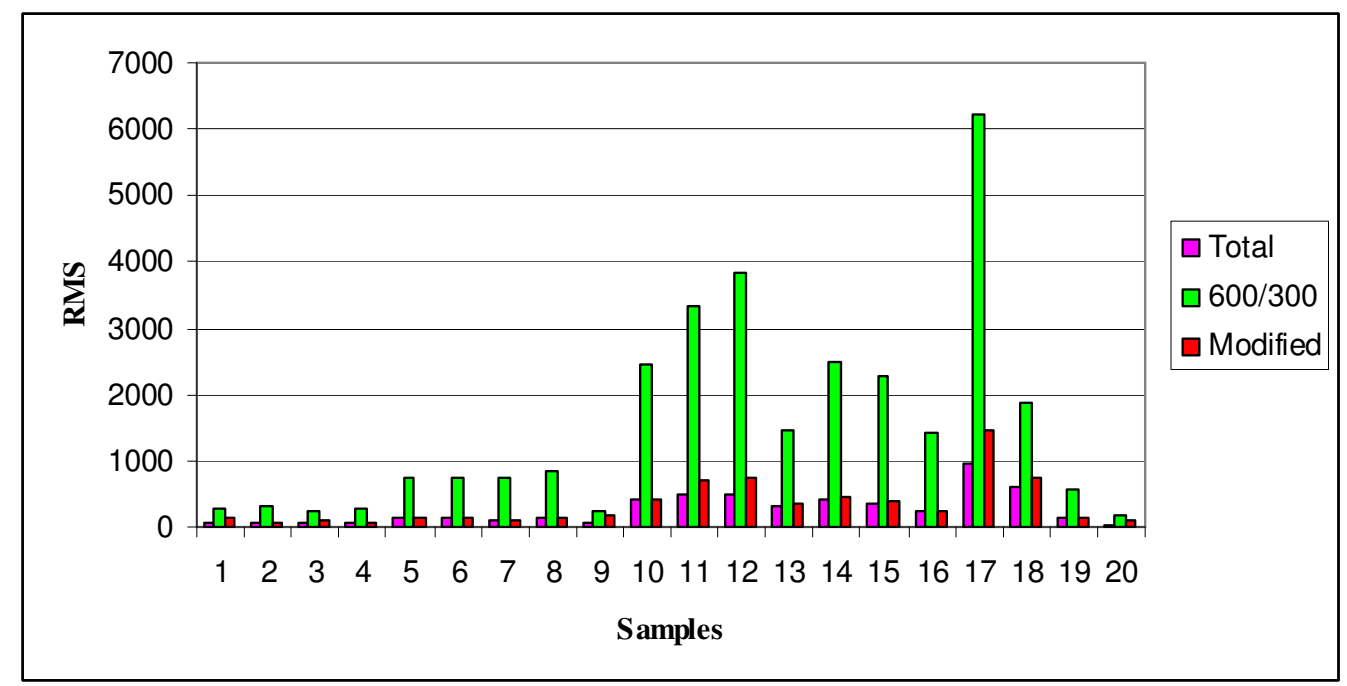

Figure 6.29: RSM values for Bingham-Plastic model (Total regression, direct calculation from 600/300 combination, and modified model)
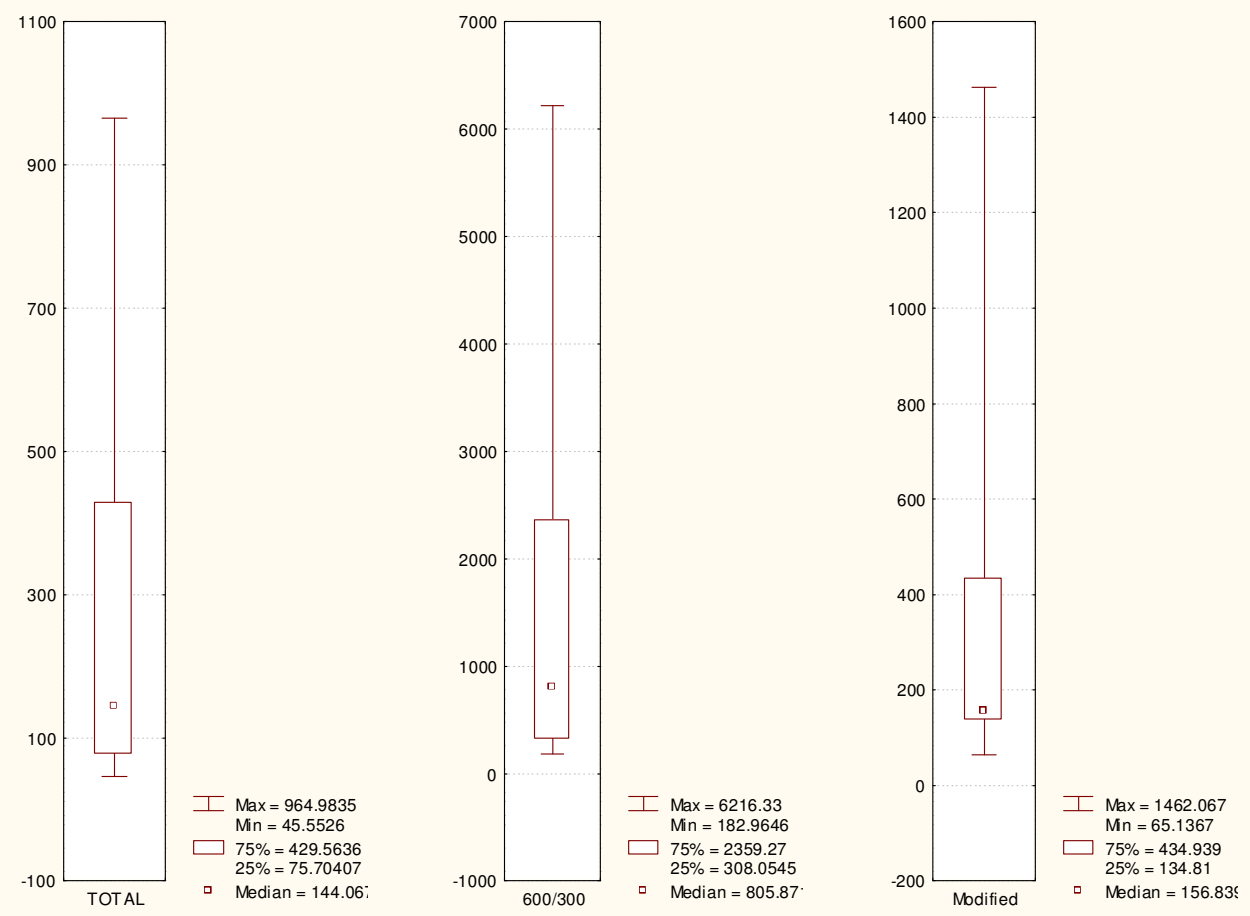

Figure 6.30: Box-Whisker plot of Bingham-Plastic model (Total regression, direct calculation from 600/300 combination, and modified model) 


\subsection{Modified Herschel-Bulkley model}

Herschel-Bulkley is one of the best rheological models that can describe rheological behavior of drilling fluids. In the gel system that is used in this study HerschelBulkley also showed reasonable results. Since Herschel-Bulkley is not a twoparameter model, it is not possible to find its parameters directly. Moreover, regression analysis sometimes gives non-meaning negative values for yield stress. Therefore there are some methods to estimate yield stress. Then with a known yield stress, the other two parameters can be obtained by regression analysis.

Shear stress at very low shear rate, $0.1 \mathrm{rpm}$, was assumed as yield point which later was proved to be a good estimation of yield stress. It is called true yield stress (YP) and it is compared with four other methods of yield stress estimation:

1. Shear stress at $3 \mathrm{rpm}\left(\tau_{3}\right)$

2. Shear stress at $6 \mathrm{rpm}\left(\tau_{6}\right)$

3. Low Shear Yield Point ( $\left.\mathrm{LSYP}=2 \tau_{3}-\tau_{6}\right)$

4. Yield point obtained from regression analysis of all data points

Yield points obtained from regression analysis were compared to what was measured at $0.1 \mathrm{rpm}$ in Figure 6.31. There is a moderate correlation between these two parameters. 


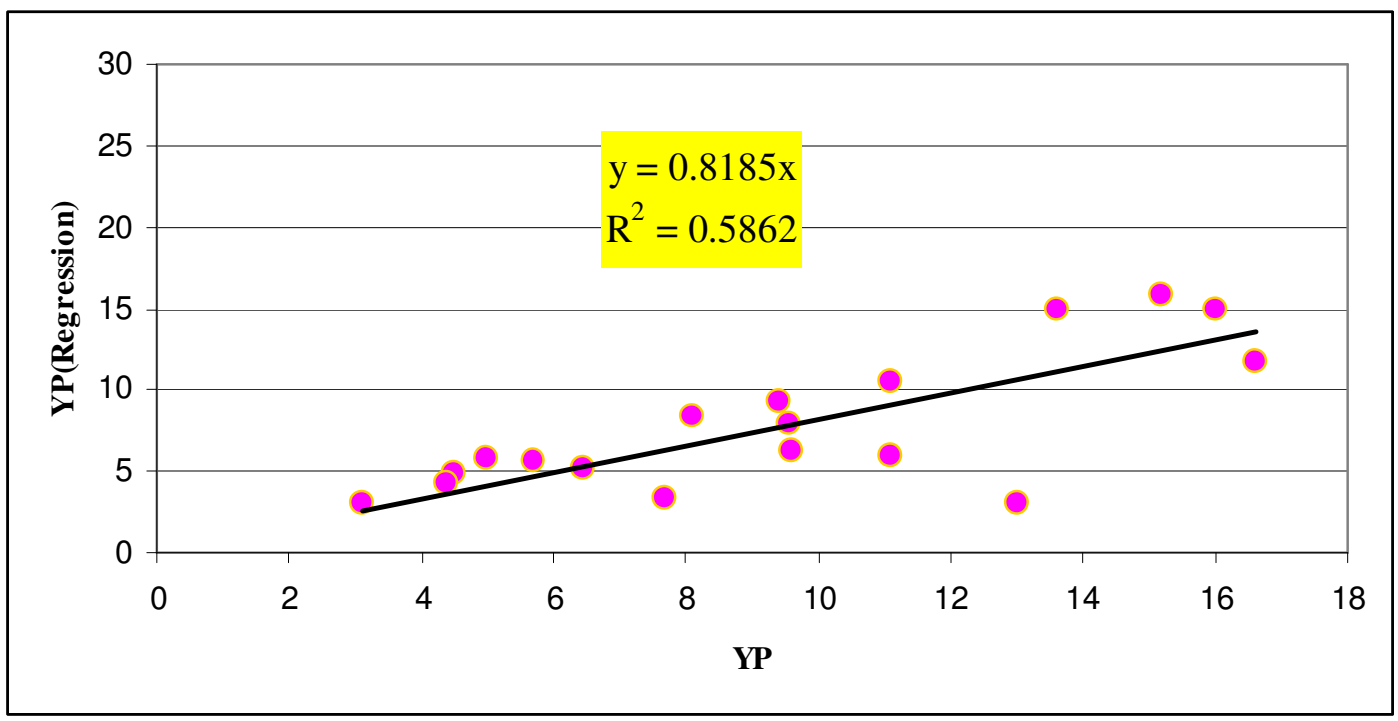

Figure 6.31: Yield point obtained from regression analysis correlation with true yield point

Figure 6.32 and Figure 6.33 show low correlation between shear stress at 3 and 6 rpm respectively with true yield point since the correlated line obtained from least square method shows almost two times of yield point for shear stress at 3 and $6 \mathrm{rpm}$. This situation is worse for $6 \mathrm{rpm}$; that is why it was omitted from further studies.

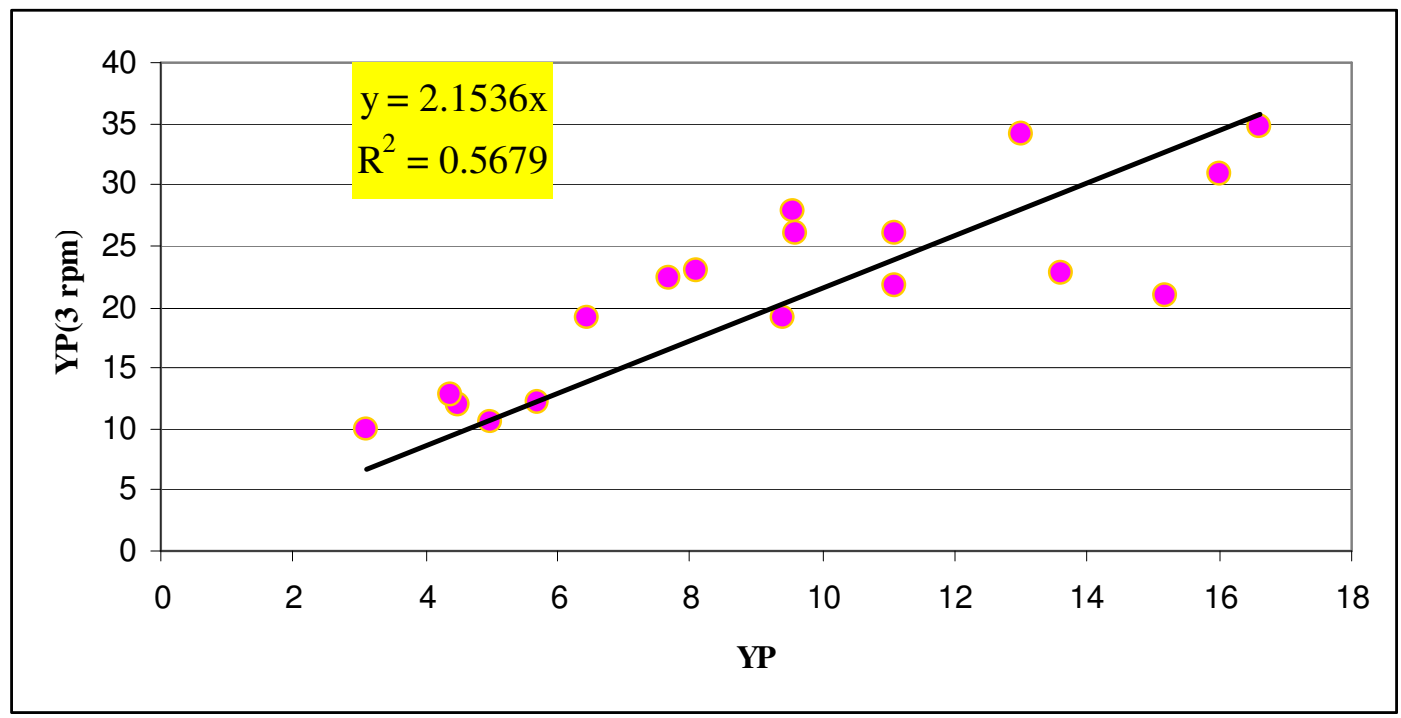

Figure 6.32: shear stress at $3 \mathrm{rpm}$ correlation with true yield point 


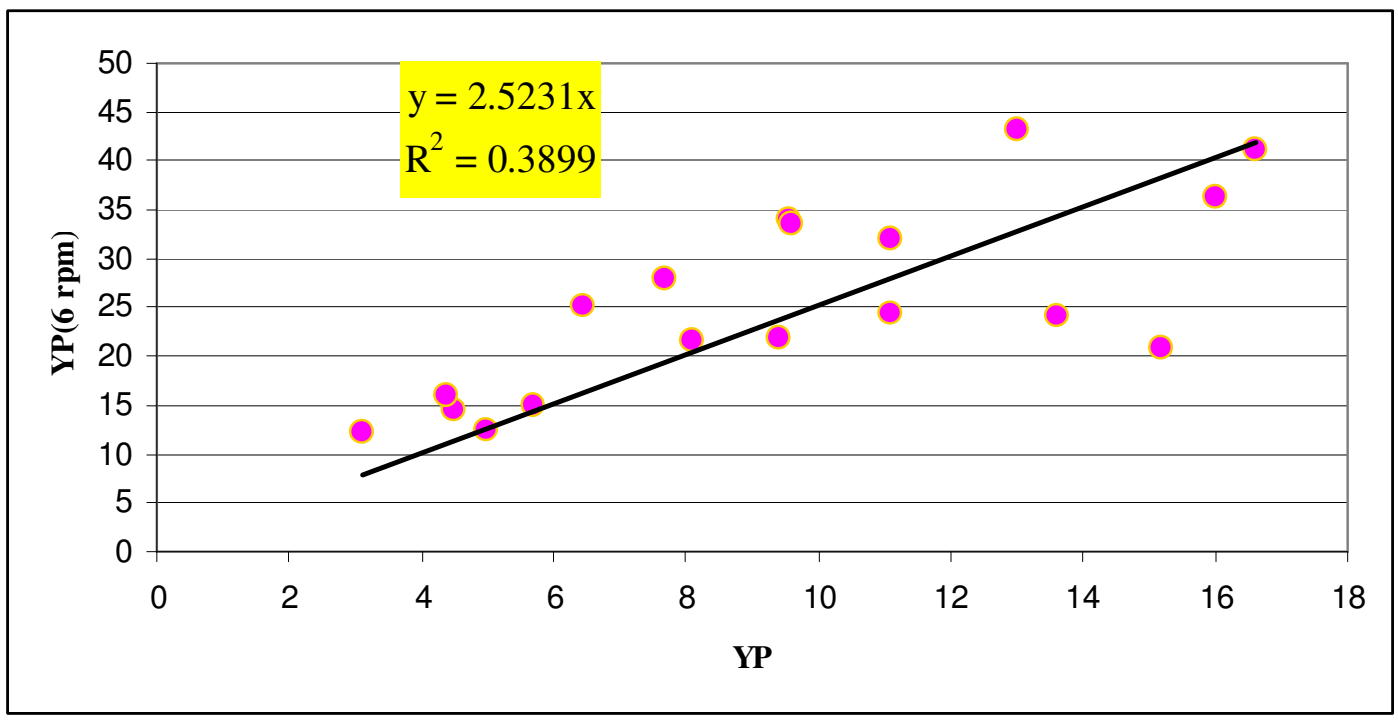

Figure 6.33: Shear stress at $6 \mathrm{rpm}$ correlation with true yield stress

Low shear yield point is one of common methods of direct yield stress estimation but it did not exhibit reasonable results for this drilling fluids. Figure 6.34 shows the correlation between LSYP and the true yield point.

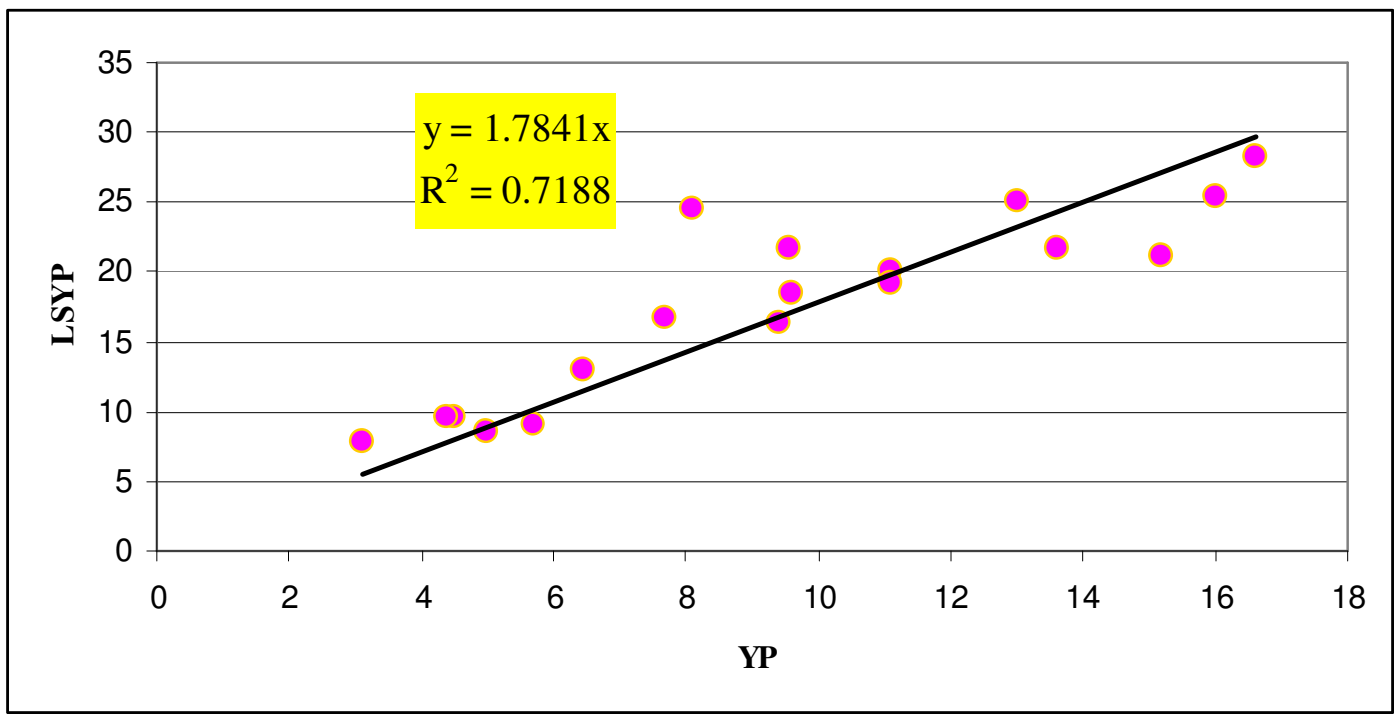

Figure 6.34: Low shear yield point correlation with true yield point 
Many new models based on low shear rate data points combination were investigated for yield point determination. Then the results from those models were compared to true yield stress and residual values were calculated. Finally the following model could demonstrate the best behavior:

$Y P=\tau_{3}-0.5 \tau_{6}$

Figure 6.35 shows the relation between the modified yield point and the true yield point.

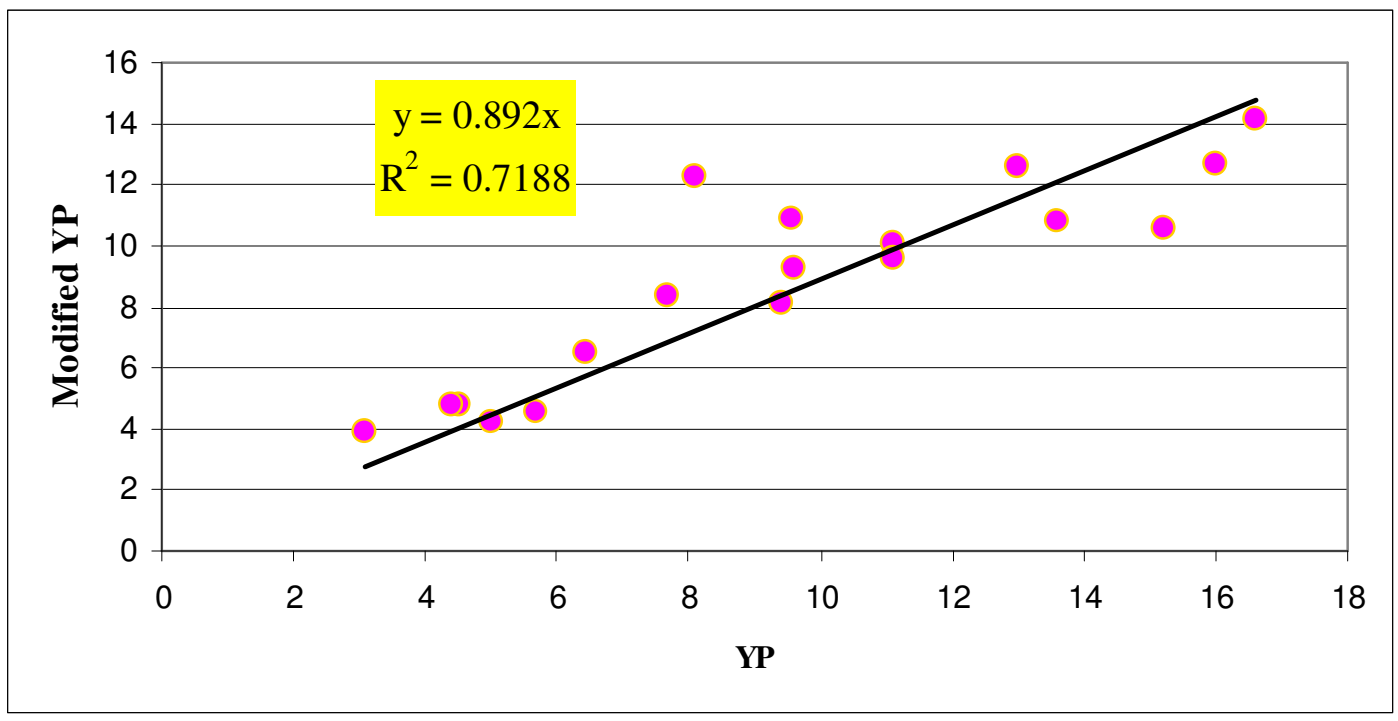

Figure 6.35: Modified yield point correlation with true yield point

Then yield points obtained from shear stress at $3 \mathrm{rpm}$, LSYP, and the proposed model, were substituted in the Herschel-Bulkley model. The other parameters were obtained by regression. Then residual sum of squares were calculated and were divided by (n-p), 8, to get RMS values. 
RMS values of four cases are compared in the Figure 6.36. The modified yield point gives almost similar median of RMS value to what was obtained from regression analysis (3.251 for the proposed model in comparison to 2.39 for regression analysis). The good behavior of proposed model also confirms that assumption of shear stress at 0.1 shear rate to be a good criterion. Finally rheological model of this gel system can be predicted very well with direct estimation of yield point by the proposed model.
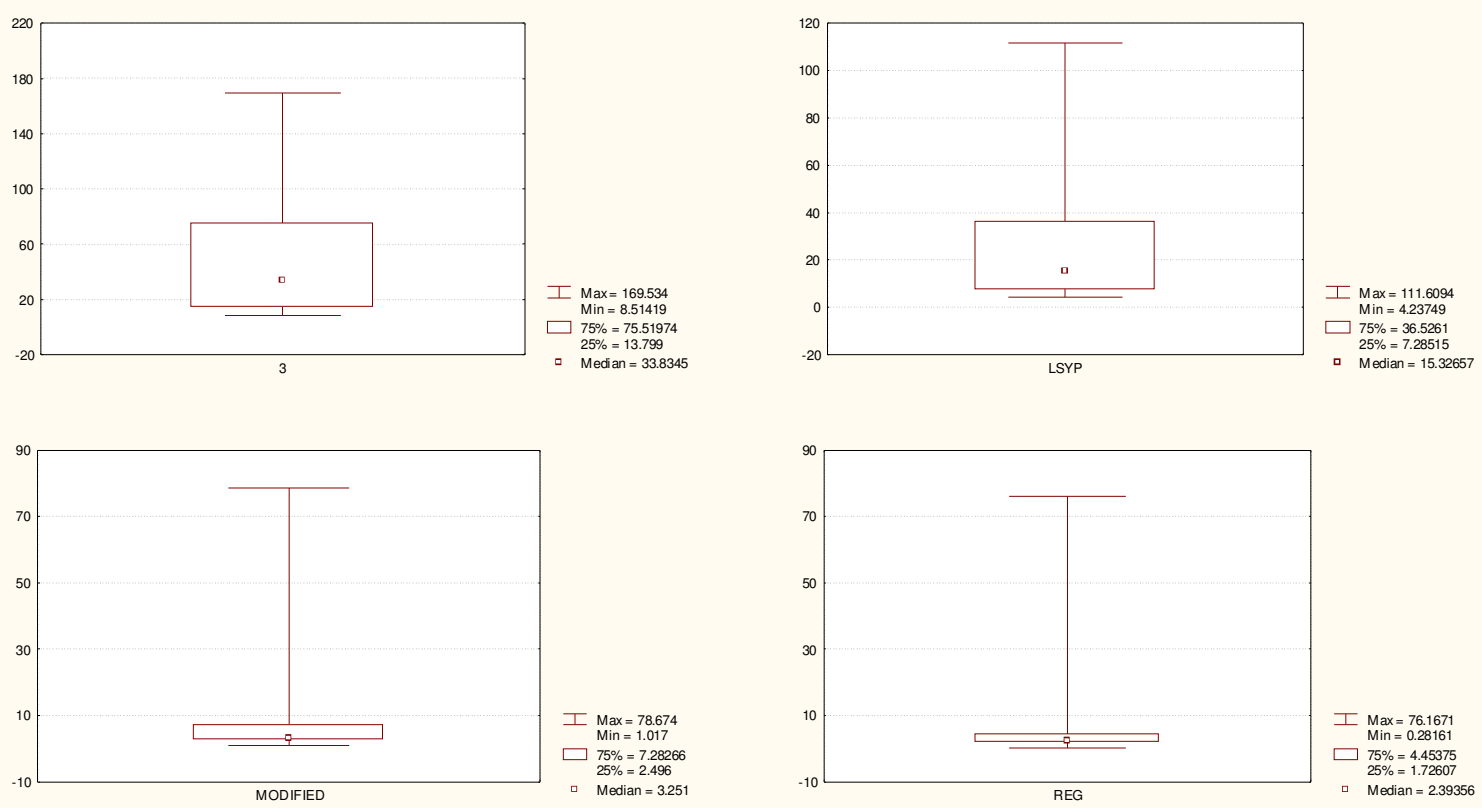

Figure 6.36: Box-Whisker illustration of RMS values for LSYP (yield point by 3rpm, modified model, yield point by LSYP, yield point by regression) 


\section{CHAPTER 7}

\section{CONCLUSIONS}

In this thesis, use of a gel system for combating lost circulation was investigated. A system composed of xanthan, borax, accelerator, and retarder was prepared and steady shear viscometry method was employed to study the gel behavior. A main parameter, initial gelation time, besides three other parameters: final gelation time, initial viscosity and final viscosity were obtained at different concentrations of polycross, accelerator, retarder as well as temperature. With the knowledge of initial gelation time, the time allowed for pumping of gel system can be obtained. With a rough estimation of final gelation time, the time required for waiting on gel can be found. The gel system should be pumped in the first period of gelation, before initial gelation time, as a fluid; therefore initial viscosity helps to have a comparative knowledge on gel behavior in this period. Finally final gel viscosity is a comparative measure of gel quality. The following conclusions can be obtained from this study:

1. Poly-cross concentration contributes significantly to the system by increasing initial and final viscosity. Consequently final gel quality improves. Initial and final gelation times are insignificantly affected.

2. Accelerator shortens initial and final gelation times by manipulating $\mathrm{pH}$, consequently release of more borate ions. Initial viscosity is not affected. Final viscosity is also not affected unless the amount of $\mathrm{pH}$-controller is not enough for the amount of poly-cross. It also contributes to rate of crosslinking. 
3. Retarder, magnesium chloride, decreases the initial viscosity and final viscosity. Therefore it is useful for high-polymer-concentration samples. It does not almost change initial gelation time but postpones the final gelation time. It reduces the rate of crosslinking significantly.

4. Increasing mixing time does not postpone the initiation of gelation. In other words it does not help to gain time since the summation of initial gelation time and mixing time is constant for a specific sample. Final gelation time is also decreased by increasing the mixing period. Initial and final viscosities are not affected.

5. Shear history of the conducted experiments at $3 \mathrm{rpm}$ does not change initial gelation time or final one.

6. Decreasing temperature postpones initiation of gelation and final gelation time. The initial and final viscosities are affected insignificantly.

7. Good empirical models were obtained that can estimate initial gelation time, final gelation time, initial viscosity and final viscosity. Therefore lost circulation treatment job can be managed to optimize time and materials for a specific well.

8. Sisko model is the best representative of the rheological data of this gel system in comparison to other available models analyzed since it showed lowest median of RMS values.

9. Modified Bingham-Plastic model and yield point model were suggested for this gel system as they are simpler and almost the same accurate as regression and complicated models. Therefore they can be more suitable for field applications. 


\section{CHAPTER 8}

\section{RECOMMENDATIONS}

The following recommendations for further study are suggested:

1. Acid solubility of this gel system can be studied. Then if the results are reasonable, the gel system can be applied for combating lost circulation in productive zones.

2. Effect of pressure on the gel system can be studied. Then the resistance of gel system against wellbore pressure can be thoroughly understood.

3. The mixing system employed on rig is different from mixing method in the laboratory in this thesis. Therefore it should be considered.

4. Viscoelastic properties can be obtained by oscillatory method. Then gelation time obtained from oscillatory method can be compared with the results of this study.

5. Using enzymes for breaking of gel when it is used for lost circulation treatment in productive zone can be investigated.

6. Experiments can be conducted on more popular drilling fluids to investigate modified Bingham-Plastic and yield point models. 
7. More polymer/ crosslinker combinations can be studied to determine which one has better gel quality required for lost circulation treatment.

8. More investigation is needed for control over initial gelation time. For instance, crosslinker encapsulation can be considered. 


\section{REFERENCES}

Al-Muntasheri, G., Hussein, A.I, Nasr-El-Din, H A., Amin,M. B., “ Viscoelastic Properties of a High Temperature Cross-Linked Water Shut-off Polymeric Gel", Journal of Petroleum Science and Engineering 2007,55,55-66

Al-Muntasheri G.A., Nasr-El-Din H.A., Al-Noaimi K.R., Zitha P.L.J, "A Study of Polyacrylamide-Based Gels Crosslinked with Polyethyleneimine” SPE 105925, Texas, USA, March 2007

Al-Muntasheri, G., Zitha, P., Nasr-El-Din, H., IPTC 11080, Dubai, UAE, 4-6 December, 2007

Al-Zahrani, S, "A Generalized Rheological Model for Shear Thinning Fluids", Journal of Petroleum Science and Engineering, 1997, 17,211-215

Asghari, K., Taabbodi, L., "Laboratory Investigation of Indepth Gel Placement for Carbon Dioxide Flooding in Carbonate Porous Media”, SPE 90633, Puebla, Mexico, 8-9 November, 2004

Avery, M.R., Burkholder, L.A., Gruenenfelder M.A., “ Use od Crosslinked Xanthan Gels in Actual Profile Modification" SPE 14114, Beijing, China, 17-20 March, 1986

Awang, M., Seng, G.M., "Development of a Correlation for Estimating Gelation in Porous Media Using Bottle Test Measurement”, SPE 84862, Kuala Lumpur, Malaysia, 20-21 October, 2003 
Bailey, W., Weir I.., "Investigation of Methods for Direct Rheological Model Parameters Estimation", Journal of Petroleum Science and Engineering, 1998, 21, 113

Basta, M., Piccciarelli, V., Stella, R., "Electrical Conductivity in the Kinetic Gelation Process", European Journal of Physics 1991, 12, 210-213

Boey, F.Y.C., Qiang, W., "Determining the Gel Point of an Epoxy-Hexaanhydro-4methylphthalic Anhydride(MHHPA) System" Journal of Applied Polymer Science, $2000,76,1248-1256$

Broseta, D, Marquer, O, Blin, N., Zaithoun, A., "Rheological Screening of LowMolecular-Weight Polyacrylamide/Chromium(III)Acetate Water Shutoff Gels", SPE 59319, Oklahoma, USA, 3-5 April, 2000

Caughron, D. E., Renfrow, D. K., Bruton, J. R., Ivan, C. D., Brousssard, P. N., Bratton, T. R., Standifird, W. B., " Unique Crosslinking Pill in Tandem with Fracture Prediction Model Cures Circulation Losses in Deewater Gulf of Mexico", IADC/SPE 74518, Dallas, Texas, 2002

Cole, C., Ali, S., Foley. K., “A New Environmentally Safe Crosslinked Polymer for Fluid-Loss Control”, SPE 29525, Oklahama, USA, April 2-3, 1995

Davison, J.M., Clary, S., Saasen, A., Allouche, M., Bodin, D., Nguyen, V-A., "Rheology of Various Drilling Fluid systems Under Deepwater drilling Conditions and the Importance of Accurate Predictions of Downhole Fluid Hydraulics", SPE 56632, Texas, USA, 3-6 October 1999

Dawson, J.C., "A Thermodynamic Study of Borate Complexation with Guar and Guar Derivatives", SPE 22837, Texas, USA, 6-9 October, 1991 
Dovan, H.T., Hutchins, R.D., "New Polymer Technology for Water Control in Gas Wells", SPE production facilities, November 1994, V 9, No 4, 280-286

Egger R.W., Willhite G.P., Green D.W., "Experimental Measurement of the Persistence of Permeability Reduction in Porous Media Treated with Xanthan/Cr(III) Gel System, SPE Reservoir Engineering, February 1992

Eoff, L., Dalrymple, D., Everett, D., "Global Field Results of a Polymeric Gel System in Conformance Applications”, SPE 101822, Russia, 3-6 October, 2006

Gao, S., Gao, J., Wu,L., Wang Shan, "Gelation of Konjac Glucomannan Crosslinked by Organic Borate” Carbohydrate Polymers 2008,73, 498-505

Gao, S., Guo J., Nishinari, K., "Thermoreversible Konjac Glucomannan Gel Crosslinked by Borax”, Carbohydrate Polymers, 2008, 72, 315-325

Gucuyener, I.H., “A Rheological Model for Drilling Fluids and Cement Slurries”, SPE 11487, Manama, Bahrain, 14-17 March 1983

Gucuyener, I.H., "Pet E 426 Drilling Fluids Engineering Lecture Notes", Middle East Technical University

Harris, P.C., "Chemistry and Rheology of Borate-Crosslinked Fluids at Temperatures to $300^{\circ} \mathrm{F}$, JPT, March 1993

Harris, P.C., Batenburg, D.V., “ A Comparison of Freshwater and Seawater-Based Borate Crosslinked Fracturing”, SPE 50777, Texas, USA, 16-19 February, 1999

Harris, P.C., Heath, S.J., "Rheological Properties of Low-Gel-Loading Borate Fracture Gels", SPE Production and Facilities, November 1998 
Harris, P.C., Sabhapondit, A., "Chemistry Applied to Fracture Stimulation of Petroleum Wells”, Bahrain, 15-18 March, 2009

Harris, P.C., Walters, H., "Real-Time Control of Low-Polymer Fracturing Fluids", SPE 63238, Texas, USA, 1-4 October, 2000

Hejri,S., Jousset, F., Green D.W., McCool C.S., Willhite G.P., “ Permeability Reduction by Xanthan/Chromium(III) System in Porous Media”, SPE Reservoir Engineering, November 1993

Jousset F., Green D.W., Willhite G.P., McCool C.S., "Effect of High Shear Rate on In-Situ Gelation of a Xanthan/Cr(III) System, SPE/DOE 20213, Oklahoma, April, 1990

Kakadjian, S., Rauseo, O., Mejias, F., "Dynamic Rheology as a Method for Quantify Gel Strength of Water Shutoff Systems", SPE 50751, Hoston, USA, 16-19 February, 1999

Kelessidis, V.C., Maglione, R., Tsamantaki, C., Aspirtakis,Y., “ Optimal Determination of Theological Parameters for Herschel-Bulkley Drilling Fluids and Impact on Pressure Drop, Velocity Profile and Penetration Rate During Drilling", Journal of Petroleum Science and Engineering,2006,53,203-224

Kesavan, S., Prud'homme, R., "Rheology of Guar and HPG Cross-linked by Borate", Macromolecules, 1992, 25, 2026-2032

Khachatoorian, R., Petrisor, I.G., Kwan, C., Yen, T.F., "Biopolymer Plugging Effect: Laboratory-Pressurized Pumping Flow Studies", Journal of Petroleum Science and Engineering, 2003, 38, 13-21 
Kok, M. V., "Determination of Rheological Models for Drilling Fluids(A Statistical Approach), Energy Sources,Part A: Recovery,Utilization,and Enviromental Effects,2004, 26, 153-165

Kok, M.V., Batmaz, T., Gucuyener, I.H., "Rheological Behavior of Bentonite Suspensions", Petroleum Science and Technology, 2000, Vol. 18, Issue 5\&6, 519536

Kolnes, J., Stavland, A., Ersdal, T., "Effect of $\mathrm{pH}$ on Gelation Time for Xanthan/Cr(III) Gels”, SPE 37301,18-21 February, 1997

Kruijf, A.S., Roodhart, L.P., Davies, D.R., "Relation Between Chemistry and Flow Mechanics of Borate-Crosslinked Fracturing Fluids", SPE Production and Facilities, August 1993

Lachemet, A., Touil, D., Belaadi, S., Bentaieb N., Frances, C., "Rheological Behavior of Raw Cement", Journal of Applied Sciences, 2008, Vol: 8, Issue 19, pp: 3485-3490

Lecolier, E., Herzhaft, B., Rousseau, L., Neau, L., Quillien, B., Kieffer, J., “ Development of Nanocomposite Gel for Lost Circulation Treatment, SPE 94686, Netherland, 25-27 May, 2005

Lee Imshik, Bai Chunli, Wang Xinwen, Wang Nai-Xin, "Chemical Cross-linked Gelation of Hydroxypropyl Quar(HPG) Under Shear Flow, Polymer Journal, Vol. 29,No.1, pp 17-20(1997)

Llamedo, M.A., Fernandez, I.J., Perez, D.L., Rauseo, O., Valero, E., Espinoza, J., "Evaluation of the Effect of the Water Formation Salinity in the Performance of Gels for Water Shutoff", SPE 93005, Texas, USA, 2005 
Mata, F., Viega M., "Crosslinked Cements Solve Lost Circulation Problems" SPE 90496, Texas, USA, 26-29 September, 2004

Mesmer, R.E., Baes, C.F., Sweeton, F.H., "Acidity Measurement at Elevated Temperatures, VI, Boric Acid Equibiliria”, Inorganic Chem., 1972, 6, 537-543

M-I SWACO product sheet: FORM-A-PLUG II

M-I SWACO drilling fluid manual

Moradi-Araghi, A., "A review of Thermally Stable Gels for Fluid Diversion in Petroleum Production" Journal of Petroleum and Science Engineering 2006, 26, 110

Nguyen, T.Q., Green, D.W., Willhite, G.P., McCool, C.S., "Effect of Composition of Polyacrylamide-Chromium(III) Acetate Gel on the Magnitude of Gel Dehydration and Disproportionate Permeability Reduction", SPE 89404, Tulsa, Oklahoma, USA, 17-21 April, 2004

Nimerick K.H., Temple, H.L., Card, R.J., “ New pH-Buffered Low Polymer Borate Crosslinked Fluids for Hydraulic Fracturing", SPE 35638, Gas Technology Conference, Alberta, Canada, 28 April-1 May, 1996

Nishinari, K., Zhang, H., Ikeda, S., "Hydrocolloid Gels of Polysaccharides and Proteins", Current opinion in colloid and interface science, 2000, 5, 195-201

OFITE Model 900 Viscometer Manual

Okafor, M.N., Evers J.F., "Experimental Comparison of Rheology Models for Drilling Fluids", SPE 24086, California, USA, March 30-April1, 1992 
Ozkan, N., "Rheology Lecture Notes", Characterization Techniques for Polymeric Materials, Middle East Technical University, 2009

Parks, J., "Application of Low-Polymer Cross-Linked Fluid in the Mid-Continent Region”, SPE 80896, Oklahoma, USA, 22-25 March, 2003

Power,D., Zamora, M., “ Drilling Fluid Yield Stress: Measurement Techniques for Improved Understanding of Critical Drilling Fluid Parameters", AADE National Technology Conference, Houston, Texas, April 1-3, 2003

Quinn, D., Sunde, E., Baret J.F., "Mechanism of a Novel Shear-Sensetive Plugging Fluid to Cure Lost Circulation" SPE 50722, Texas, USA, 16-19 February, 1999

Raje, M., Asghari, K., Vossoughi, S., Green, D.W., Willhite, G.P., “ Gel Systems for controlling $\mathrm{CO}_{2}$ mobility in carbon dioxide miscible flooding, April 1999, SPE reservoir evaluation engineering, 205-210

Romero-Zeron,L., Manalo F., Kantzas A., " Characterization of Crosslinked Gel Kinetics and Gel Strength by Use of NMR", SPE Reservoir Evaluation and Engineering, June 2008

Schlumberger,www.glossary.oilfield.slb.com/Display.cfm?Term=acrylamideacrylate\%20polymer, access @ 01/08/2009

Scorsone, J. T, Sanders, M W, Patel, A.D, "An Improved Oil-Based Chemical Gel System for Wellbore Stabilization” SPE 121676, Texas, USA, 20-22 April 2009

Shah, S.N., Lord, D.L., Rao, B.N., "Borate-Crosslinked Fluid Rheology Under Various pH, Temperature, and Shear History Conditions", SPE 37487, Oklahoma, USA, 9-11 March, 1997 
Sydansk, R.D., "A New Conformance-Improvement-Treatment Chromium(III) Gel Technology”, SPE/DOE 17329, Tulsa, Oklahoma, 17-20 April 1988

Sydansk, R.D., Xiong, Y., Al-Dhafeeri, A.M., Schrader, R.J., Seright, R.S., "Characterization of Partially Polymer Gels for Application to Fractured Production Wells for Water-Shutoff Purposes", SPE 89401, Oklahoma, USA, 17-21 April, 2004

Topguder, N.N.S, “ Laboratory Studies on Polymer Gels for $\mathrm{CO}_{2}$ Mobility Control at Bat Raman Heavy Oilfield, Turkey" SPE 50798, Houston, Texas, 16-19 February, 1999

Vossoughi, S., "Profile Modification Using in Situ Gelation Technology-A Review" Journal of Petroleum Science and Engineering, 2000, 26, 199-209

Walters, H., Morgan, R.G., Harris P.C., "Kinetic Rheology of Hydraulic Fracturing Fluids", SPE 71660, Louisiana, USA, 30 September-3 October, 2001

Wang, H.L.J., Yang, Y., Wang, F., "A New Method for Profile Control With Compound Ion Gel Before polymer Flooding", SPE 93359, Bahrain, 12-15 March, 2005

Wawro, K.J., Wassmuth, F.R., Smith, J.E., "Reducing Water Production in Naturally Fractured Gas Well Using Sequential Gel/Gas Slug Injection", SPE 59746, Alberta, Canada, 3-5 April, 2000

Weir, I.S., Bailey, W.J., "A Statistical Study of Rheological Models for Drilling Fluids", SPE Journal, December 1996

www.scientificpsychic.com/fitness/carbohydrates, access @ 01/08/ 2009 
Zhang, Y, Gao P,Mengmeng, C., Huang G., “ Rheological Behavior of Partially Hydrolyzed Polyacrilamide Hydrogel Produced by Chemical Gelation" Journal of Macromolecular Science, Part B,2008, 47,26-38 


\section{APPENDIX A}

\section{POLYMERS}

Polymers are long molecular structures composed of one or more elementary units. Hundred of thousands or millions of such units can exist in a single polymer chain. These units are called monomers. When a polymer is made up from just one type of monomer, it is called homopolymer and it is called copolymer when two or more types of monomers make a polymer. The length of chains or number of monomers in a chain is expressed by the degree of polymerization. Molecular weight is also another way of characterizing polymers. However an average value is appointed to them since they can exhibit molecular weights in a range due to the length of chains. Polyacrylamides and polysaccharides are two most common groups of polymers in petroleum industry.

\section{A1. Polyacrylamides}

The monomer of polyacrylamides, acrylamide, is made up of carbon, hydrogen, oxygen, and nitrogen ( $\mathrm{C}_{3} \mathrm{H}_{5} \mathrm{NO}$ ). Partially hydrolyzed polyacrylamide (PHPA) is a copolymer in which some amide groups of polyacrylamide are substituted with carboxyl groups. The degree of hydrolysis is defined as ratio of carboxyl groups to the total number of carboxyl and amide groups. This copolymer can be generated from heating of homopolymer with dilute sodium hydroxide or by copolymerization of acrylamide (non-ionic) and acrylate (ionic). 


\section{A2. Polysaccharides}

The polymer used in this study, xanthan, is a polysaccharide. That is why the description of this type of polymer is given in more detail below. Basic forms of carbohydrates are sugars or monosaccharides. Carbohydrates with two to ten sugars are defined as oligosaccharides and those with larger number of sugars are called polysaccharides. They are composed of carbon $(\mathrm{C})$, hydrogen $(\mathrm{H})$, and oxygen $(\mathrm{O})$ in which there are two times hydrogen in structure than oxygen and carbon.

Monosaccharides or sugars are water soluble crystalline carbohydrates that are classified according to their number of carbons. Table B.1 gives the classification of sugars and table B.2 shows chemical structure of some of these sugars.

Table A.1: Classification of monosaccharides [www.scientificphysics.com]

\begin{tabular}{|c|l|l|}
\hline Number of carbons & Name & \multicolumn{1}{|c|}{ Examples } \\
\hline 4 & Tetrose & Erythtrose, Threose \\
\hline 5 & Pentose & Arabinose,Ribose, riboluse,Xylose, Lyxose \\
\hline 6 & Hexose & $\begin{array}{l}\text { Allose, Altrose, Fructose, Galactose, Glucose, } \\
\text { Gulose, Idose, Mannose, Sorbose, Talose, Tagatose }\end{array}$ \\
\hline 7 & Heptose & Sedoheptulose \\
\hline
\end{tabular}

Table A.2: Chemical structure of some linear sugars [www.scientificphysics.com]

\begin{tabular}{|c|c|c|c|}
\hline D-Erythrose & D-Ribose & D-Allose & D- Sedoheptulose \\
\hline $\begin{array}{l}\mathrm{H}-\mathrm{O} \\
\mathrm{I}-\mathrm{OH} \\
\mathrm{H}-\mathrm{I}-\mathrm{OH} \\
\mathrm{I} \mathrm{H}_{2} \mathrm{OH}\end{array}$ & $\begin{array}{l}\mathrm{H}-\mathrm{O} \\
\mathrm{H}-\mathrm{C}-\mathrm{OH} \\
\mathrm{H}-\mathrm{C}-\mathrm{OH} \\
\mathrm{H}+\mathrm{C}-\mathrm{OH} \\
51 \mathrm{CH}_{2} \mathrm{OH}\end{array}$ & $\begin{array}{l}\mathrm{H}-\mathrm{O} \\
\mathrm{H}-\mathrm{C}-\mathrm{OH} \\
\mathrm{H}-\mathrm{C}-\mathrm{OH} \\
\mathrm{H}-\mathrm{C}-\mathrm{OH} \\
\mathrm{H}-\mathrm{C}-\mathrm{OH} \\
\mathrm{I} \mathrm{H}_{2} \mathrm{OH}\end{array}$ & $\begin{array}{c}\mathrm{CH} \mathrm{H}_{2} \mathrm{OH} \\
\mathrm{C}=\mathrm{O} \\
\mathrm{HO}-\mathrm{C}-\mathrm{H} \\
\mathrm{H}-\mathrm{I}-\mathrm{OH} \\
\mathrm{H}-\mathrm{I}-\mathrm{OH} \\
\mathrm{H}-\mathrm{I}-\mathrm{OH} \\
\mathrm{l}-\mathrm{OH} \\
\mathrm{C} \mathrm{H}_{2} \mathrm{OH}\end{array}$ \\
\hline
\end{tabular}


Sugars exist in chain as well as in a ring form. Figure B.1 illustrates glucose in these two forms. However orientation of hydroxyl groups $(-\mathrm{OH})$ can also make difference. In alpha glucose, hydroxyl group is in the opposite side of $-\mathrm{CH}_{2} \mathrm{OH}$ group, but in beta glucose it is on the same side.

\begin{tabular}{|c|c|c|c|}
\hline & \\
\hline
\end{tabular}

Figure A.1: D-Glucose, $\alpha$-D-Glucose, $\beta$-D-Glucose [www.scientificphysics.com]

Starch is a very common material in drilling fluids. It is a mixture of $10-20 \%$ amylase and $80-90 \%$ amylopectin. Both of them are composed of $\alpha$-D-Glucose. However amylase is a linear polysaccharide and amylopectin is a branched one.Figure B.2 shows these two components of starch. 


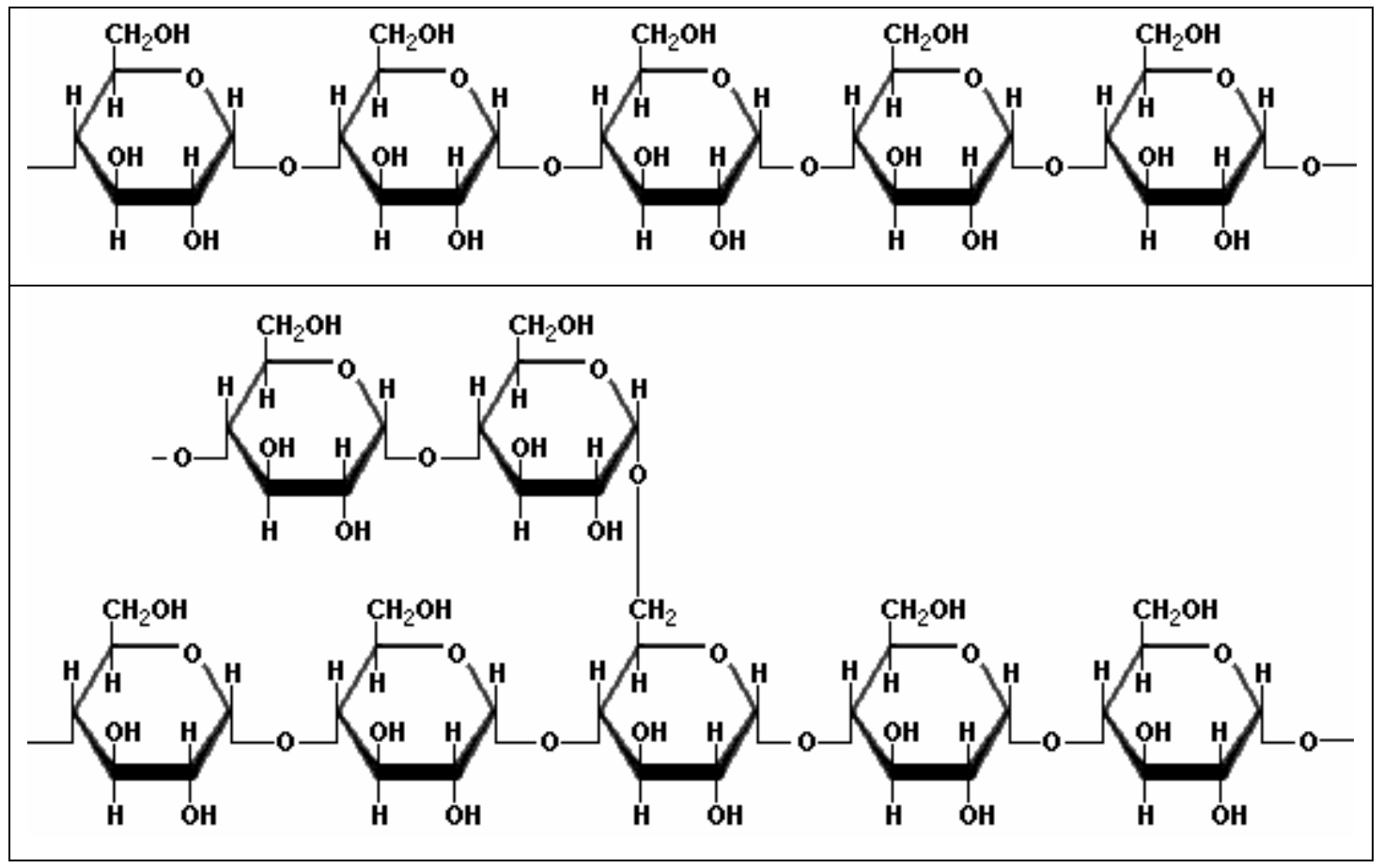

Figure A.2: Chemical structure of amylase (top) and amylopectin (bottom) [www.scientificphysics.com]

Cellulose is composed of $\beta$-D-Glucose with $-\mathrm{CH}_{2} \mathrm{OH}$ alternating in the top and bottom of structure. It is an unbranched polymer which exists in plant like cotton and which is almost totally cellulose. Figure B.3 depicts cellulose structure.

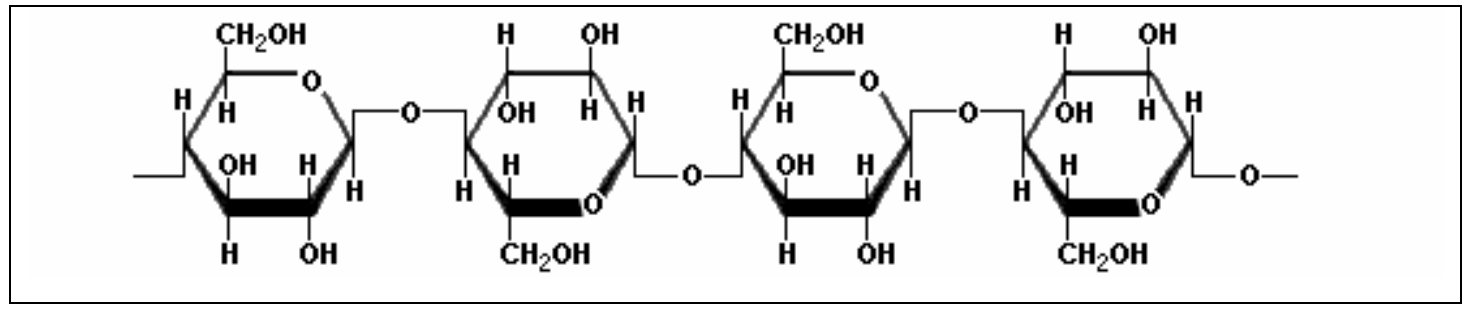

Figure A.3: Cellulose structure [www.scientificphysics.com]

Xanthan gum is a polysaccharide with a backbone of $\beta$-D-Glucose similar to cellulose. However every other glucose is linked to a trisaccharide composed of a mannose, glucuronic acid, and again another mannose. Figure B.4 shows xanthan gum structure. It is produced by a bacterium available at cruciferous vegetables like cabbage called Xanthomonas Campestris. 


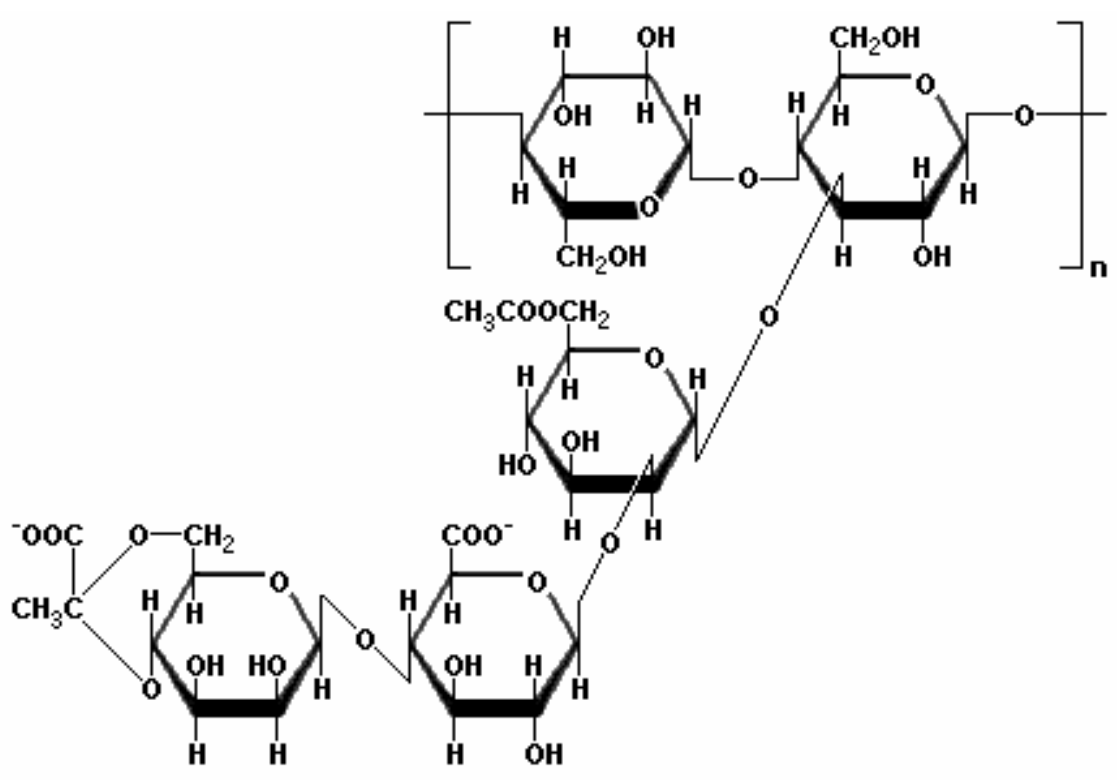

Figure A.4: Xanthan gum structure [www.scientificphysics.com]

Chromium, aluminum, and boron are among common crosslinkers in petroleum industry. Since heavy metal ions cause environmental concerns, there have been some efforts to replace them. Organic crosslinkers like polyethyleneimine are also suggested by some authors (Vossoughi, 2000).

Borax $\left(\mathrm{Na}_{2} \mathrm{~B}_{4} \mathrm{O}_{7} \cdot 10 \mathrm{H}_{2} \mathrm{O}\right)$ is the raw crosslinker used in this thesis. Borax at certain $\mathrm{pH}$ can release boric acid and borate ion. Boric acid also will be converted to borate ion. Therefore concentration of borate ion $\left(B^{-}\right)$is function of borax, $\mathrm{pH}$ and temperature.

$\mathrm{B}_{4} \mathrm{O}_{7}^{2-}+7 \mathrm{H}_{2} \mathrm{O} \rightarrow 2 \mathrm{~B}(\mathrm{OH})_{3}+2 \mathrm{~B}(\mathrm{OH})_{4}^{-}$

$B(\mathrm{OH})_{3}+\mathrm{H}_{2} \mathrm{O} \stackrel{K_{A}}{\longrightarrow} B(\mathrm{OH})_{4}^{-}+H^{+} \quad p k_{A}=9-9.2$ 


\section{APPENDIX B}

\section{RHEOGRAMS}

The unit of shear rate is rpm and the unit of shear stress is dial reading (DR).

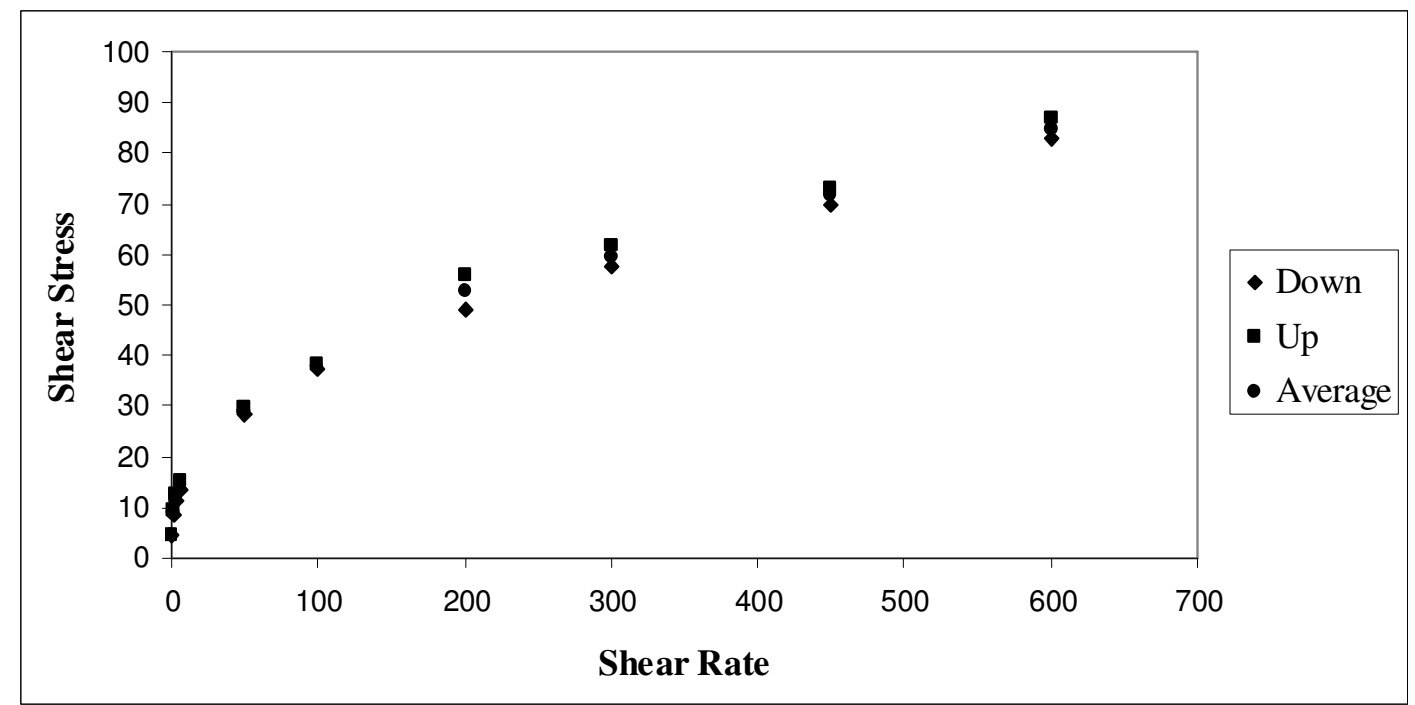

Figure B.1: Sample No. 2 


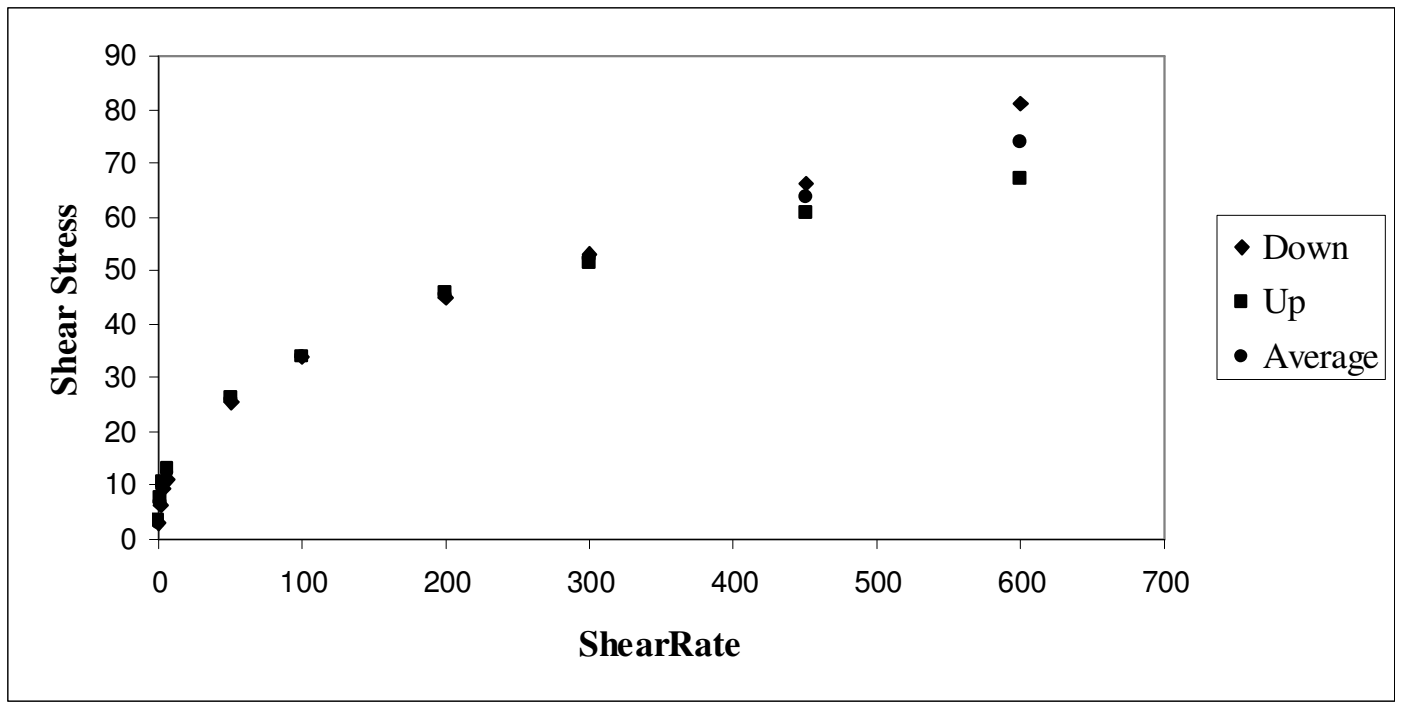

Figure B.2: Sample No.4

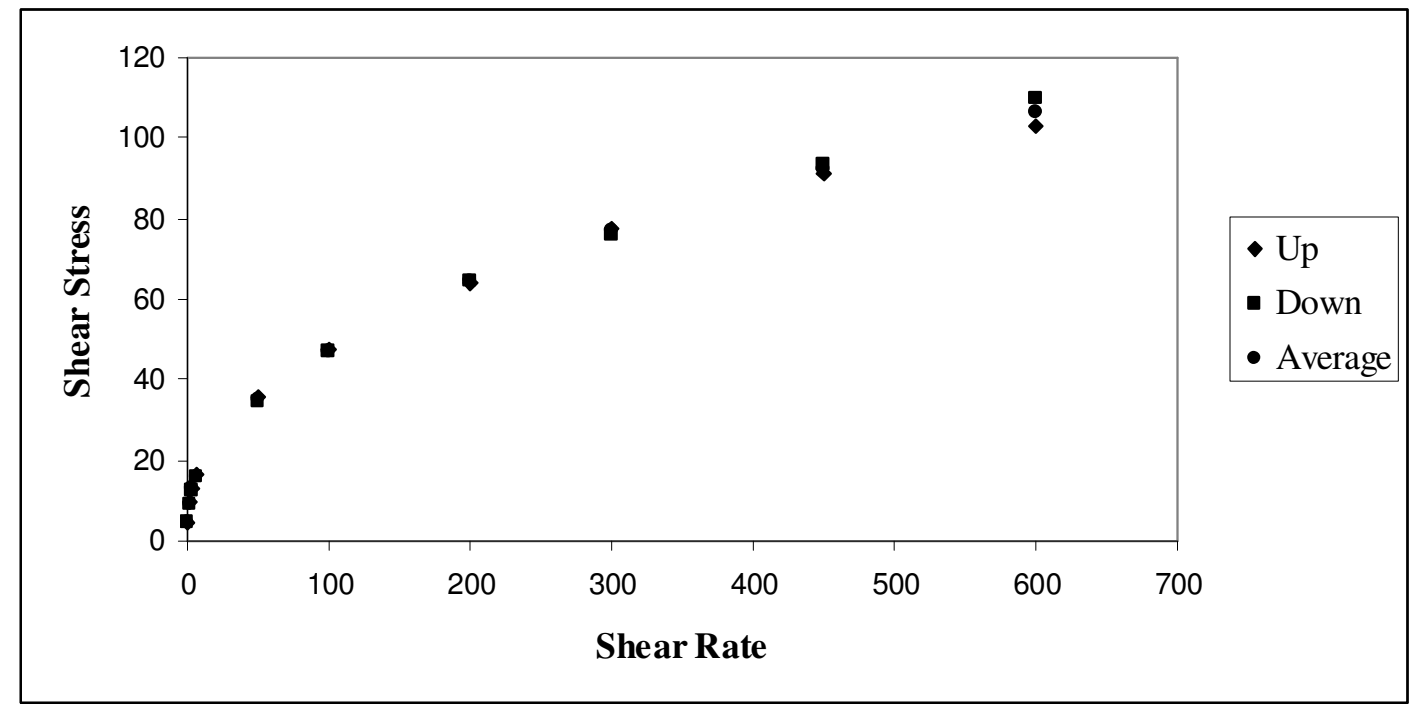

Figure B.3: Sample No.7 


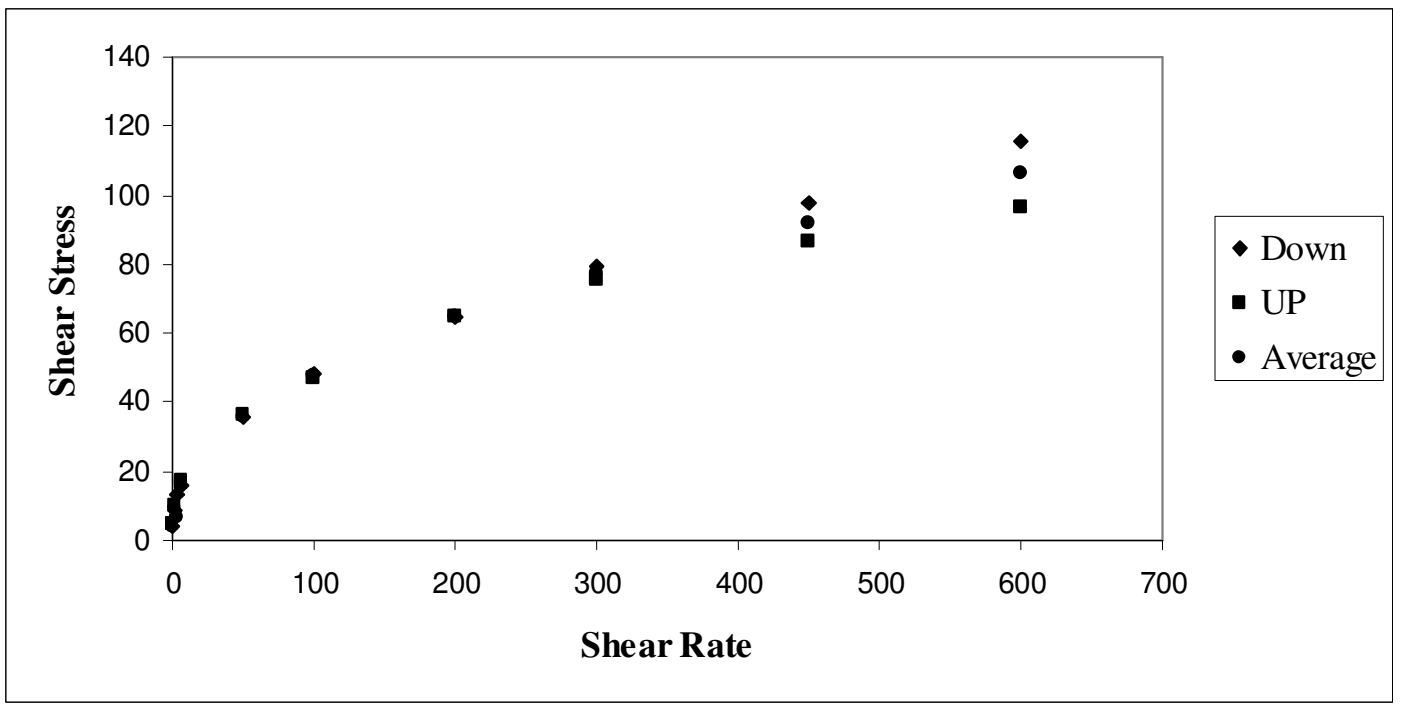

Figure B.4: Sample No.8

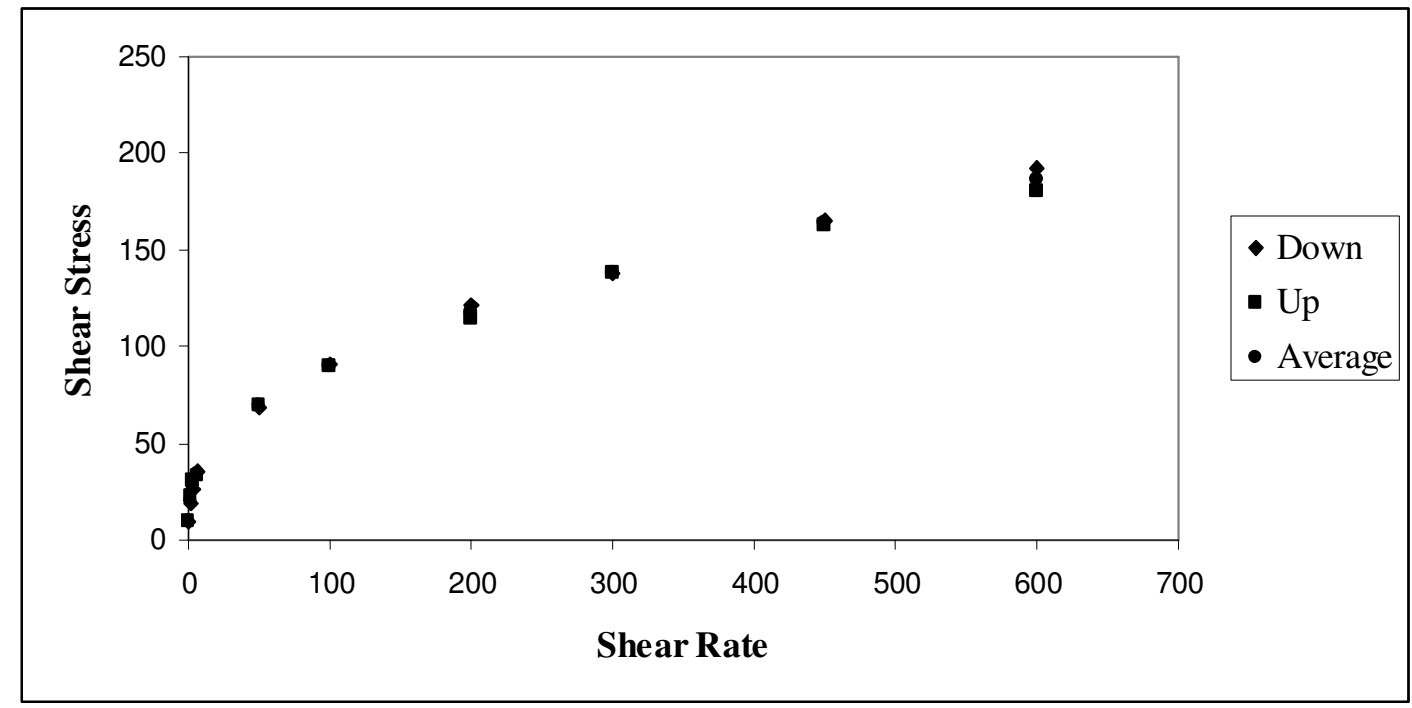

Figure B.5: Sample No.12 


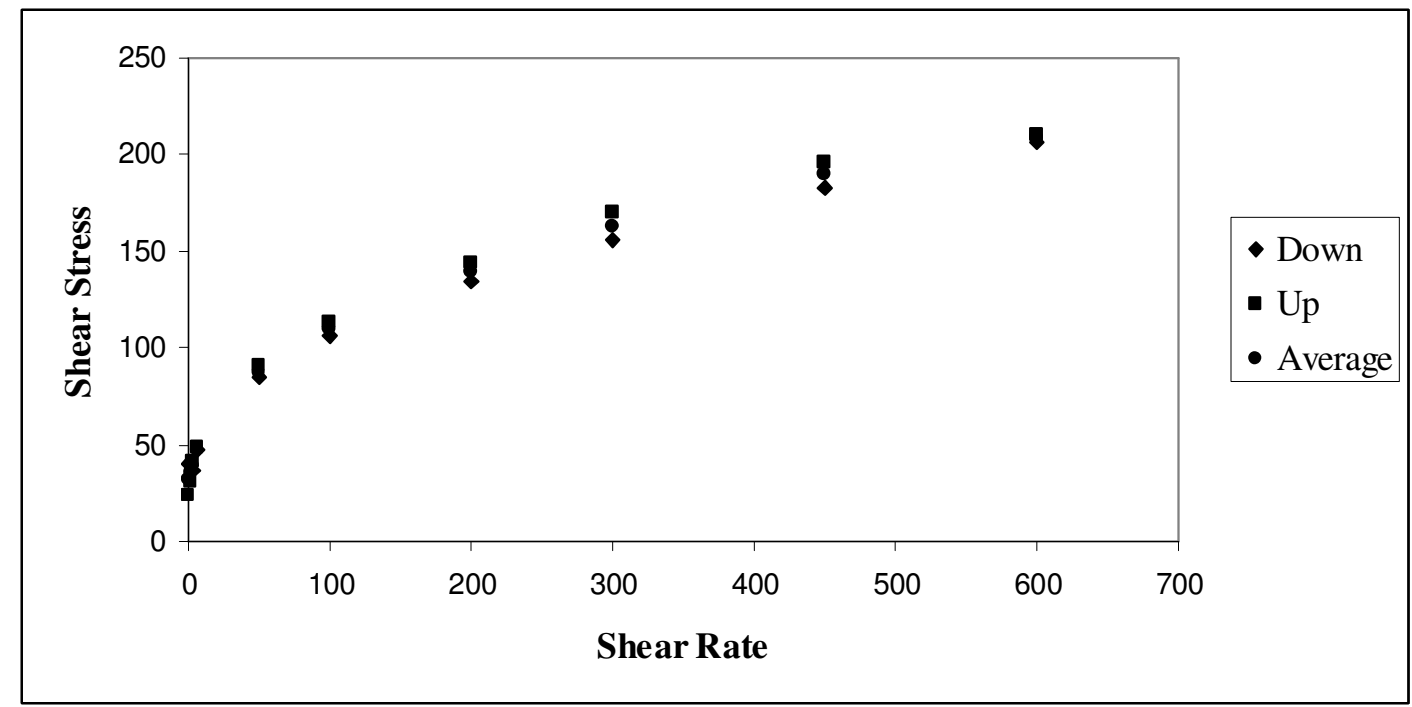

Figure B.6: Sample No.13

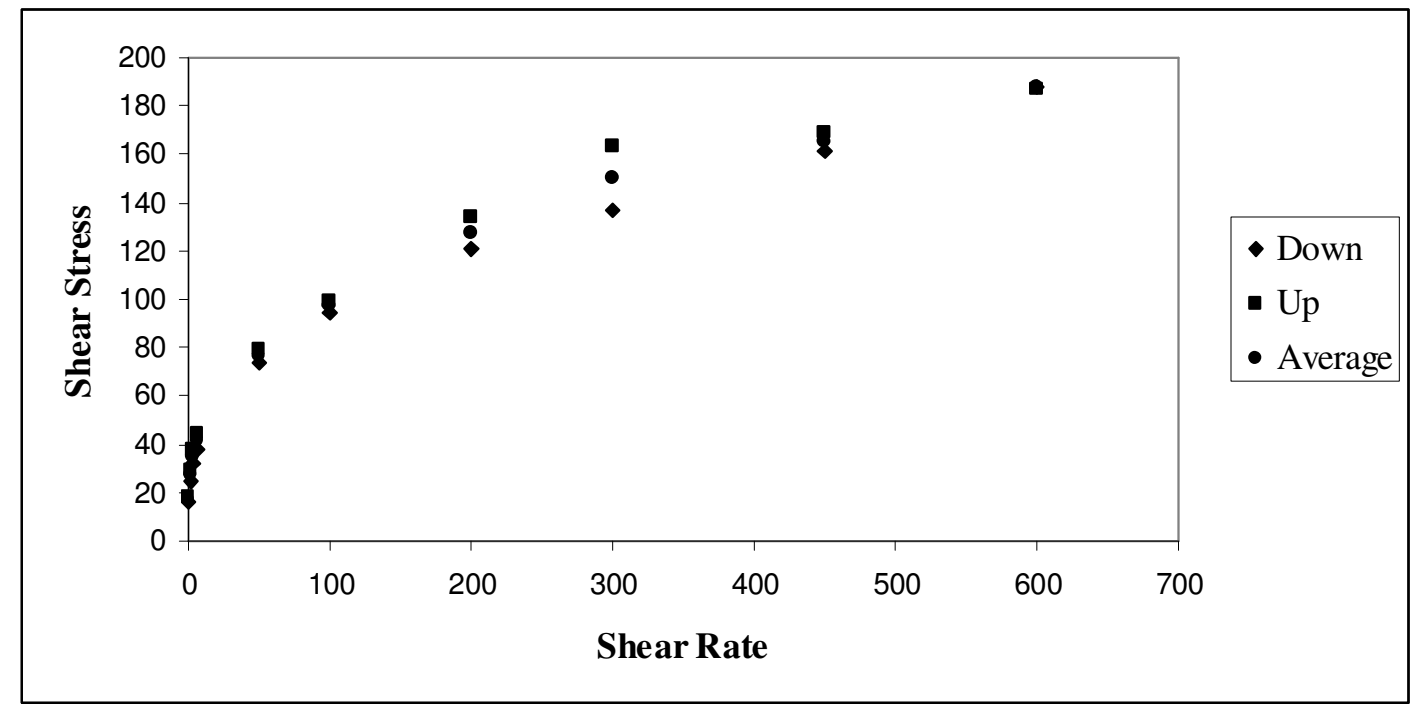

Figure B.7: Sample No.14 


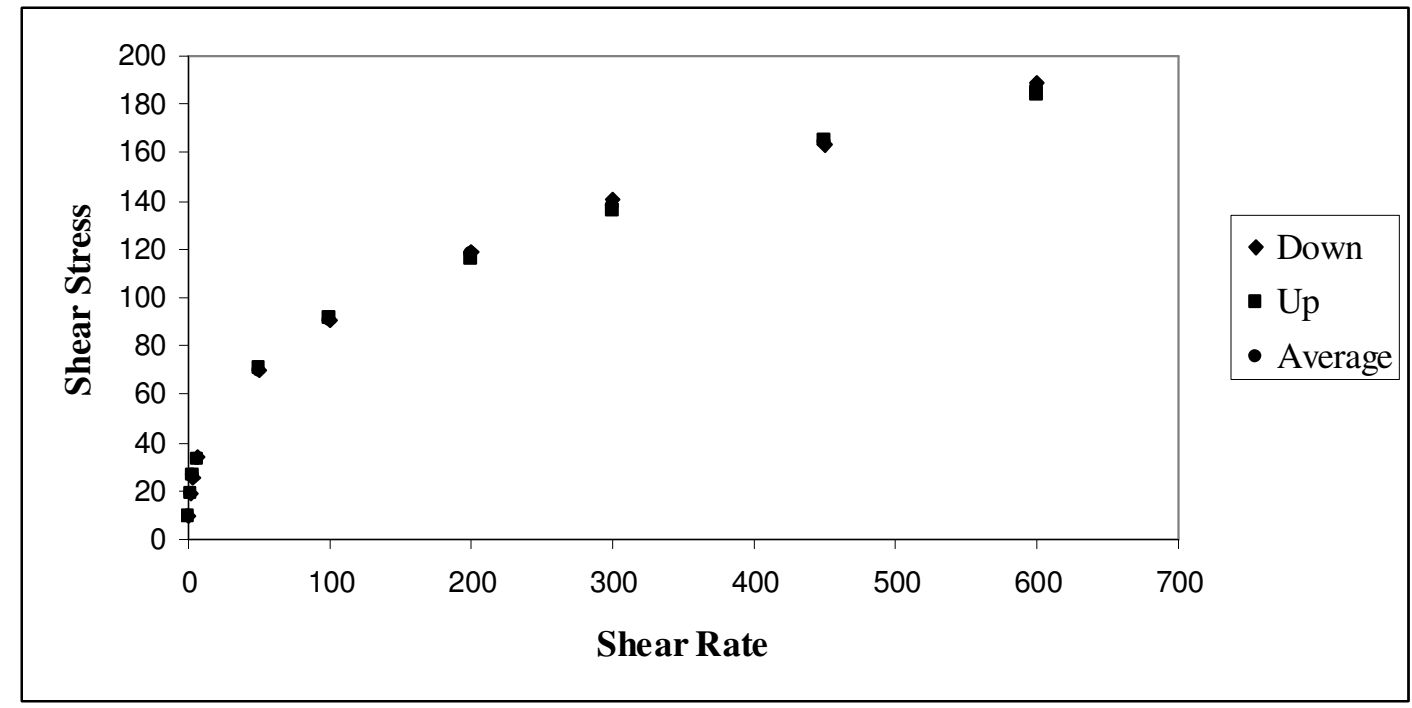

Figure B.8: Sample No.16

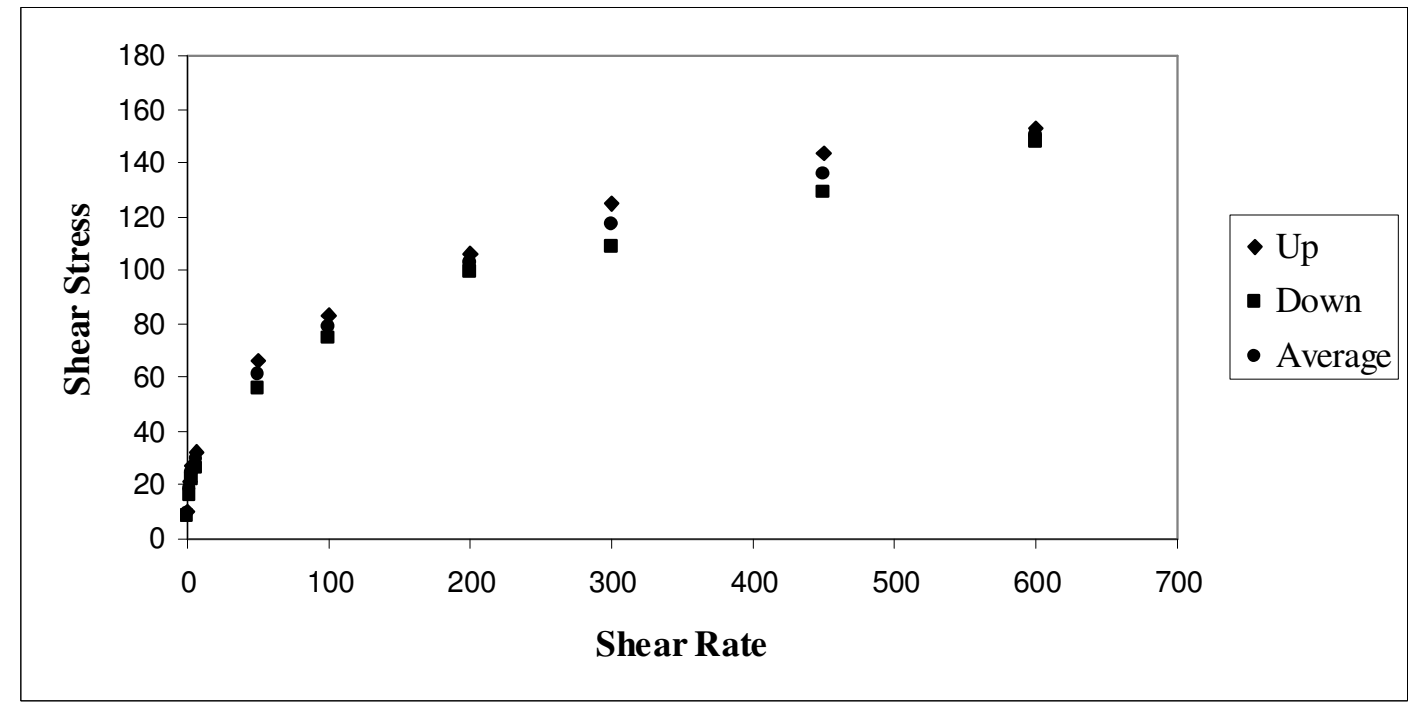

Figure B.9: Sample No.17 


\section{APPENDIX C}

\section{OTHER APPLICATIONS OF GELS IN PETROLEUM INDUSRY}

Although application of gels for lost circulation treatment is new and there are quite few papers in this subject, gels have been widely used in petroleum industry for three other purposes: water shut-off, profile modification, and hydraulic fracturing. The successful history of these operations and some similarities between them and lost circulation problem have led the petroleum industry to the opening of a new solution to the problem of lost circulation during drilling. The understanding of these applications can help to develop the application for lost circulation treatment easier as well as to distinguish the differences of this study from other studies. For instance, most of studies on gel applications in hydraulic fracturing have used xanthan/borate system. Therefore they should be reviewed to understand the gel system of this thesis, although the concentration range in hydraulic fracturing is very low and physical gel structure is not necessary. In addition, the use of gels for water shut-off and profile modification has similar purpose as the lost circulation treatment has: blocking flow from or to a zone. However the initial gelation time should be faster for the lost circulation treatment in comparison to profile modification or water shut-off. In general, they are all studies on gel properties and have been useful in conducting this thesis or giving ideas for recommendations for further studies. For instance, breaking of a gel after hydraulic fracturing is well established. It can be also useful in recovery of gels used for the lost circulation treatment in productive zones. 


\section{C1. Application of gels for water shut-off}

For producers, oil production is desirable. However some amount of water is associated with this oil. The rising of water production leads to oil production decline as well as a considerable increase in cost of production due to treating and disposal of the water. Since water has higher density than oil and gas, it increases the hydrostatic pressure inside wellbore. Consequently oil production rate decreases or cease at the end. Gels can be used to reduce water production.

Kakadjian et al. (1999) studied gel strength of three gels systems, two polyacrylamide/ chrome (III) and one polyacrylamide/ organic crosslinker using the dynamic rheology method. Sodium acetate was proved to make gel system weaker and more viscous. Moreover, the elastic and loss modulus were the functions of gelling time and final consistency as well as frequency.

Wawro et al. (2000) studied the use of gel alternating gas (GAG) for reducing water production from a naturally fractured gas well. Since the injection of gel in to gas wells displaces the gas in near wellbore zone to residual amount, alternative gas injection can recover the gas permeability reduction while water permeability falls down (Dovan and Hutchins, 1994). In this case, water gas ratio (WGR) decreased $75 \%$ after treatment while gas rate increased 20 to $70 \%$. Moreover the cost of treatment operation was compensated by 4 months extra gas production.

Broseta et al. (2000) studied the rheological behavior of low-molecular-weight polyacrylamide crosslinked with chromium (III) acetate for water shut-off purposes by steady viscometry method. The gel system was observed to be a strong function of temperature with activation energy of $115 \mathrm{~kJ} / \mathrm{mol}$. Moreover it was a weak function of crosslinker in comparison to polymer concentration. On the other hand, it was independent of shear rate. In addition polymers with lower hydrolysis degree had longer gelation. 
Awang and Seng( 2003) intended to make a link between bottle testing results and permeability reduction in porous media. It is concluded that for a specific polymer and crosslinker, Sydansk codes can be used to estimate permeability reduction.

Sydansk et al. (2004) compared partially formed( less than 8-hr-old) chromium(III)carboxylate/acrylamide-polymer with fully formed gel( higher than 15-hr-old). The former had less effective viscosity during its placement in 1-mm-wide fracture than fully formed with the same composition.

Al-Muntasheri et al. (2004) stated the four mechanisms for water production:

1. Water coning: in this mechanism, the water is produced from the aquifer beneath the oil reservoir since the rate of oil production is very high.

2. There are some fractures that connect the aquifer to reservoir.

3. There is an aquifer above the reservoir and a leakage in casing results in water production.

4. There is a breakthrough of water injected for pressure maintenance or enhanced oil recovery.

Llamedo et al. (2005) explained the effect of salinity of formation water on performance of a gel system for water shut-off. Residual resistance factor (RRF) was lower when the water used for preparation of gel and formation water had similar salinity. On the other hand RRF increased when formation water had higher salinity.

Eoff et al. (2006) reported eight-year successful application of acrylamide/t-butyl acrylate copolymer (PAtBA) crosslinked with polyethyleneimine (PEI) for water shut-off which included over 200 jobs reviews.

Al-Muntasheri et al. (2007) demonstrated the use of acrylamide and t-butyl acrylate crosslinked with polyethyleneimine for water shut-off treatment. Polymer 
concentration was 3-7 wt.\% and crosslinker concentration is in range of 0.3 to $1.2 \%$. The properties of the gel were studied by dynamic mechanical analysis (DMA).

Al-Muntasheri (2007) demonstrated a comparative study on crosslinking of polyacrylamide teributyl acrylate (PAtBA) copolymer and polyacrylamide (PAM) homopolymer with polyethyleneimine (PEI) by steady shear viscometry. Gas chromatography (GC) showed isobutene release when PAtBA reacts with PEI in the temperature range of $60-130^{\circ} \mathrm{C}$. Sodium chloride increased gelation time of both systems and lower initial $\mathrm{pH}$ postponed gelation time of PAM with PEI.

\section{C2. Application of gels for profile modification}

Oil reservoirs have mostly a natural driving force to produce oil in the beginning of reservoir age. However the depletion of oil rate begins and makes oil production uneconomical while a major part of oil is still remained in the reservoir. Water injection is a method aimed at maintaining the reservoir pressure. In this method, water is injected to a well nearby in order to compensate the pressure drop due to oil production. Enhanced oil recovery (EOR) methods are the variety of methods used to push the oil toward wellbore while they were not able to be moved by natural driving force. In these methods, a fluid such as a gas or water in combination with some chemicals are injected to an injection well nearby to push the oil toward production well. Two kinds of sweep efficiency are effective in EOR: volumetric sweep efficiency and microscopic sweep efficiency. In the former one, the portion of reservoir that is affected by injected fluid is evaluated. In the later one, the amount of oil moved due to interaction with injected fluid is taken in to account.

Volumetric sweep efficiency is the subject of profile modification by gels. Since reservoirs are heterogeneous, the injected fluid looks for the most permeable parts and goes through those layers. Consequently some parts remain unswept by injected fluid. Mostly the permeability variation is in vertical direction since the sedimentary layers could occur in this way. Therefore, some reservoirs are multilayer reservoirs 
with permeability variation in vertical axes or in some cases mostly in fractured reservoirs; there are some fractures that connect the injection well to production well. As a result, a breakthrough can occur when large part of oil is still unswept.

Gels are a solution to this problem. Cross-linked polymeric materials are injected to block the high permeable zones. Consequently, the fluids injected later will be diverted to low permeability zones. Application of crosslinked polymer gels for profile modification started in early 1980s (Avery et al., 1986) and Vossoughi(1999) gave a comprehensive review of profile modification by in situ gelation.

Avery et al. (1986) explained the use of xanthan gum/ trivalent chrome gel system for profile modification. They presented successful field result (75-80\%) and the advantages of xanthan/Cr (III) gel system.

Buller et al. (1990) developed a gel system called KUSP1 in which a B-1,3polyglucan as a biopolymer is produced from fermentation of a bacterial called Alcaligenes Faecalis and certain species of Agrobacterium. The gelation starts when $\mathrm{pH}$ reduced to 10.8 or lower. Therefore, the gel system can be used in porous media by using acid (Vosoughi et al. 1991), by $\mathrm{CO}_{2}$ (Raje et al. 1999), or by hydrolysis of an ester (Raje et al. 1999).

Eggert et al. (1992) conducted experiments on sandpack in order to investigate the persistence of permeability reduction by xanthan/Cr (III) gel system. Samples were prepared with 2,000 ppm xanthan concentration and 25 to $200 \mathrm{ppm} \mathrm{Cr}$ (III). The gel system was injected to the sandpack and they waited up to 4 months to set. The sandpacks were flushed by brine at a constant pressure drop of $13.3 \mathrm{psi} / \mathrm{ft}$. Bulk-gel syneresis was not a right detector of the gel behavior in porous media since the best permeability reductions were obtained with gels that exhibited 35 to $60 \%$ shrinkage of volume due to syneresis. 
Hejri et al. (1993) employed xanthan/ chromium (III) gel system for permeability reduction. At frontal velocity of 3 to $35 \mathrm{ft} / \mathrm{D}$, the plugging of porous media was detected but at high frontal velocity of 83 to $118 \mathrm{ft} / \mathrm{D}$ which is typical for wellbore region, high flow resistance was not detected.

Hutchins et al. (1996) applied polyacrylamide with a combination of hydroquinone (HQ) and hexamethylenetetramine (HMTA) as crosslinker and demonstrated that it was stable at $149{ }^{\circ} \mathrm{C}$ for 12 months and at $176.7^{\circ} \mathrm{C}$ for 5 months. By this system, oil production raised to 660 bopd from 340 bopd before treatment and water production fall to 1490 bwpd from 3760 before treatment.

Moradi-Araghi (1999) stated that a typical gel system for profile modification has 0.7-1.0\% polymer concentration and 500-2000 ppm crosslinker concentration. He also reviewed and recommended some gel systems useful for high temperature reservoirs since gel systems with metallic cross-linker $(\mathrm{Cr}, \mathrm{Al}, \mathrm{Zr})$ have low thermal stability.

Vossoughi (1999) elucidated two types of gel placement: 1. near wellbore 2. indepth. If there is a cross-flow between layers, in depth placement or injection of gel to a large radius should be performed. Gao et al. (1990) demonstrated the inadequate gel sweep efficiency occurred due to near wellbore gelation of crossflowing wells since the injected flow diverts to high permeability zone again in this case. Sydansk et al. (1987) reported successful field testing of in-depth profile modification by gels and Rajeet al. $(1995,1999)$ reported $80 \%$ permeability reduction to brine and $\mathrm{CO}_{2}$ for Berea sandstone cores.

Topguder (1999) compared profile modification by a weak gel with in-depth penetration and a strong gel with wellbore nearby penetration for $\mathrm{CO}_{2}$ injection at Bati Raman heavy oilfield. The strong gel could resist 2000 psi in core flooding 
experiment without any breakthrough. The weak gel exhibited a breakthrough; however it could reduce permeability significantly.

Asghari et al. (2004) investigated in-depth gel profile modification for carbon dioxide flooding in carbonate reservoirs. AlcoFlood 935-Cr (III) gel system reduced the brine permeability from 2.43 Darcy to $21.9 \mathrm{md}$. Moreover the residual resistance factors were in the range of a few hundreds to a few thousands. The thinning effect of sodium lactate on the gel system was also confirmed.

Nguyen et al. (2004) studied the effect of composition of polyacrylamide/Cr (III) acetate on disproportionate permeability reduction (DPR) which is the measure of permeability reduction to water in comparison to oil. The effect of composition on dehydration of gel system was also studied. DPR was a strong function of composition and pressure gradient while gel dehydration was affected very weakly.

Wang et al. (2005) reported the successful application of compound ion gel for the profile modification in highly heterogeneous reservoirs of Daqing oilfield.

\section{C3. Application of gels in hydraulic fracturing operation}

Hydraulic fracturing is a stimulation technique for enhancing the production of oil/gas wells. A fracturing fluid is injected to wellbore which cause the reservoir to break and a solid agent, proppant, is used to hold the fracture open. Hydraulic fracturing creates a conductive path in reservoir which gives more area available for oil/gas toward well. A fracturing fluid should be designed in a way to facilitate the fracture creation and to increase proppant carrying capacity while the damage to the near fracture zone should be minimized. There are varieties of fracturing fluids in industry such as: water-based, oil-based, alcohol-based, foam-based, and emulsion based. Cross-linked polymer gels are one of the oldest fracturing fluids. Crosslinking initiation time is vital to have enough fracture penetration. Moreover, 
the cross-linked gels should be broken by a chemical agent in order to be back produced to surface.

Kruijf et al. (1993) elucidated the chemistry of guar or hydroxypropyl guar (HPG) crosslinked with borate for hydraulic fracturing application. The viscosity was dependent on borate ion equilibrium which was a function of $\mathrm{pH}$ while $\mathrm{pH}$ was a function of temperature.

Kenneth et al. (1997) reported unsuccessful application of low concentration gel systems for hydraulic fracturing in the past due to inability to control $\mathrm{pH}$. However the proposed $\mathrm{pH}$ buffer technology could solve this problem even at temperatures up to $210^{\circ} \mathrm{F}$. Moreover due to low polymer concentration, the clean up of fractures was better than that of conventional systems and 10 to $25 \%$ higher conductivity was achieved based on laboratory conductivity experiments. Moreover duration of clean up reduced to half of that for conventional ones.

Harris et al. (1998) studied the rheological properties of low concentration borate gel, 15 to $25 \mathrm{lbm} / 1000 \mathrm{gal}$, instead of common 40 and $50 \mathrm{lbm} / 1000$ gal gels. A turbulent flow-loop viscometer was used to simulate the fracturing fluid condition in surface equipments as well as in tubing. Then the fluid is heated under laminar flow in order to simulate the fluid condition in fracture. An appropriate proppant transport was observed in a transparent slot model. The gel system exhibited shear degradation resistance while it was transmitted in tubing.

Harris and Walters (2000) stated that lower polymer concentration in hydraulic fracturing jobs causes less residues in fractures. Consequently the damage decreases. As a result a low loading gel, 15-25 lbm/Mgal, was optimized as a function of preconditioning shear rate, temperature, $\mathrm{pH}$, ionic strength, gel stabilizer, gel breaker, surfactant, and proppant type in order to have appropriate properties for a certain well. 
Weaver et al. (2003) explained the gel breakers were used to lower the viscosity of fracturing fluids after the proppant placement and consequently in order to allow the reservoir pressure to force the fracturing fluid to go out of fracture. For this reason, a reverse cross-linking materials or an enzyme can be used.

Although less polymer concentration can place less polymer in fractures, it may also decrease viscosity to a level that is not suitable for proppant transportation. Therefore the use of carboxymethyl guar (CMG) instead of common carboxymethyl hydrapropal guar (CMHPG) was suggested since CMG can give the same viscosity with half concentration. Parks (2003) addressed the application of this gel system to the Mid-Continent region. By comparing the results of hydraulic fracturing using CMG with the offset well which used CMHPG, more production was observed with the later one. 